\title{
New observations on cardiac arrhythmias
}

Citation for published version (APA):

Rodriguez, L. M. (1994). New observations on cardiac arrhythmias. [Doctoral Thesis, Maastricht University]. Datawyse / Universitaire Pers Maastricht. https://doi.org/10.26481/dis.19940520lr

Document status and date:

Published: 01/01/1994

DOI:

10.26481/dis.19940520lr

Document Version:

Publisher's PDF, also known as Version of record

\section{Please check the document version of this publication:}

- A submitted manuscript is the version of the article upon submission and before peer-review. There can be important differences between the submitted version and the official published version of record.

People interested in the research are advised to contact the author for the final version of the publication, or visit the DOI to the publisher's website.

- The final author version and the galley proof are versions of the publication after peer review.

- The final published version features the final layout of the paper including the volume, issue and page numbers.

Link to publication

\footnotetext{
General rights rights.

- You may freely distribute the URL identifying the publication in the public portal. please follow below link for the End User Agreement:

www.umlib.nl/taverne-license

Take down policy

If you believe that this document breaches copyright please contact us at:

repository@maastrichtuniversity.nl

providing details and we will investigate your claim.
}

Copyright and moral rights for the publications made accessible in the public portal are retained by the authors and/or other copyright owners and it is a condition of accessing publications that users recognise and abide by the legal requirements associated with these

- Users may download and print one copy of any publication from the public portal for the purpose of private study or research.

- You may not further distribute the material or use it for any profit-making activity or commercial gain

If the publication is distributed under the terms of Article $25 \mathrm{fa}$ of the Dutch Copyright Act, indicated by the "Taverne" license above, 
NEW OBSERVATIONS ON CARDIAC ARRHYTHMIAS 
Layout and printing: Datawyse I Universitaire Pers Maastricht

\section{CIP-DATA KONINKLIJKE BIBLIOTHEEK, DEN HAAG}

\section{Rodriguez, Luz-Maria}

New observations on cardiac arrhythmias / Luz-Maria

Rodriguez. - Maastricht : Universitaire Pers Maastricht.

- Ill.

Thesis Maastricht. - With ref.

ISBN 90-5278-139-7

Subject headings: supraventricular tachycardias / ventricular arrhythmias / myocardial infarctions. 


\title{
NEW OBSERVATIONS ON CARDIAC ARRHYTHMIAS
}

\author{
PROEFSCHRIFT \\ ter verkrijging van de graad van doctor \\ aan de Rijksuniversiteit Limburg te Maastricht, \\ op gezag van de Rector Magnificus, Prof.Dr. H. Philipsen, \\ volgens het besluit van het College van Dekanen, \\ in het openbaar te verdedigen op \\ vrijdag 20 mei 1994 om 14.00 uur \\ door
}

\section{Luz-Maria Rodriguez}

geboren te Guadalajara, Mexico

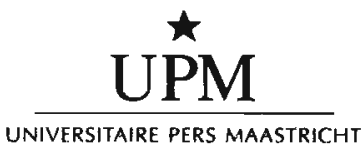




\section{Promotor:}

Prof. Dr. H.J.J. Wellens

\section{Co-promotor:}

Dr. J.L.R.M. Smeets

\section{Beoordelingscommissie:}

Prof. Dr. M. A. Allessie, voorzitter

Prof. Dr. P.J.C. van Breda Vriesman

Prof. Dr. H.E. Kulbertus, University of Liège, Belgium

Prof. Dr. K.I. Lie, Rijksuniversiteit Groningen

Prof. Dr. R.S. Reneman

Het onderzoek beschreven in deze dissertatie werd uitgevoerd als lid van de vakgroep Cardiologie van het Academisch Ziekenhuis Maastricht, Nederland

De uitgave van dit proefschrift werd mede mogelijk gemaakt door financiële steun van: De Nederlandse Hartstichting, Stichting RESCAR, Bakker Research Centrum (Medtronic), Knoll, Bristol-Myers, Sanofi, Bard, Cordis, Merck Sharp \& Dohme en Ciba Geigy.

Deze ondersteuning wordt zeer op prijs gesteld. 
Observe le monde qui est l'école par excellence, lis beaucoup, medite encore plus, travaille enfin et rapporte tout à l'utilité de l'humanité.

Kijk naar de wereld om je heen die immers de beste leerschool is, lees veel, denk veel na, ga dan aan het werk en stel al je kennis ter beschikking van de mensheid.

Observe the world which is the best school of life, read a lot, meditate even more, finally work and bring all knowledge to humanity.

To my mother Bernice

To Monique and Olivier 


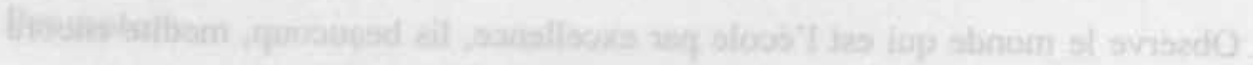

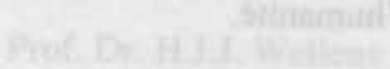

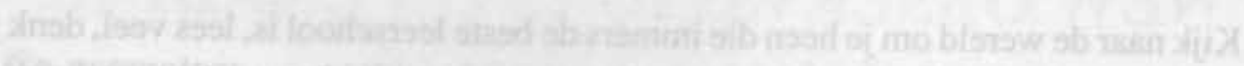

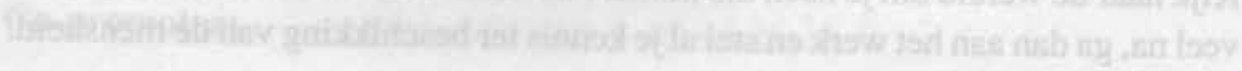

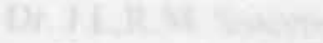

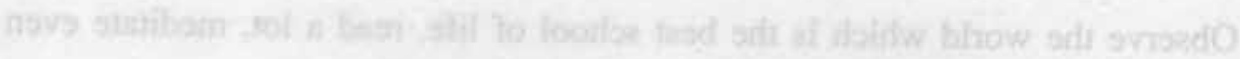

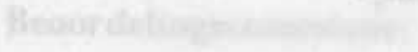

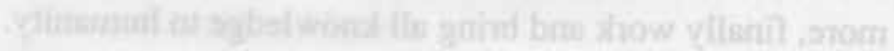

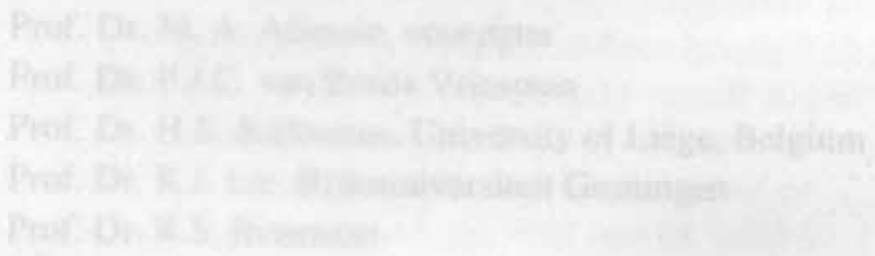

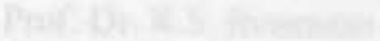

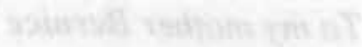

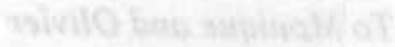

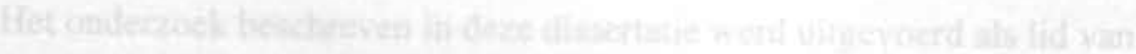

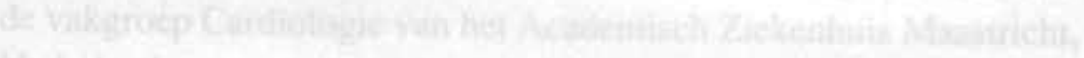
Notertiand

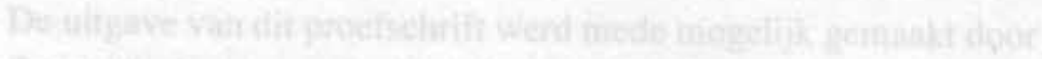

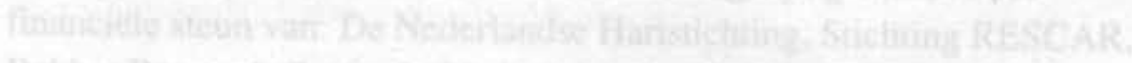

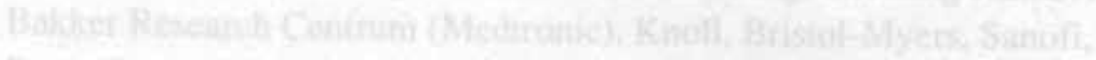

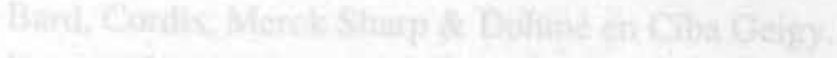

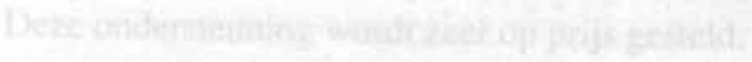




\section{Acknowledgements}

My thesis honors those persons who by their teaching, collaboration, support and encouragement contributed to its completion.

First of all, my gratitude goes to Prof. Hein J.J Wellens, my mentor. He has contributed by shaping "this rough stone" into what I am. From him I have learned not only clinical electrophysiology and electrocardiography, but he also has taught me perseverance in reaching my goals. His interest and patience in correcting the material of my thesis always encouraged me to continue.

I should like to declare my indebtedness to Prof. Henri E Kulbertus who accepted me in his Department of Cardiology at the University of Liège and who with his scientific personality contributed to my learning process.

I appreciate the immense collaboration of Joep Smeets. In the last three years, I have welcomed the opportunity to work with him. His constructive criticism helped greatly in the completion of this work.

I thank Simon Braat and Emile Cheriex who are the "Paranimfs" during the defense of this thesis.

For the help and advice from colleagues who directly or indirectly contributed to this thesis I want to thank Frits Bär, Xie Baiyan, Johannes Brachmann, Pedro Brugada, Christian de Chillou, Javier Chorro, Karel den Dulk, Barbara Dijkman, Herman Frank, Peter Geelen, Anton Gorgels, Apostolos Katsivas, Ruud Krijne, Györgi Lipcsei, Eduardo Medina, Jacques Metzger, Gilles O'Hara, Vincent van Ommen, Giuseppe Oreto, Otto Orning, Rodulfo Oyarzun, Frans Pieters, Pièrre Rigo, Jürg Schläpfer, Jacques Schmitz, Claus Schmitt, Eduardo Sternick, Jan Stappers, Hans de Swart, Carl Timmermans, Eddy Vanagt, Frank Vermeer, Marc Vos, And Weide, Chris de Zwaan.

I will not forget to thank Dr. Gabriel Lopez-Habib. He was one of the pioneers in my learning progress.

I am grateful to Adri van den Dool for her special contribution with ECG tracings and drawings. 
Rob Mulleneers and Berto Bleylevens who gave me the first lessons in informatics.

I thank Prof. Adelin Albert and Jacques Sabatier from the University of Liège and Willem Dassen, PhD from the Academic Hospital Maastricht for their help with the statistical analysis.

Also my gratitude is directed to the personel from the catheterization laboratory for their cooperation.

Secretaries of the Department of Cardiology, thank you very much for your help and patience.

To all of you, I want to express my thanks and gratitude for your support and inspiration. 


\section{Contents}

Chapter 1. Introduction

Chapter 2. Age at onset and gender of patients with different types of supraventricular tachycardias.

Chapter 3. The 12-lead electrocardiogram in mid-septal, anteroseptal, posteroseptal and right free wall accessory pathways.

Chapter 4. Radiofrequency catheter ablation of three accessory pathways in a single session.

Chapter 5. Improvement in left heart function by ablation of AV nodal conduction in selected patients with lone atrial fibrillation.

Chapter 6. Time course and prognostic significance of serial signal-averaged electrocardiogram after acute myocardial infarction.

Chapter 7. Observations on the QRS complex in post-infarction and non-ischemic ventricular tachycardias.

Chapter 8. Identification of patients at high risk for recurrence of sustained ventricular tachycardia after healing of acute myocardial infarction.

Chapter 9. Incidence and timing of recurrences of sudden death and ventricular tachycardia during antiarrhythmic drug treatment after myocardial infarction.

Chapter 10. Induction of ventricular fibrillation, but not of sustained monomorphic ventricular tachycardia predicts sudden death in patients on amiodarone treatment because of ventricular tachyarrhythmias after myocardial infarction. 
Summary

133

Samenvatting 137

Resumé 142

$\begin{array}{ll}\text { Resumen } & 147\end{array}$

Curriculum Vitae 352 


\section{Chapter 1}

\section{Introduction}

In 1967 programmed electrical stimulation of the heart was introduced into clinical cardiology $(1,2)$ and revolutionized our methods of diagnosis and treatment of cardiac arrhythmias (3). It not only resulted in the ability to localize the site of origin of an arrhythmia but also in better understanding of arrhythmia mechanisms and the development of new treatment modalities like antitachycardia pacing and the surgical or electrical ablation of the tachycardia focus or pathway. It is of interest that 25 years later, we are still expanding our knowledge about the diagnosis and treatment of the tachycardias. This is reflected in the contents of this thesis which discusses new information on supraventricular and ventricular arrhythmias.

The first part of our study is devoted to patients suffering from supraventricular arrhythmias and the second part reports on new findings in ventricular arrhythmias.

Supraventricular tachycardias may originate in the atrium, in the atrioventricular junction, or they may be based upon the incorporation in the tachycardia circuit of both atrium and ventricle because of the presence of an accessory atrioventricular connection next to the AV node- His pathway. Accessory connections may also be present between the AV node and the ventricle (nodo-ventricular connections) (4) or between the bundle of His and the ventricles (fasciculo-ventricular connections) (5).

Based on their site of origin the following supraventricular tachycardias can be observed: atrial tachycardia, atrial flutter, atrial fibrillation, atrioventricular nodal reentrant tachycardia and circusmovement tachycardia utilizing an accessory connection.

It is of interest that little is known about age at onset of tachycardia and gender of these different types of supraventricular tachycardias. 
This was therefore studied (and reported in Chapter 2) in a large series of patients with atrial tachycardia, AV nodal tachycardia and tachycardias in the presence of an accessory atrio-ventricular pathway.

An accessory atrioventricular connection is frequently capable of conduction in both the atrio-ventricular and ventriculo-atrial direction. Paroxysmal supraventricular tachycardia due to reentry circus movement tachycardia may occur in these patients in orthodromic or antidromic direction. Orthodromic circusmovement tachycardia uses the AV conduction system in anterograde direction and the accessory atrioventricular connection in a retrograde (ventriculo-atrial) way. Antidromic circusmovement tachycardia utilizes the accessory atrioventricular connection in anterograde direction and the AV conduction system or a second accessory connection in retrograde direction. However, it is not uncommon that accessory atrioventricular connections exhibit only retrograde conduction from ventricle to atrium (a so called concealed atrioventricular connection). In these patients the electrocardiogram in sinus rhythm does not show preexcitation.

In patients suffering from tachycardias in the presence of an accessory atrio-ventricular pathway treatment may consist of antiarrhythmic drug therapy or the interruption of the extraconnection by surgical or electrical ablation $(6,7)$. In recent years the introduction of radiofrequency ablation opened a new way for definitive cure of arrhythmias based on the presence of an accessory atrioventricular pathway $(8,9)$. This necessitates careful localization of the accessory pathways.

The accessory atrioventricular connections can be located at any site along the atrioventricular junction (10). Several studies have been reported on the value of the 12-lead electrocardiogram in localizing these pathways (11-14). Recently, special attention has been given to those accessory atrioventricular connections arising in the septal area $(15,16)$.

In Chapter 3, the value of the 12-lead ECG in differentiating accessory atrio-ventricular connections located in the mid-septal, right free wall, true posteroseptal and anteroseptal areas are discussed.

As pointed out radiofrequency catheter ablation has revolutionized the treatment of supraventricular tachycardias using accessory pathways.

Chapter 4 reports on the use of radiofrequency current catheter ablation in a patient with multiple accessory atrio-ventricular connections.

Most patients with atrial fibrillation have some underlying cardiac, or humoro-endocrinologic abnormality but the arrhythmia can also occur as an independent arrhythmic entity, so called "lone atrial fibrillation" (17). The occurrence of a high ventricular rate and loss of atrial contribution to ventricular filling during atrial fibrillation may not only lead to the unpleasant sensation of palpitations and dizziness but also to cardiac dilatation and congestive failure even in the absence of an underlying cardiovascular abnormality. In Chapter 5 
we describe how in patients with long-standing lone atrial fibrillation, left ventricular function and left sided dimensions are affected by the arrhythmia and discuss the consequences of ventricular rate control by ablation of the atrioventricular junction and the insertion of a physiologic rate-responsive pacemaker.

In the second part of this thesis we report on some clinically applicable methods to identify risk of developing a life-threatening ventricular arrhythmia after a myocardial infarction. In addition, we will analyze risk factors in patients who have already suffered from a life-threatening ventricular-arrhythmia late after myocardial infarction to recognize their susceptibility to recurrent episodes of life-threatening ventricular arrhythmias or sudden death.

In spite of enormous efforts made both at the basic and clinical level to decrease morbidity and mortality of coronary heart disease, sudden cardiac death (SCD) remains one of the major causes of mortality in the Western world. Over the past two decades, there have been only limited advances in prevention of SCD. The incidence of SCD is probably decreasing in parallel with an overall reduction in cardiovascular mortality (18) and some progress has been made in the identification of high risk individuals.

In patients surviving from an acute myocardial infarction, recognition of those at high risk of developing ventricular tachycardia and sudden death is of obvious importance. As listed in Table 1 several different non-invasive and invasive methods have been advanced to perform such risk stratification.

Table 1. Risk stratification after a myocardial infarction

1. Pumpfunction: Exercise duration

LVEF

2. Ischemia: Exercise Testing

Holter

3. Arrhythmias: Signal averaged ECG Holter

QT-Interval duration
Exercise Testing
Programmed electrical stimulation

4. Neurohumoral: Heart rate variability

Baroreflex sensitivity

Psycho-social factors

Abbreviations: $E C G$ = electrocardiogram, $\mathrm{LVEF}=$ left ventricular ejection fraction 
In the absence of new ischemia spontaneous ventricular tachyarrhythmias occurring late ( $>3$ days) after myocardial infarction arise from areas of myocardium with slow conduction. These areas can be recorded either directly from the heart by cardiac mapping or by a signal-averaging electrocardiogram technique $(19,20)$. It is accepted that delayed and fractionated potentials occurring after the QRS complex ("so called late potentials") recorded by signal-averaging techniques reflect slow conduction in scarred myocardium in patients with an old myocardial infarction. Their presence has been considered a marker for risk of developing life-threatening ventricular arrhythmias. In most of the studies, recordings have been obtained at varying time intervals after acute myocardial infarction $(21,22)$. In order to obtain insight into the most appropriate time of recording this signal, signal averaged electrocardiograms were obtained at three time intervals after myocardial infarction. Chapter 6 discusses the time course and prognostic significance of these serial recordings.

Ventricular tachycardia and ventricular fibrillation are in $75 \%$ of cases associated with ischemic heart disease. In the remaining patients cardiomyopathy, valvular heart disease, right ventricular dysplasia, and long QT syndrome are among the underlying cardiac causes. Ventricular tachycardia or ventricular fibrillation may also occur in the absence of any other cardiac abnormality and is then called idiopathic.

Previous reports $(23,24)$ have indicated that the value of a sustained ventricular tachycardia or ventricular fibrillation as a prognostic indicator for cardiac death is different in patients with an old myocardial infarction as compared to the patients with arrhythmogenic right ventricular dysplasia or without heart disease.

In patients with a sustained ventricular tachycardia, it would be important therefore if the 12-lead electrocardiogram during ventricular tachycardia could be of help to identify the possible etiology (25). Chapter 7 discusses specific electrocardiographic features helpful in the differentiation between ventricular tachycardias originating from infarcted tissue (post-infarction ventricular tachycardia) and those with another etiology (non-ischemic ventricular tachycardia) such as arrhythmogenic right ventricular dysplasia, idiopathic ventricular tachycardia and preexcited tachycardia.

An important question in patients with sustained ventricular tachycardia late after a myocardial infarction is how to discriminate between patients at low and at high risk of developing a recurrence of their arrhythmia. For this purpose a prognostic index was developed based upon the careful evaluation of several parameters like the clinical history, the electrocardiogram, left ventricular function, coronary anatomy etc (26-29). This index discussed in Chapter 8 was retrospectively developed using information from Maastricht patients and thereafter prospectively tested in a group of patients from Heidelberg. Chapter 9, discusses the incidence and timing of recurrences of sudden death and ventri- 
cular tachycardia after a myocardial infarction. It also analyzes the importance of the type of the first arrhythmic event (ventricular tachycardia or ventricular fibrillation) and the left ventricular ejection fraction in predicting subsequent arrhythmic events (recurrent ventricular tachycardia or sudden death).

In patients with symptomatic ventricular tachyarrhythmias after a myocardial infarction selection of the appropriate antiarrhythmic therapy remains a problem (33). It is also not clear how to evaluate the protective effect of amiodarone, the most potent antiarrhythmic drug currently available (34-44). Chapter 10 examines the value of programmed electrical stimulation of the heart in predicting sudden death in patients receiving amiodarone because of serious ventricular tachyarrhythmias after a myocardial infarction. 
1. Durrer D, Schoo L, Schuilenburg RM, Wellens HJJ. The role of premature beats in the initiation and termination of supraventricular tachycardias in the Wolff-Parkinson-White syndrome. Circulation 1967;36:644-662

2. Coumel Ph, Cabrol C, Fabiato A, Gourgon R, Slama R. Tachycardie permanente par rythme réciproque en dehors du syndrome de Wolff-Parkinson-White. Arch Mal Coeur 1967;60:1830-1837.

3. Wellens HJJ. Electrical stimulation of the heart in the study and treatment of tachycardias. University Park Press. Baltimore, 1971.

4. Mahaim I, Winston MR: Recherchers d'anatomie compareé et de pathology expermintale sur les connexions hautes de His-Tawara. Cardiologia 1941; 5:189-192.

5. Anderson R, Becker A, Brechenmacher C, Davies M, Rossi L. Ventricular preexcitation. A proposed nomenclature for its substrates. Eur J Cardiol 1975;27-36.

6. Wellens HJJ, Brugada P, Penn OC. The management of preexcitation syndromes. J.A.M.A. 1987;257:2325-2333.

7. Warin JF, Haissaguerre M, Lematayer P, Guillem JP, Blanchot P. Catheter ablation of accessory pathways with a direct approach. Results in 35 patients. Circulation 1988;78:800-815.

8. Jackman W, Wang X, Friday KJ. et al. Catheter ablation of accessory pathways (WolffParkinson-White syndrome) by radiofrequency current. New Engl J Med 1991;3241605-1611.

9. Kuck HK, Schluter M, Geiger M, Siebels J, Duckeck W. Radiofrequency current catheter ablation of accessory pathways. Lancet 1991;337:1557-1561.

10. Becker AG, Anderson RW, Durrer D, Wellens HJJ. The anatomical substrates of Wolff-Parkinson-White syndrome. A clinicopathologic correlation in seven patients. Circulation 1978;57:870-874.

11. Gallagher JJ, Pritchett ELC, Sealy WC, Kassel J, Wallace AG. The pre-excitation syndromes. Prog Cardiovasc Dis 1978;20:285-327.

12. Milstein S, Sharma AD, Guiraudon GM, Klein GJ. An algorithm for the electrocardiographic localization of accessory pathways in the Wolff-Parkinson-White syndrome. PACE 1987; 10:555-563.

13. Lemery R, Hammill SC, Wood DL, Danielson GK, Mankin HT, Osborn MJ, Gersh BJ, Holmes DR. Value of the resting 12 lead electrocardiogram and vectocardiogram for locating the accessory pathway in patients with the Wolff-Parkinson-White syndrome. Brit Heart J 1987;58:324-332.

14. Lindsay BD, Crossen KJ, Cain ME. Concordance of distinguishing electrocardiographic features during sinus rhythm with the location of accessory pathways in the WolffParkinson-White syndrome. Am J Cardiol 1987;59:1093-1102.

15. Epstein AE, Kirklin JK, Holman WL, Plumb VJ, Kay GN. Intermediate septal pathways: Electrocardiographic characteristics, electrophysiologic observations and their surgical implications. J Am Coll Cardiol 1991;17:1570-1578.

16. Scheinman MM, Wang YS, Van Hare GF, Lesh MD. Electrocardiographic and electrophysiologic characteristics of anterior, midseptal and right anterior free wall accessory pathways. J Am Coll Cardiol 1992;20:1220-1229.

17. Evans W, Swann P. Lone atrial fibrillation. Brit Heart J 1954;16:189-194. 
18. Gillem RF. Sudden coronary deaths in the United States, 1980-1985.Circulation 1989;79:756-765.

19. Utereker WJ, Spielman SR, Waxman HL, Horowitz LN, Josephson ME. Ventricular activation in normal sinus rhythm: abnormalities with recurrent sustained tachycardia and history of myocardial infarction. Am J Cardiol 1985;55:974-979.

20. Simson MB. Use of signal in terminal QRS complex to identify patients with ventricular tachycardia after myocardial infarction. Circulation 1981;64:235-242.

21. El-Sherif N, Ursell SN, Bekheit S, Fontaine J, Turitto G, Henkin R, Caref E. Prognostic significance of the signal-averaged electrocardiogram depends on the time of recording in postinfarction period. Am Heart J. 1989;118:256-264.

22. Gomes AJ, Winters SL, Stewart D, Horowitz S, Milner M, Barreca P. A new non-invasive index to predict sustained ventricular tachycardia and sudden death in the first year after myocardial infarction based on signal averaged-electrocardiogram, radionuclide ejection fraction and Holter monitoring. J Am Coll Cardiol 1987; 10:349357.

23. Trappe HJ, Brugada P, Talajic M, Della Bella P, Lezaun R, Mulleneers R, Wellens HJJ. Prognosis of patients with ventricular tachycardia and ventricular fibrillation: role of underlying etiology. J Am Coll Cardiol 1988;12:166-169.

24. Wellens HJJ, Brugada P. Treatment of cardiac arrhythmias: When, How and Where? J Am Coll Cardiol 1989;14:1417-1420

25. Coumel Ph. Diagnostic significance of the QRS wave form in patients with ventricular tachycardia. Cardiology Clinics 1987;5:527-540.

26. Wellens HJJ, Bär FWHM, Vanagt EJDM, Brugada P. Medical treatment of ventricular tachycardia: considerations in the selection of patients for surgical treatment. Am J Cardiol 1982;49:186-193.

27. Brugada P, Talajic M, Smeets JLRM, Mulleneers R, Wellens HJJ. Risk stratification of patients with ventricular tachycardia or ventricular fibrillation after myocardial infarction. the value of the clinical history. Eur Heart J 1989;10:747-751.

28. Willems AR, Tijssen JGP, Van Capelle FJC, Kingma JH, Hauer RW, Vermeulen FEE, Brugada P, van Hoogenhuyze, Janse MJ. On behalf of the Dutch ventricular tachycardia study group of the Interuniversity Cardiology Institute on The Netherlands. Determinants of prognosis in symptomatic ventricular tachycardias or ventricular fibrillation late after myocardial infarction. J Am Coll Cardiol 1990;16:521-530.

29. Moss AJ, Bigger TJ, Case RB. The multicenter postinfarction research group risk stratification and survival after myocardial infarction. N Engl J Med. 1983;309:331-336.

30. Ruskin JN, DiMarco JP, Garan H. Out-of hospital cardiac arrest: Electrophysiologic observations and selection of long-term antiarrhythmic therapy. New Eng $\mathbf{J}$ Med 1980;303:607-613.

31. Hamer A, Vhora J, Hunt D, Sloman G. Prediction of sudden death by electrophysiologic studies in high risk patients surviving acute myocardial infarction. Am J Cardiol 1982;50:223-229

32. Roy D, Waxman HL, Kienzle MG, Buxton AE, Marchlinski FE, Josephson ME. Clinical characteristics and long-term follow-up in 119 survivors of cardiac arrest: Relation to inducibility at electrophysiologic testing. Am J Cardiol 1983;52:969-974.

33. Swerdlow CR, Winkle RA, Mason JW. Determinants of survival in patients with ventricular tachycardia. New Engl J Med 1983;308:1436-1442. 
34. Heger JJ, Prystowsky EN, Jackman WM, Nacarelli GV, Warfel KA,Rinkenberger RL, Zipes DP. Amiodarone: Clinical efficacy and electrophysiology during long-term therapy for recurrent ventricular tachycardia or ventricular fibrillation. $\mathrm{N}$ Engl J Med 1981;305:539-545.

35. Hamer AW, Finerman WB, Peter T, Mandel WJ. Disparity between the clinical and electrophysiologic effects of amiodarone in the treatment of recurrent ventricular tachyarrhythmias. Am Heart J 1981;102:992-1000.

36. Waxman HL, Groh WC, Marchlinski FE, Buxton AE, Sadowski LM, Horowitz LN, Josephson ME, Kastor JA. Amiodarone for control of sustained ventricular tachycarrhythmias. Clinical and electrophysiologic effects in 51 patients. Am J Cardiol 1982;50:1066-1074.

37. Nademanee K, Hendrickson JA, Jannan R, Singh BH. Antiarrhythmic efficacy and electrophysiologic actions of amiodarone in patients with life-threatening ventricular arrhythmias: Potent suppression of spontaneously occurring tachyarrhythmias versus inconsistent abolition of induced ventricular tachycardia. Am Heart J 1982;103:950-959.

38. Horowitz LN, Greenspan AM, Spielman SR, Webb CR, Morganroth J, Rotmensch H, Sokoloff NM, Rae AP, Segal BL, Kay HR. Usefulness of electrophysiologic testing in evaluation of amiodarone therapy for sustained ventricular tachyarrhythmias associated with coronary artery disease.. Am J Cardiol 1985:55:367-371.

39. Mc Govern B, Garan H, Malacoff RF, DiMarco JP, Garant G, Sellers D, Ruskin JN. Long-term clinical outcome of ventricular tachycardia or fibrillation treated with amiodarone. Am J Cardiol 1984;53:1558-1563.

40. Nacarelli GV, Fineberg NS, Zipes DP, Heger JJ, Duncan G, Prystowsky EN,. Amiodarone: Risk factors for recurrences of symptomatic ventricular tachycardia identified at electrophysiologic study. J Am Coll Cardiol 1985;68:814-821.

41. Kadish AH, Buxton AE, Waxman HL, Flores B, Josephson ME, Marchlinski FE. Usefulness of electrophysiologic study to determine the clinical tolerance of arrhythmia recurrences during amiodarone therapy. J Am Coll Cardiol 1987;10:90-96.

42. Zhu J, Haines DE, Lerman BB, DiMarco JP. Predictors of efficacy of amiodarone and characteristics of recurrence of arrhythmia in patients with sustained ventricular tachycardia and coronary artery disease. Circulation 1987;76:802-809.

43. Manolis AS, Urichio F, Estes ME. Prognostic value of early electrophysiologic studies for ventricular tachycardia recurrence in patients with coronary artery disease treated with amiodarone. Am J Cardiol 1989;63:1052-1057

44. Kim SG, Felder SD, Figura I, Johnston DR, Mercado AD, Fisher JD. Prognostic value of changes in the mode of ventricular tachycardia induction during therapy with amiodarone and class 1A antiarrhythmic agent. Am J Cardiol 1987;59:1314-1318. 


\section{Chapter 2}

\section{Age at onset and gender of patients suffering from different types of supraventricular tachycardias}

Luz-Maria Rodriguez, MD, Christian de Chillou, MD, Jürg Schläpfer, MD, Jacques Metzger, MD, Xie Baiyan, MD, Adri van den Dool, BS, Joep LRM Smeets, MD, Hein J.J Wellens, MD. 


\section{Age at onset and gender of patients suffering from different types of supraventricular tachycardias}

Sex differences between certain types of arrhythmias have been reported. For example the Wolff-Parkinson-White syndrome is more common in males than females (1). Atrioventricular (AV) nodal tachycardia has been observed to occur more frequently in females (2). Little is known about the age at onset of different types of supraventricular tachycardias.

The purpose of our study was 2 fold: 1) to obtain insight into a possible relation between gender of the patients and type of supraventricular tachycardia and, 2) to look for possible differences in age at the time of the first arrhythmic event in relation to the type of arrhythmia. Three groups of patients were studied, patients with atrial tachycardia, AV nodal tachycardia and patients suffering from tachycardias in the presence of an accessory atrioventricular pathway. Following an invasive electrophysiologic study (3), 623 consecutive patients were selected because they suffered from atrial tachycardia, AV nodal tachycardia and tachycardias in the presence of an accessory atrio-ventricular connection. After informed consent patients were studied from January 1979 to August 1991 for evaluation and treatment of their arrhythmia. Four hundred and nine patients $(66 \%)$ were found to have an accessory atrio-ventricular pathway. One hundred and 65 patients (26\%) had AV nodal tachycardia, and 49 patients (12\%) suffered from an atrial tachycardia. All patients were carefully questioned as to their age at the time of their first tachycardia. The mean age at the time of electrophysiologic study was: accessory pathways patients; $34 \pm 14$ (6-65) years, AV nodal tachycardia patients; $42 \pm 20$, (7-71) years atrial tachycardia patients $35 \pm 19$ (2-73) years. Anterogradely conducting accessory pathways (Wolff-Parkinson-White syndrome) were present in 317/409 (77\%). The remaining 92 patients (23\%) had an accessory pathway only conducting in ventriculo-atrial direction (a so called "concealed" accessory pathway). Sixteen out of these 92 patients had a concealed accessory pathway of the slow conducting type (4). Three hundred and eighty nine out of 409 patients had a single $(95 \%)$ and 20 patients more than one accessory pathway $(5 \%)$. Eight patients were found to have a left bundle branch block Mahaim type tachycardia during electrophysiologic study. The AV nodal tachycardia was of the common (slow-fast) 
type in 160 patients $(97 \%)$ and the uncommon (fast-slow) type in 5 patients (3\%). Atrial tachycardia was present in 49 patients. The arrhythmia was paroxysmal in $30(61 \%)$ and incessant in the remaining 19 patients $(39 \%)$ (4). Of 409 patients with accessory pathways, 180 patients had electrocardiographic documentation of their arrhythmia prior to the electrophysiologic study. One hundred and thirty patients had orthodromic circus movement tachycardia and 66 patients atrial fibrillation with only or predominantly preexcited QRS complexes. Twelve patients were resuscitated from ventricular fibrillation $(3 \%)$. These findings indicate that some patients with an accessory pathway had electrocardiographic documentation of more than one type of arrhythmia.

Continuous variables are expressed as mean $+\mathrm{SD}$. Group of patients were compared with the analysis of variance test. Statistical significance was assumed for $p$ values of $<0.05$. Sex ratio was used to calculate the sex distribution in arrhythmic groups.

Arrhythmias in patients with accessory pathways were more often observed in males than females (273 (67\%) vs $136(33 \%)$ respectively; sex ratio Male/ Female: 2.00 ). In contrast AV nodal tachycardias were about twice as common in females (113 (68\%) women vs $52(32 \%)$ men); sex ratio Men/Female: 0.46$)$. Atrial tachycardias occurred in similar proportions in males $(23(47 \%)$, and females $=26(53 \%)$.

Two hundred and eight spontaneous tachycardias were electrocardiographically documented in 180 patients with accessory pathways (1.16 per patient), 123 were males and 57 were females. Orthodromic circus movement tachycardia occurred relatively more often in females (49 patients) than in males ( 81 patients), (Sex ratio M/F 1.65) ( $<<0.001$ ). Also atrial fibrillation and ventricular fibrillation occurred more often in male than female patients, (atrial fibrillation 51 males and 15 females (Sex ratio M/F $3.4(p=0.06)$, ventricular fibrillation 11 males and 1 female (Sex ratio M/F 11.0)). Both differences did not reach statistical significance. In three out of the 12 patients with ventricular fibrillation, that arrhythmia was the first arrhythmic event (Table I,II).

As shown in Table III, arrhythmias in patients with accessory atrio-ventricular pathways tend to occur at a younger age than atrial and AV nodal tachycardia (Fig 1). It should also be noted that the first episode of a regular supraventricular tachycardia may occur after middle age, although this is rare in patients with accessory pathways.

Half of the patients with accessory pathways had their first tachycardia before the age of 20 years. While circus movement tachycardia can occur for the first time at a relatively advanced age, atrial fibrillation and ventricular fibrillation occur relatively early in patients with an AV accessory pathway.(Fig 2) 
Table I. Gender of patients with supraventricular tachycardias

\begin{tabular}{|c|c|c|c|c|}
\hline \multirow[b]{2}{*}{ Type arrhythmia } & \multicolumn{4}{|c|}{ Sex ratio } \\
\hline & Male & Female & $\mathrm{M} / \mathrm{F}$ & \\
\hline Accessory pathways & 273 & 136 & 2.00 & \\
\hline AV nodal tachycardia & 52 & 113 & 0.46 & \\
\hline Atrial tachycardia & 23 & 26 & 0.88 & \\
\hline
\end{tabular}

Table II. Gender of patients in relation to different types of supraventricular tachycardias

Type of arrhythmia Gender Sex ratio

Males $\quad$ Females $(M / F)$

1) Atrial tachycardia

Paroxysmal

Incessant

12

11

18

0.66

1.37

2) AV Nodal tachycardia

Common type

Uncommon type

$\begin{array}{rrr}51 & 109 & 0.47 \\ 0 & 5 & 0.00\end{array}$

3) Accessory Pathways

Overt

21

Concealed

62

106

$62 \quad 30$

$12 \quad 4$

1.96

Slow

49

27

3.00

Fast

81

49

1.92

Circusmovement tachy

Atrial fibrillation

51

1.65

Ventricular fibrillation

LBBB Mahaim type tachy

11

15

3.4

$\begin{array}{lll}11 & 1 & 11.0\end{array}$

6

2

3.00

Abbreviations: $\mathrm{F}=$ female, $\mathrm{M}=$ male, $\mathrm{LBBB}=$ left bundle branch block, Tachy = tachycardia

In our study, we observed that the first arrhythmic event occurred at a younger age in patients with accessory pathways (overt and concealed) as compared to patients with AV nodal tachycardia or atrial tachycardias. Half of the accessory pathways patients had their first arrhythmic episode before they were 20 years 
Table III. Age at onset of first arrhythmic event in documented supraventricular tachycardias

Age at onset (years)

\begin{tabular}{lrrrrrrrrr}
\cline { 3 - 9 } Type of Tachycardia & $0-9$ & $10-19$ & $20-29$ & $30-39$ & $40-49$ & $50-59$ & $60-69$ & \multicolumn{1}{c}{ T } \\
\hline Atrial tachycardia & 7 & 13 & 8 & 12 & 1 & 3 & 5 & 49 \\
AVN tachycardia & 15 & 38 & 38 & 23 & 30 & 16 & 5 & 165 \\
& CMT & 21 & 42 & 25 & 25 & 13 & 3 & 1 & 130 \\
Accessory & AF & 4 & 24 & 14 & 15 & 7 & 1 & 0 & 65 \\
pathway & VF & 1 & 7 & 3 & 1 & 0 & 0 & 0 & 12 \\
& & & & & & & & & \\
\end{tabular}

Abbreviations: $\mathrm{AF}=$ atrial fibrillation, $\mathrm{AVN}=\mathrm{AV}$ nodal tachycardia, $\mathrm{CMT}=$ circus movement tachycardia, $\mathrm{T}=$ total $\mathrm{VF}=$ ventricular fibrillation.

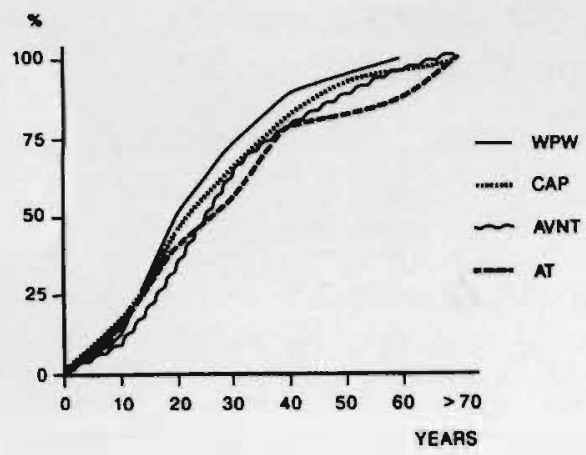

Figure 1: Graph showing the age at onset of first arrhythmic event in patients with different supraventricular tachycardias: $\mathrm{AT}=$ atrial tachycardia; AVNT = atrio-ventricular nodal tachycardia; CAP = Concealed accessory pathway; WPW = Wolff-ParkinsonWhite syndrome.

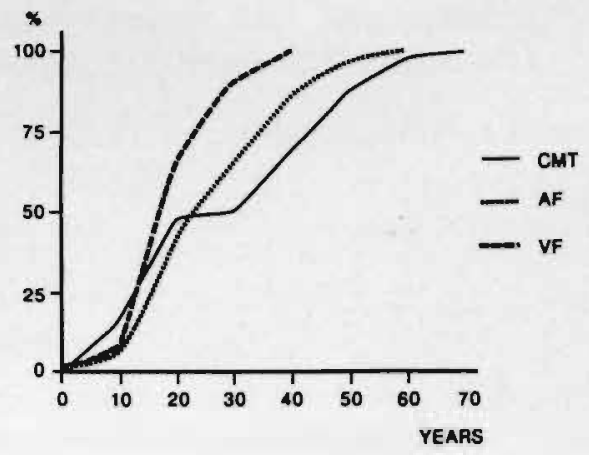

Figure 2: Age at onset of first arrhythmic event in patients with accessory atrioventricular pathways. $\mathrm{AF}=$ atrial fibrillation; $\mathrm{CMT}=$ circus movement tachycardia; $\mathrm{VF}=$ ventricular fibrillation.

old. We also observed that AV nodal tachycardia occurs more often in females, whereas arrhythmias using accessory pathways were more often seen in males. Although patients symptomatic because of an accessory pathway were more frequently male, a circus movement tachycardia occurred relatively more often in females than in males. In contrast atrial fibrillation and ventricular fibrillation 
was found more often in males than in females. Our observations were made in patients referred to our institution for electrophysiologic study and treatment of their tachycardia, therefore it may not reflect the natural history of supraventricular tachycardia in the whole (in- and out of hospital) population. The last finding was also reported by Torner et al (6). 


\section{References}

1. Wellens HJJ. The electrophysiologic properties of the accessory pathway in the WolffParkinson-White syndrome. In The conduction system of the heart. Wellens HJJ, Lie KI, Janse MJ. (Eds). Leiden; HE Stenfert Kroese B. V. 1976: pp 567-588.

2. Wellens HJJ, Bär FW, Farre J, Wiener J, Ross DL, Gorgels AP, Vanagt EJ, Brugada P. Diagnosis and incidence of concealed accessory pathways in patients suffering from paroxysmal AV junctional tachycardias. Rev Lat Cardiol 1980;1:60-67.

3. Ross D, Farre J, Wellens HJJ. Comprehensive electrophysiologic studies in the investigation of documented or suspected tachyarrhythmias. Time, staff, problems and costs. Circulation 1980;61:1010-1016.

4. Wellens HJJ, Brugada P. Mechanisms of supraventricular tachycardias. Am J Cardiol 1988;62:10-15.

5. Tchou P, Lehmann MH, Jazayeri M, Akthar M. Atriofascicular connection or a nodoventricular Mahaim fiber?. Electro-physiologic elucidation of the pathway and associated reentrant circuit. Circulation 1988;4:837-848.

6. Tomer Montoya P, Brugada P, Smeets J, Talajic M, Della Bella P, Lezaun R, Vd Dool A, Wellens HJJ, Bayes de Luna A, Oter R, Breithardt G, Borggrefe M, Klein H, Kuck KH, Kunze H, Coumel Ph, Leclercq JF, Chouty F, Frank R, Fontaine G. Ventricular Fibrillation in the Wolff-Parkinson-White syndrome. Eur Heart J 1991;12:144-150. 



\section{Chapter 3}

\section{The 12-lead electrocardiogram in mid-septal, anteroseptal, posteroseptal and right free wall accessory pathways}

Luz-Maria Rodriguez, MD, Joep LMR Smeets, MD, Christian de Chillou, MD, Jacques Metzger, MD, Jürg Schläpfer, MD, Olaf Penn*, MD, Arnd Weide, MD, Hein J.J Wellens, MD. 


\section{The 12-lead electrocardiogram in mid-septal, anteroseptal, posteroseptal and right free wall accessory pathways}

\section{Abstract}

The 12 lead electrocardiogram of 50 patients with a single anterogradely conducting accessory pathway was analyzed to obtain characteristics electrocardiographic findings in relation to mid-septal, anteroseptal, true posteroseptal and right free wall accessory pathway location. Location was confirmed by surgery (33 patients) or radiofrequency catheter ablation (17 patients). We analyzed: 1) QRS and 2) delta wave axis in the frontal plane, 3) the angle between QRS and delta wave axis, 4) the R/S ratio in lead III, 5) negativity of delta wave in inferior leads, 6) the R/S ratio in precordial leads. Results.1) QRS axis in the forntal plane in: right free wall: ranged from $+15^{\circ}$ to $-65^{\circ}\left(-32 \pm 19^{\circ}\right)$; true posteroseptal: ranged from $+30^{\circ}$ to $-60^{\circ}\left(-38 \pm 22^{\circ}\right)$; mid-septal: ranged from $+15^{\circ}$ to $+60^{\circ}(+49$ $\left.\pm 11^{\circ}\right)$; anteroseptal: ranged from $0^{\circ}$ to $+75^{\circ}\left(+46 \pm 22^{\circ}\right)$; 2) delta wave axis: right free wall: $0^{\circ}$ to $-60^{\circ}\left(-32 \pm 22^{\circ}\right)$; true posteroseptal: $0^{\circ}$ to $-60^{\circ}\left(-43 \pm 18^{\circ}\right)$; mid-septal: $0^{\circ}$ to $+45^{\circ}\left(+24 \pm 15^{\circ}\right)$ and anteroseptal: $0^{\circ}$ to $+60^{\circ}\left(+45 \pm 17^{\circ}\right)$. 3) QRS/ delta wave axis angle: right free wall: $7 \pm 6^{\circ}$, true posteroseptal: $9 \pm 7^{\circ}$, mid-septal: $22 \pm 6^{\circ}$ and anteroseptal accessory pathways: $\left.3 \pm 5^{\circ} ;(p=0.006) .4\right)$ the $\mathrm{R} / \mathrm{S}$ ratio lead III was $<1$ in true posteroseptal and right free wall, $>1$ in anteroseptal and equal to $1 \mathrm{in} \mathrm{mid-septal} \mathrm{accessory} \mathrm{pathways.} \mathrm{5)} \mathrm{Delta} \mathrm{negativity}$ in at least 2 inferior leads was observed in right free wall: $90 \%$, in true posteroseptal: $90 \%$, in mid-septal; $0 \%$ and anteroseptal accessory pathways: $0 \%$ $(\mathrm{p}<0.0001) .6)$ The R/S ratio $>1$ in V2 was: right free wall: $20 \%$, true posteroseptal: $100 \%$, mid-septal: $12 \%$, anteroseptal: $0 \%$ ( $<<0.0001)$. Conclusions: Mid-septal and anteroseptal accessory pathways can be differentiated from a right free wall and true posteroseptal location by the QRS axis and delta wave polarity in inferior leads. Mid-septal can be distinguished from anteroseptal by the difference between the QRS and delta wave axis and the R/S ratio in lead III. QRS/delta wave axis angle of $\geq 20^{\circ}$ and an $\mathrm{R} / \mathrm{S}$ ratio equal to 1 in lead III favor a mid-septal accessory pathway location 


\section{Introduction}

Several authors have suggested criteria for the localization of accessory pathways using the 12-lead electrocardiogram (1-8). Most of these criteria are developed to differentiate four principal location sites: right free wall, left free wall, anteroseptal and posteroseptal. Little is known about the electrocardiographic features of mid-septal accessory pathways $(9,10)$. In view of the fact that catheter ablation procedures enabling very localised tissue destruction have become the treatment of choice in patients with accessory pathways suffering from symptomatic arrhythmias, the precise localization of accessory pathways has become of increasing importance. Therefore, this study examines electrocardiographic criteria to differentiate mid-septal accessory pathways from those located in the right free wall, the posteroseptal and the anteroseptal areas.

\section{Patients and Methods}

In our institution 245 patients (May 1985 through May 1991) had surgical and 138 patients (May 1991 to December 1992) radiofrequency ablation of their accessory atrio-ventricular pathway(s). Fifty patients with a single anterogradely conducting accessory pathway are the subject of this study. There were 27 males and 23 females with a mean age of $29 \pm 12$ years ( $12-59$ years). A medical history, 12-lead electrocardiogram, and a 2-dimensional echocardiogram was available in all patients. Location of the accessory pathway was obtained during programmed electrical stimulation and confirmed during intraoperative mapping (33 patients) or by radiofrequency catheter ablation (17 patients). Surgical (11) and radiofrequency catheter ablation techniques (12) for accessory pathways used in our institution have been described elsewhere. None of our patients had additional congenital or acquired cardiac abnormalities which could have affected the QRS morphology. All electrocardiograms showed a clear delta wave with a combined delta-QRS width of at least $0.12 \mathrm{sec}$. The electrocardiograms were analyzed at a paper speed of $25 \mathrm{~mm} / \mathrm{sec}$ by four independent observers. The electrocardiographic data analyzed were: 1) QRS axis and 2) delta wave axis in the frontal plane, 3) the angle between QRS and delta wave axis, 4) the R/S ratio in lead III, 5) the negativity of the delta wave in inferior leads and 6) the R/S ratio in precordial leads. The accessory pathway distribution was as follows: right free wall 10 patients ( 6 confirmed by surgery and 4 by radiofrequency catheter ablation), true posteroseptal 20 patients ( 11 confirmed by surgery and 9 by radiofrequency catheter ablation), mid-septal 9 patients (confirmation by surgery 8 and radiofrequency catheter ablation 1 ) and anteroseptal $=11$ patients (confirmed by surgery 8 , by radiofrequency catheter ablation $3)$. 


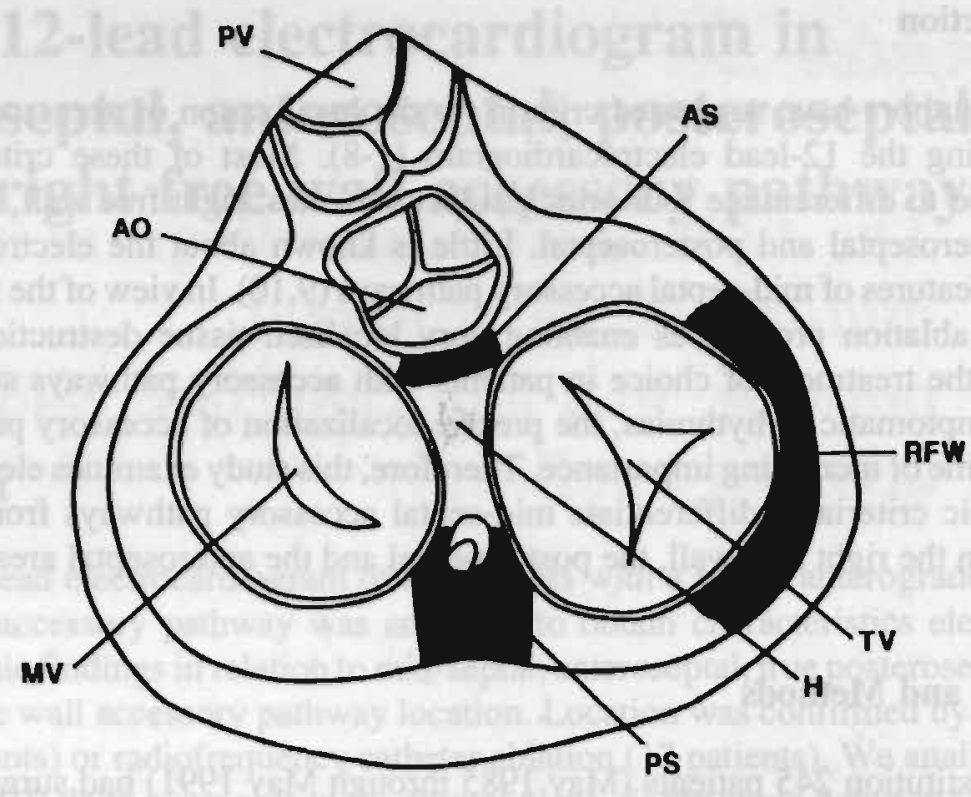

Figure 1A: Cross-sectional diagram of the heart at the level of the atrio-ventricular rings showing the location of different accessory pathways: Anteroseptal (AS), $\mathrm{Ao}=$ Aorta, $\mathrm{H}=$ His bundle, $\mathrm{P}=$ Pulmonary artery, True posteroseptal (PS), right free wall (RFW).

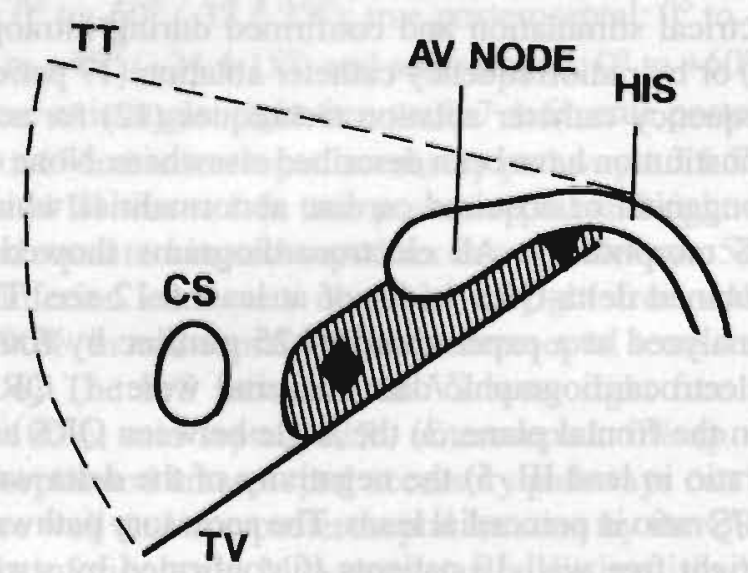

Figure 1B: Scheme depicting the location of the triangle of Koch (cross hatched area). Abbreviations: CS = coronary sinus, $\mathrm{TT}=$ tendon of Todaro, $\mathrm{TV}=$ tricuspid valve. indicates the base and $\nabla$ the apex of the triangle of Koch. 
Table 1. Electrocardiographic findings in right free wall, true posteroseptal, mid-septal and anteroseptal accessory pathways

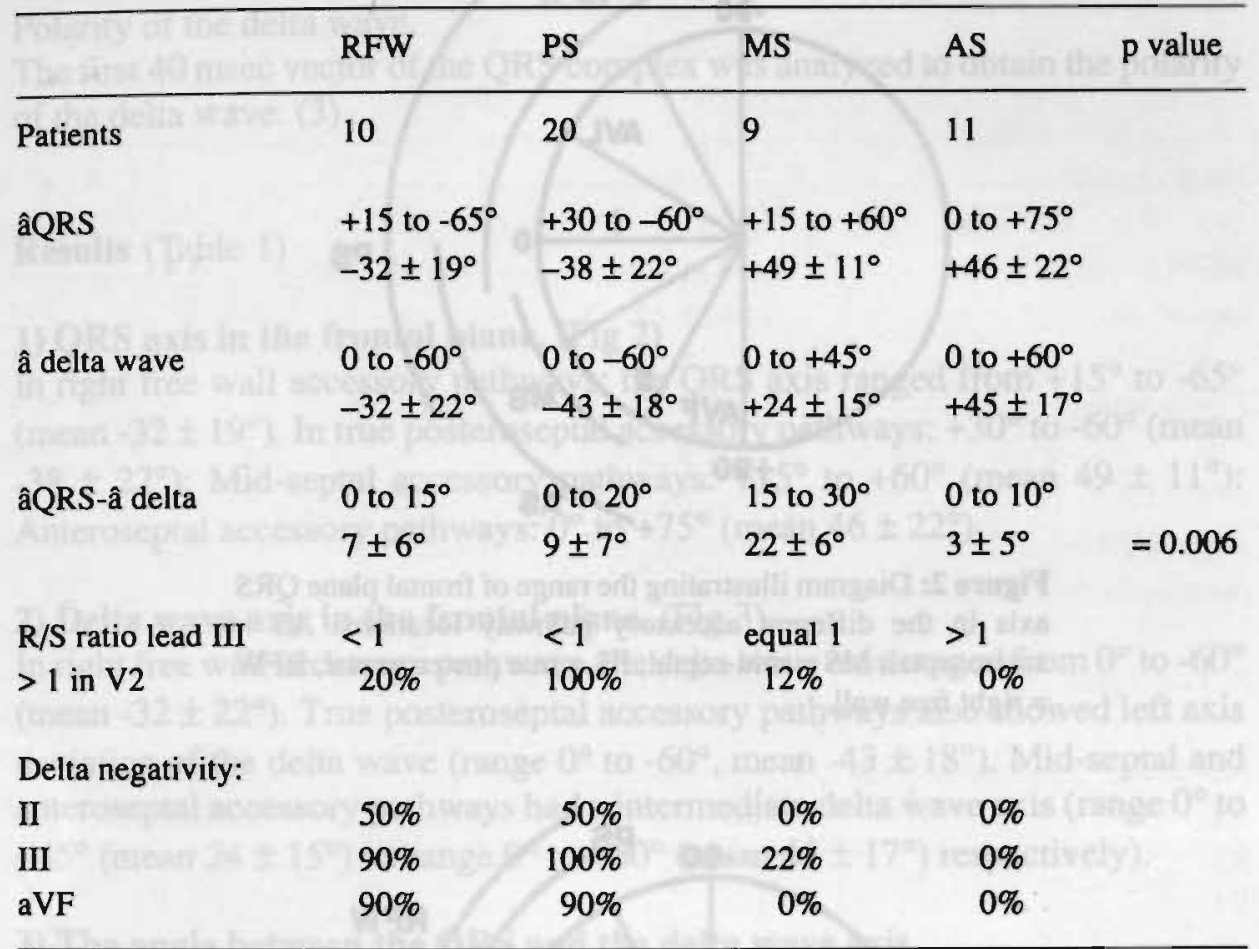

Abbreviations: $\hat{\mathrm{Q} Q R S}=, \mathrm{QRS}$ axis, â delta = delta wave axis, âQRS-â delta = difference between $\mathrm{QRS}$ axis and delta wave axis $\mathrm{AS}=$ anteroseptal, $\mathrm{MS}=$ mid-septal, $\mathrm{PS}=$ true posteroseptal, RFW = right free wall.

\section{Statistical analysis}

Comparison between accessory pathway location groups were analyzed using the 2- way analysis of variance and the Student Newman-Keuls test. The mean are reported with the standard deviation. Statistical significance was assumed for $p$ values of $<0.05$.

\section{Definitions.}

Location of the accessory pathways (Fig 1)

Right free wall: accessory pathways located in the area shown in figure 1.

True posteroseptal: Accessory pathways located posterior and/or apical to the os of the coronary sinus.

Anteroseptal: Accessory pathways situated above the His bundle with ventricular activation cephalad and anterior to the membranous septum. 


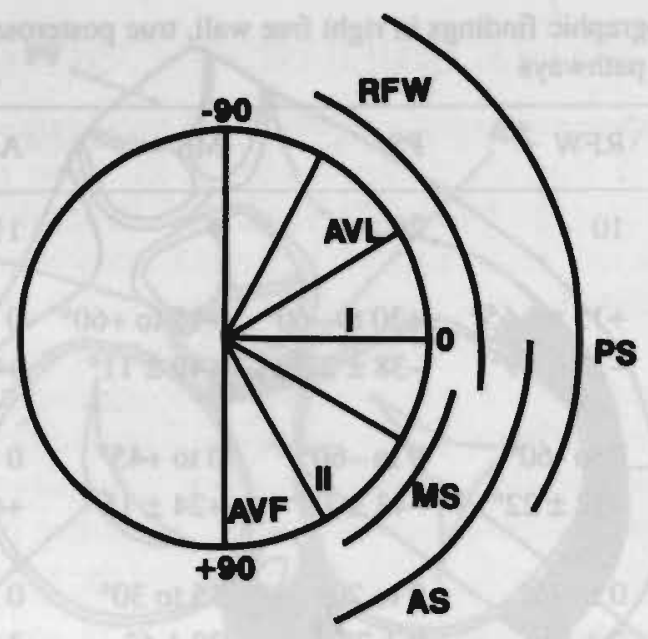

Figure 2: Diagram illustrating the range of frontal plane QRS axis in the different accessory pathway locations. AS = anteroseptal, MS = mid-septal, PS = true posteroseptal, RFW $=$ right free wall.

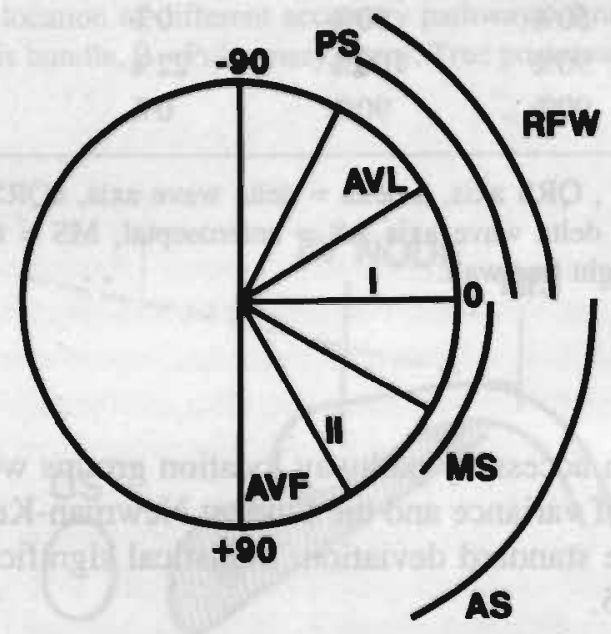

Figure 3: Diagram showing the frontal plane axis of the delta wave in the different accessory pathway locations. AS = anteroseptal, MD- mid-septal, PS = true posteroseptal, RFW $=$ right free wall. 
Mid-septal: Accessory pathways located in the area anterior of the coronary sinus but below the His bundle (Fig 1B)

Polarity of the delta wave.

The first $40 \mathrm{msec}$ vector of the QRS complex was analyzed to obtain the polarity of the delta wave. (3)

\section{Results (Table 1)}

\section{1) QRS axis in the frontal plane. (Fig 2)}

In right free wall accessory pathways: the QRS axis ranged from $+15^{\circ}$ to $-65^{\circ}$ (mean $-32 \pm 19^{\circ}$ ). In true posteroseptal accessory pathways: $+30^{\circ}$ to $-60^{\circ}$ (mean $-38 \pm 22^{\circ}$ ); Mid-septal accessory pathways: $+15^{\circ}$ to $+60^{\circ}$ (mean $49 \pm 11^{\circ}$ ); Anteroseptal accessory pathways: $0^{\circ}$ to $+75^{\circ}$ (mean $46 \pm 22^{\circ}$ ).

\section{2) Delta wave axis in the frontal plane. (Fig 3)}

In right free wall accessory pathways, the delta wave axis ranged from $0^{\circ}$ to $-60^{\circ}$ (mean $-32 \pm 22^{\circ}$ ). True posteroseptal accessory pathways also showed left axis deviation of the delta wave (range $0^{\circ}$ to $-60^{\circ}$, mean $-43 \pm 18^{\circ}$ ). Mid-septal and anteroseptal accessory pathways had a intermediate delta wave axis (range $0^{\circ}$ to $+45^{\circ}$ (mean $24 \pm 15^{\circ}$ ) vs range $0^{\circ}$ to $+60^{\circ}$ (mean $45 \pm 17^{\circ}$ ) respectively).

\section{3) The angle between the QRS and the delta wave axis.}

The angle between the $\mathrm{QRS}$ and the delta wave axis measured in: right free wall: $0^{\circ}$ to $15^{\circ}$ (mean $7 \pm 6^{\circ}$ ), true posteroseptal: $0^{\circ}$ to $20^{\circ}$ (mean $9 \pm 7^{\circ}$ ), mid-septal: $15^{\circ}$ to $30^{\circ}$ (mean $22 \pm 6^{\circ}$ ), anteroseptal accessory pathways: $0^{\circ}$ to $10^{\circ}$ (mean 3 $\left.\pm 5^{\circ}\right)(\mathrm{p}=0.006)$.

\section{4) The $R / S$ ratio in lead III.}

Right free wall and true posteroseptal accessory pathway patients all had a R/S ratio $<1$ in lead III. In all anteroseptal accessory pathway patients the R/S ratio in lead III was $>1$. Seven out of 9 mid-septal accessory pathways patients had a R/S ratio equal to 1 in lead III and in the remaining 2 patients the R/S ratio was $<1$. All 7 patients with a R/S ratio equal to 1 had their accessory pathway located in the apical part of the triangle of Koch just below the bundle of His (Fig 1B)

\section{5) Delta negativity in inferior leads}

Right free wall accessory pathways showed negative delta waves in all 3 inferior leads in $5 / 10$ patients $(50 \%)$. The remaining 5 patients $(50 \%)$ showed a negative delta wave in 2 inferior leads (III and aVF). In true posteroseptal accessory pathways lead III showed in all cases a negative delta wave (100\%). This was 
Table 2. Electrocardiographic findings in mid-septal accessory pathways

\begin{tabular}{lll}
\hline & \multicolumn{2}{l}{ Triangle of Koch } \\
\cline { 2 - 3 } & Apex & Base \\
\hline No.patients & 7 & 2 \\
$\begin{array}{l}\text { âQRS (range) } \\
\text { (mean) }\end{array}$ & $\begin{array}{l}+30 \text { to }+60^{\circ} \\
\left(+46 \pm 12^{\circ}\right)\end{array}$ & +15 and $+25^{\circ}$ \\
â delta wave & 0 to $+45^{\circ}$ & 0 and $+10^{\circ}$ \\
& $\left(+24 \pm 19^{\circ}\right)$ & \\
$\begin{array}{l}\text { Angle âQRS-â } \\
\text { delta wave }\end{array}$ & 15 to $30^{\circ}$ & 10 and $15^{\circ}$ \\
R/S ratio lead III & $\left(22 \pm 13^{\circ}\right)$ & \\
R/S ratio $>$ 1 precordial leads & & $<1(2 / 9)$ \\
V2 & equal to $1(7 / 9)$ & \\
V3 & - & 1 \\
V4 & 5 & - \\
\hline
\end{tabular}

Abbreviations: See Table 1

the case in lead aVF in $18 / 20$ patients; ( $90 \%$ ). Lead II showed a negative delta wave in $10 / 20$ patients (50\%). Therefore posteroseptal accessory pathways presented negative delta waves in at least 2 inferior leads in $18 / 20$ patients (90\%). Mid-septal accessory pathways usually showed positive delta waves in inferior leads ( $7 / 9$ patients; $75 \%$ ). In the remaining 2 patients ( $25 \%$ ), the polarity of the delta wave was negative in lead III. All 11 patients with anteroseptal accessory pathways showed positive delta waves in all inferior leads.

\section{6) The $R / S$ ratio in precordial leads.}

Right free wall accessory pathways: All 10 patients showed a R/S ratio $<1$ in lead $\mathrm{V} 1,8 / 10$ patients also in lead V2, and 4/10 patients also in lead V3. True posteroseptal accessory pathways had an abrupt change to an R/S ratio $>1$ in V2 (18/20 patients). Two patients showed a R/S ratio $>1$ in lead V1. Mid-septal accessory pathways: six out of 9 patients showed a change to a R/S ratio $>1$ in $\mathrm{V} 3$, in 2 patients in V4 and in 1 patient in V2. A R/S ratio > 1 was never found 
Table 3. Delta wave polarity in the 12 lead electrocardiogram of patients with mid-septal accessory pathways

\begin{tabular}{|c|c|c|c|c|c|c|c|c|c|c|c|c|}
\hline \multirow[b]{3}{*}{ Patients } & \multicolumn{12}{|c|}{ Triangle of Koch } \\
\hline & \multirow[b]{2}{*}{ I } & \multirow[b]{2}{*}{ II } & \multirow[b]{2}{*}{ III } & \multirow[b]{2}{*}{ aVR } & \multirow[b]{2}{*}{ aVL } & \multicolumn{2}{|l|}{ Apex } & \multirow[b]{2}{*}{ V2 } & \multirow[b]{2}{*}{ V3 } & \multirow[b]{2}{*}{ V4 } & \multirow[b]{2}{*}{ V5 } & \multirow[b]{2}{*}{ V6 } \\
\hline & & & & & & aVF & V1 & & & & & \\
\hline 1 & + & + & + & - & + & + & - & $-1+$ & + & + & + & + \\
\hline 2 & + & + & + & - & + & + & - & + & + & + & + & + \\
\hline 3 & + & + & + & - & + & + & - & + & + & + & + & + \\
\hline 4 & + & + & + & - & + & + & - & + & + & + & + & + \\
\hline 5 & + & + & + & - & + & + & - & $-1+$ & + & + & + & + \\
\hline 6 & + & + & + & - & + & + & - & - & + & + & + & + \\
\hline 7 & + & + & + & - & + & + & - & - & + & + & + & + \\
\hline 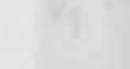 & & & & & & Base & & & & & & \\
\hline 8 & + & + & - & - & + & + & - & + & + & + & + & + \\
\hline 9 & + & + & - & - & + & + & - & $+/$ & + & + & + & + \\
\hline
\end{tabular}

in V1. Anteroseptal accessory pathways showed a shift to a R/S ratio $>1$ mainly in V4 (9/11 patients), and less frequent in V3 (2 patients). It was never observed in $\mathrm{V} 1$ or $\mathrm{V} 2$.

\section{Mid-septal accessory pathways (Table 3)}

Of the 9 patients with a mid-septal accessory pathway, 7 patients had their accessory pathway located just below the His bundle (the apex of Koch's triangle) and in the remaining 2 patients the accessory pathway was situated in the posterobasal part of the triangle of Koch (Fig 1B).

The electrocardiographic characteristics of these 2 subgroups are shown in Table 2.

Accessory pathways arising at the apex: The 7 patients with an accessory pathway in the apex of Koch's triangle showed a QRS axis ranging from $30^{\circ}$ to $60^{\circ}$; (mean $+46 \pm 12^{\circ}$ ), and a delta wave axis ranging from $0^{\circ}$ to $+45^{\circ}$ (mean $+24 \pm 19^{\circ}$ ). The angle between $\mathrm{QRS}$ and delta wave axis ranged from $+15^{\circ}$ to 


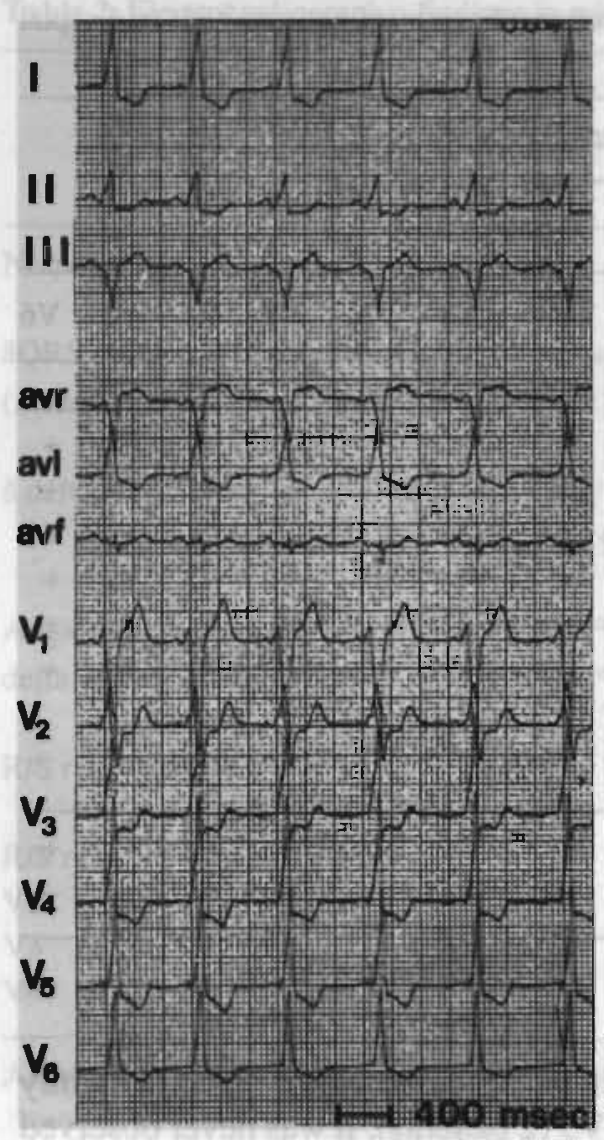

Figure 4: Twelve lead electrocardiogram from a patient with a right free wall accessory pathway. The QRS axis is $-10^{\circ}$. There is a concordant pattern between QRS and delta wave axis. The $\mathrm{R} / \mathrm{S}$ ratio in the precordial leads becomes $>1$ in V3.

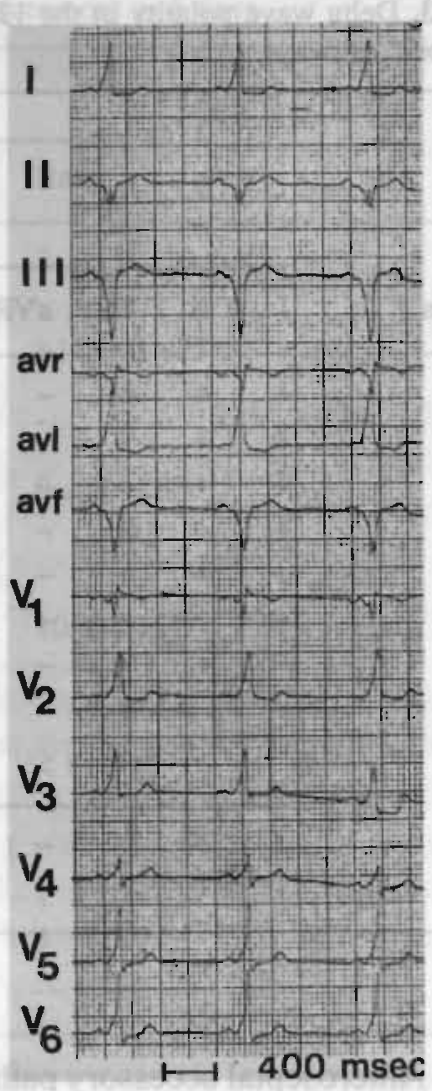

Figure 5: Electrocardiogram from a patient with a true posteroseptal accessory pathway. The QRS and delta wave axis are concordant, both $-60^{\circ}$. The delta wave is negative in all inferior leads. Abrupt change to $\mathrm{R} / \mathrm{S}$ ratio $>1$ in lead V2.

$+30^{\circ}$; mean $+22 \pm 13^{\circ}$. The R/S ratio in lead III was equal to 1 in all 7 patients. The first precordial lead to show an R/S ratio $>1$ was V3 in 5 patients and V4 in 2 patients.

Accessory pathways arising at the base: The 2 patients with an accessory pathway located at the basal (posterior) part of the Koch's triangle, showed a QRS axis of $+15^{\circ}$ and $+25^{\circ}$ and a delta wave axis of $0^{\circ}$ and $+10^{\circ}$. The angle 


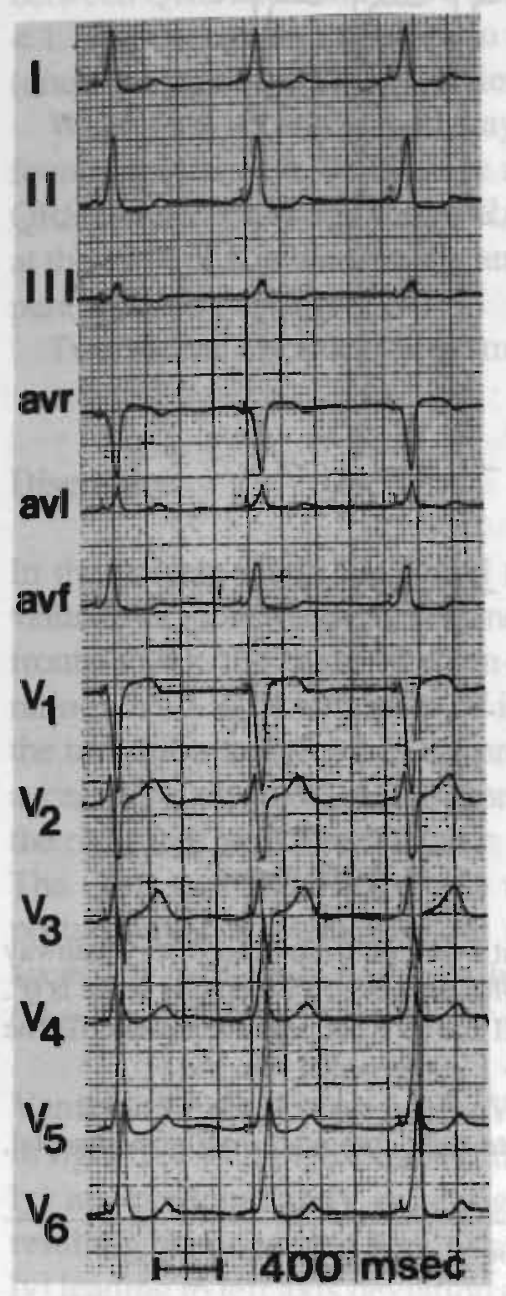

Figure 6: Twelve lead electrocardiogram of a patient with an accessory pathway in the anteroseptal region. The QRS and delta wave axis are concordant. The delta wave is positive in all inferior leads. The $\mathrm{R} / \mathrm{S}$ ratio in lead III is $>1$ and the $\mathrm{R} / \mathrm{S}$ ratio becomes $>1$ in precordial lead V4.

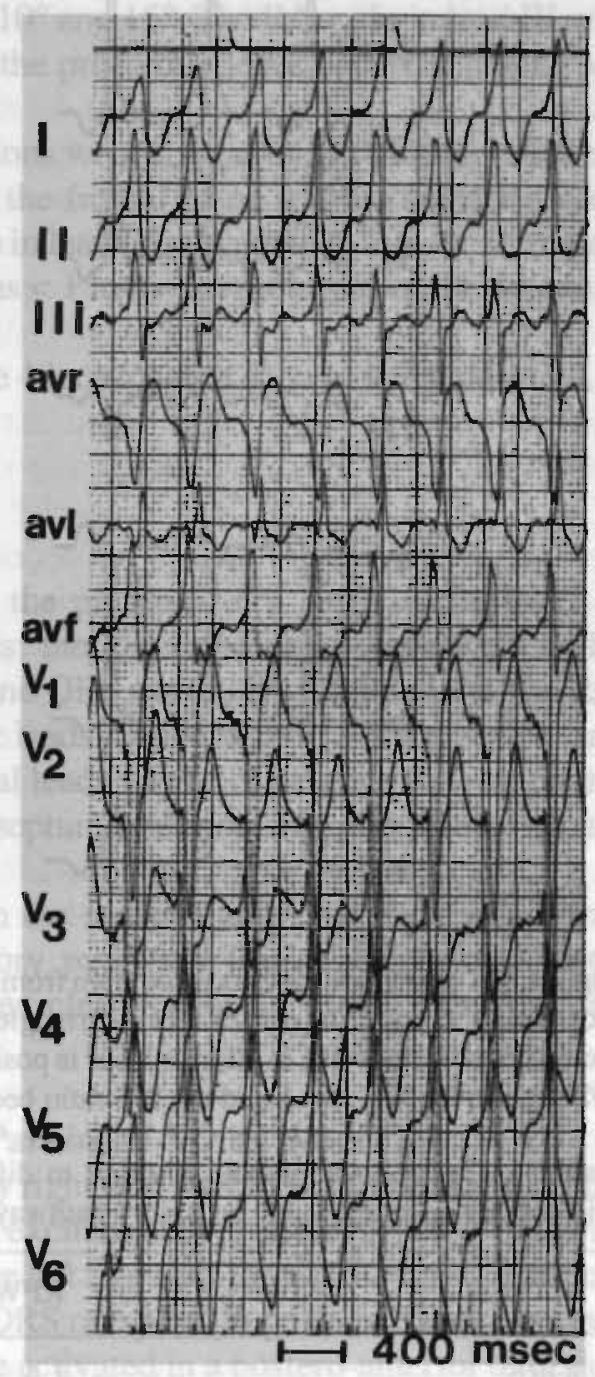

Figure 7: Twelve lead electrocardiogram in a patient with a mid-septal accessory pathway located in the apical part of Koch's triangle. The QRS axis is $+30^{\circ}$ whereas the delta wave axis is $+60^{\circ}$. The delta wave is positive in all inferior leads. The R/S ratio in lead III is $=1$ and the $R / S$ ratio becomes $>1$ in precordial lead V4. 

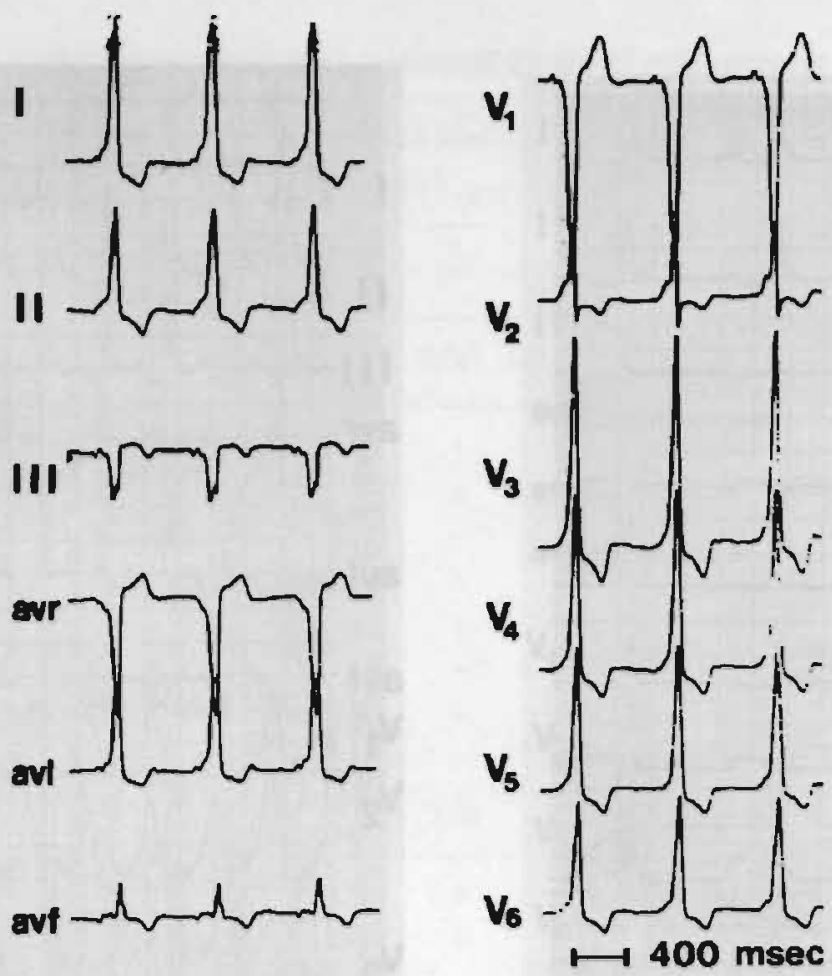

Figure 8: Twelve lead electrocardiogram from a patient with a mid-septal accessory pathway located in the posterior part of Koch's triangle. The QRS axis is $+15^{\circ}$, the delta wave is $0^{\circ}$. Note that the delta wave in inferior leads is positive in II and aVF but negative in lead III. The $\mathrm{R} / \mathrm{S}$ ratio in lead III is $<1$ and the $\mathrm{R} / \mathrm{S}$ ratio becomes $>1$ in precordial lead V2.

Table 4. Electrocardiographic findings to differentiate right free wall, true posteroseptal, mid-septal and anteroseptal accessory pathways.

\begin{tabular}{lllll}
\hline & RFW & PS & MS & AS \\
\hline 1. âRS & LA & LA & NA & NA \\
2. âDELTA & LA & LA & NA & NA \\
3. Angle âQRS-delta & $<10^{\circ}$ & $<10^{\circ}$ & $\geq 20^{\circ}$ & $<5^{\circ}$ \\
$\begin{array}{l}\text { 4. R/S ratio lead III } \\
\text { 5. Two inferior leads with }\end{array}$ & $<1$ & $<1$ & $=1$ & $>1$ \\
$\begin{array}{l}\text { delta negativity } \\
\begin{array}{l}\text { Change to R/S ratio }>1 \\
\text { in precordial leads }\end{array}\end{array}$ & + & + & - & - \\
\end{tabular}

Abbreviations: âQRS $=\mathrm{QRS}$ axis, â delta $=$ axis delta wave, Angle âQRS-â delta $=$ angle between $\mathrm{QRS}$ and delta wave axis. $\mathrm{LA}=$ left axis, $\mathrm{NA}=$ normal axis, $+=$ present, $-=$ absence 
between $\mathrm{QRS}$ and delta wave axis was $10^{\circ}$ and $15^{\circ}$. The $\mathrm{R} / \mathrm{S}$ ratio in lead III was $<1$. The change to an R/S ratio $>1$ in the precordial leads occurred in lead V2 (one patient) or lead V3 (1 patient).

When both accessory pathway locations were compared, no differences were found in QRS axis, delta wave axis in the frontal plane and the angle between $\mathrm{QRS}$ and delta wave axis. The $\mathrm{R} / \mathrm{S}$ ratio in lead III was equal to 1 in those arising at the apex of Koch's triangle and it was $<1$ in those coming from the posterior part of Koch's triangle.

Twelve lead electrocardiograms of the 4 locations are shown in figures 4 to 8 .

\section{Discussion}

In the present study we found that in the presence of a sufficient amount of ventricular preexcitation parameters as: the $Q R S$ and delta wave axis in the frontal plane, the angle between delta and QRS axis in the frontal plane, the R/S ratio in lead III, the number of inferior leads having negative delta waves, and the transition to $\mathrm{R} / \mathrm{S}>1$ in the precordial leads can be of help for differentiating accessory pathways located along the septum (anterior, mid and posterior) and the right free wall of the heart.

The QRS and delta wave axis were in the same direction in right sided, true posteroseptal and anteroseptal accessory pathways (Figs 4-6). In mid-septal accessory pathways however both axes clearly showed a different direction (Figs 7 and 8).

\section{Ventricular excitation in the Wolff-Parkinson-White syndrome.}

In right free wall preexcitation, the early right free wall forces (directed anteriorly) are predominantly resulting from excitation over the accessory pathway resulting in unopposed dominance of the left free wall forces (directed posteriorly) leading to left axis deviation of the $\mathrm{QRS}$ complex. In posteroseptal accessory pathways the right and left ventricle are activated in a postero-anterior direction also giving left axis deviation of the QRS complex. The anteroseptal accessory pathways activate the right and left ventricle in an antero-posterior direction resulting in an intermediate QRS axis (13). Mid-septal accessory pathways activate the ventricles in a complicated manner depending upon the location of the accessory pathway in the mid-septal area.

Intraoperative mapping during preexcitation showed that the earliest epicardial activation breakthrough occurs simultaneously at the base of the aorta and at the crux in those accessory pathways located in the anterior part of the triangle of Koch (below the His) and anteriorly to the base of the aorta in those accessory pathways located at the posterior part of the triangle of Koch (9). 
The electrocardiographic recognition of mid-septal accessory pathways. Our results show that the QRS and the delta wave axis, are very similar when the accessory pathway is located in the apical or posterior part of Koch's triangle. However the delta wave polarity in the inferior leads is helpful in differentiating the 2 mid-septal accessory pathway locations. The polarity of the delta wave in lead III was always positive in those accessory pathways arising below the His bundle, whereas patients in whom the accessory pathway was located at the posterior part of the Koch's triangle showed a negative delta wave in lead III. Also, the R/S ratio in lead III was of help in the differentiation of these 2 locations. It was equal to 1 in accessory pathways located in the anterior part of the Koch's triangle, and it was $<1$ in those arising in the posterior part of the Koch's triangle. The precordial site of change to a R/S ratio $>1$ was similar in both types of mid-septal accessory pathways.

\section{Differentiation of mid-septal from right free wall, true posteroseptal and anteroseptal accessory pathways.}

As shown in Table 4 we believe that mid-septal accessory pathways can be differentiated from right free wall, true posteroseptal and anteroseptal accessory pathways on the 12-lead ECG: 1) A normal QRS axis in the frontal plane suggests a mid-septal or anteroseptal accessory pathway location, whereas a left axis suggests either a right free wall or posteroseptal accessory pathway. 2) A normal delta wave axis argues for a mid-septal or anteroseptal accessory pathway, a left axis suggests a right free wall or a posteroseptal accessory pathway. 3) The angle between QRS and delta wave axis and the R/S ratio in lead III are of help to differentiate a mid-septal from an anteroseptal accessory pathway. A clear angle between the QRS and delta wave axis and an R/S ratio equal to 1 support a mid-septal localization 4) The presence of two or three inferior leads showing negative delta waves favors a right free wall or posteroseptal accessory pathway, whereas positive delta waves in all inferior leads suggest an anteroseptal accessory pathway. 5) The presence of a R/S ratio $>1$ in precordial lead V2 strongly suggests a true posteroseptal accessory pathway.

\section{Review of the literature}

Epstein et al (9) reported 4 patients with "intermediate septal" accessory pathways. Three out of 4 patients had an accessory pathway located at the base and 1 at the apex of Koch's triangle. Patients with accessory pathways located at the base of Koch's triangle showed a negative delta wave in lead III and an equiphasic delta wave in lead aVF. In the patient who had an accessory pathway situated at the apex of Koch's triangle, the delta wave was positive in lead III and aVF. 
Our findings are in agreement with those reported by Epstein et al (9).

Recently, Scheinman et al (10) reported on the electrocardiographic and electrophysiologic characteristics of anterior, mid-septal and right anterior free wall accessory pathways. In their study (10) mid-septal could not be differentiated from anteroseptal accessory pathways. A limitation of the study was that only 11 out of 27 patients had a precise localization either by surgery or radiofrequency catheter ablation with only 2 out of 6 mid-septal accessory pathways with overt preexcitation having their location confirmed by surgery or catheter ablation.

\section{Limitations of our study}

The relatively small group of patients studied remains one of the limitations of our study. We also looked at the electrocardiogram during sinus rhythm. Although a sufficient amount of ventricular preexcitation was assured (by requiring a clear delta wave and a combined delta-QRS width of at least $0.12 \mathrm{sec}$ ) a completely preexcited QRS complex as for example obtained during atrial pacing probably would allow a more precise electrocardiographic differentiation between accessory pathway locations. 


\section{References}

1. Boineau JP, Moore NM, Spear JF, Sealy WC. Basis of static and dynamic electrocardiographic variations in Wolff-Parkinson-White syndrome. Am J Cardiol 1973;32:3244.

2. Frank R, Apport des investigations endocavitaires et de cartographies épicardiques dans l'étude des syndromès de pre-excitation ventriculaire. Thése pour le doctorat en médicine 1974. Paris. Eds. Médicales et Univérsitaires.

3. Tonkin AM, Wagner GS, Gallagher JJ,. Initial forces of ventricular depolarization in the Wolff-Parkinson-White syndrome. Analysis based upon localization of the accessory pathways by epicardial mapping. Circulation 1975;52:1030-1036.

4. Nicolai P, Medvedowsky JL, Delaage M. Pre-excitations ventriculaires. Diagnostic topographyc des faisceaux de Kent. In: Les troubles du rythme cardiaque. Nanterre: RMDP Corbiere, 1978; 164-170.

5. Gallagher JJ, Pritchett ELC, Sealy WC, Kasell J, Wallace AG. The preexcitation syndromes. Prog Cardiovas Dis 1978;20:285-327.

6 Reddy GV, Schamroth L. The localization of bypass tracts in the Wolff-Parkinson-White syndrome from the surface electrocardiogram. Am Heart J 1987;113:984-994.

7. Lindsay BD, Crossen KJ, Cain ME. Concordance of distinguishing electrocardiographic features during sinus rhythm with the location of accessory pathways in the WolffParkinson-White syndrome. Am J Cardiol 1987;59:1093-1096

8. Milstein S, Sharma AD, Guiraudon GM, Klein GJ. An algorithm for the electrocardiographic localization of accessory pathways in the Wolff-Parkinson-White syndrome. PACE 1987; 10:555-558.

9. Epstein AE, Kirklin JK, Holman WL, Plumb VJ Kay GN. Intermediate septal pathways:Electrocardiographic characteristics, electrophysiologic observations and their surgical implications. J Am Coll Cardiol 1991;17:1570-1578.

10. Scheinman MM, Wang YS, Van Hare GF, Lesh MD. Electrocardiographic and electrophysiologic characteristics of anterior,midseptal and right anterior free wall accessory pathways. J Am Coll Cardiol 1992;20:1220-1229.

11. Penn OC. The epicardial technique for left free-wall accessory pathways. In: Cardiac arrhythmia surgery: Ed. JL Cox. Philadelphia, Hanley \& Belfus, Inc. 1990;123-134.

12. Rodriguez LM, Smeets JLRM, Schläpfer J, Katsivas A, Dijkman B, de Chillou C, Orning $\mathrm{OM}$, Wellens HJJ. Radiofrequency catheter ablation of three accessory pathways in a single session. J Cardiovasc Electophysiol 1992;3:141-149

13. Durrer D, Roos JP. Epicardial excitation of the ventricles in a patient with the WolffParkinson-White syndrome. Circulation 1967;35:15-21. 
Chapter 4

\section{Radiofrequency catheter ablation of three accessory pathways in a single session}

Luz-Maria Rodriguez, MD, Joep LRM Smeets, MD, Jürg Schläpfer, MD, Apostolos Katsivas, MD, Barbara Dijkman, MD, Christian de Chillou, MD, Otto M. Orning, MD, Hein J.J Wellens, MD. 


\title{
Radiofrequency catheter ablation of three accessory pathways in a single session
}

\begin{abstract}
A 19 year old patient is described having three accessory A-V pathways. All three pathways were ablated using radiofrequency current in a single electrophysiologic investigation.
\end{abstract}

\section{Introduction}

The presence of more than one accessory pathway in patients with the WolffParkinson-White (WPW) syndrome has been reported previously $(1,2)$.

A higher prevalence of multiple pathways has been reported in patients with Ebstein's anomaly (3), antidromic tachycardia (4) and ventricular fibrillation $(5,6)$.

Inability to recognize the presence of multiple accessory pathways during electrophysiologic study is a common reason for failure of surgical (7) or catheter ablation.

The following case report illustrates how important the detailed analysis of the 2-lead ECG and the electrophysiologic study are to identify the presence of multiple accessory pathways. It also shows that in such a patient using radiofrequency current catheter ablation cure can be obtained in a single session.

\section{Case report}

A 19 year old man suffered since he was 3 weeks old from monthly episodes of supraventricular tachycardia lasting from minutes to hours (Fig 1A). He was treated since childhood with several antiarrhythmic drugs including digitalis, beta blocking agents, and calcium antagonists without success. Because of an increase in tachycardia episodes the patient was referred to our hospital for treatment of his arrhythmia. The physical examination was normal. The 12-lead 

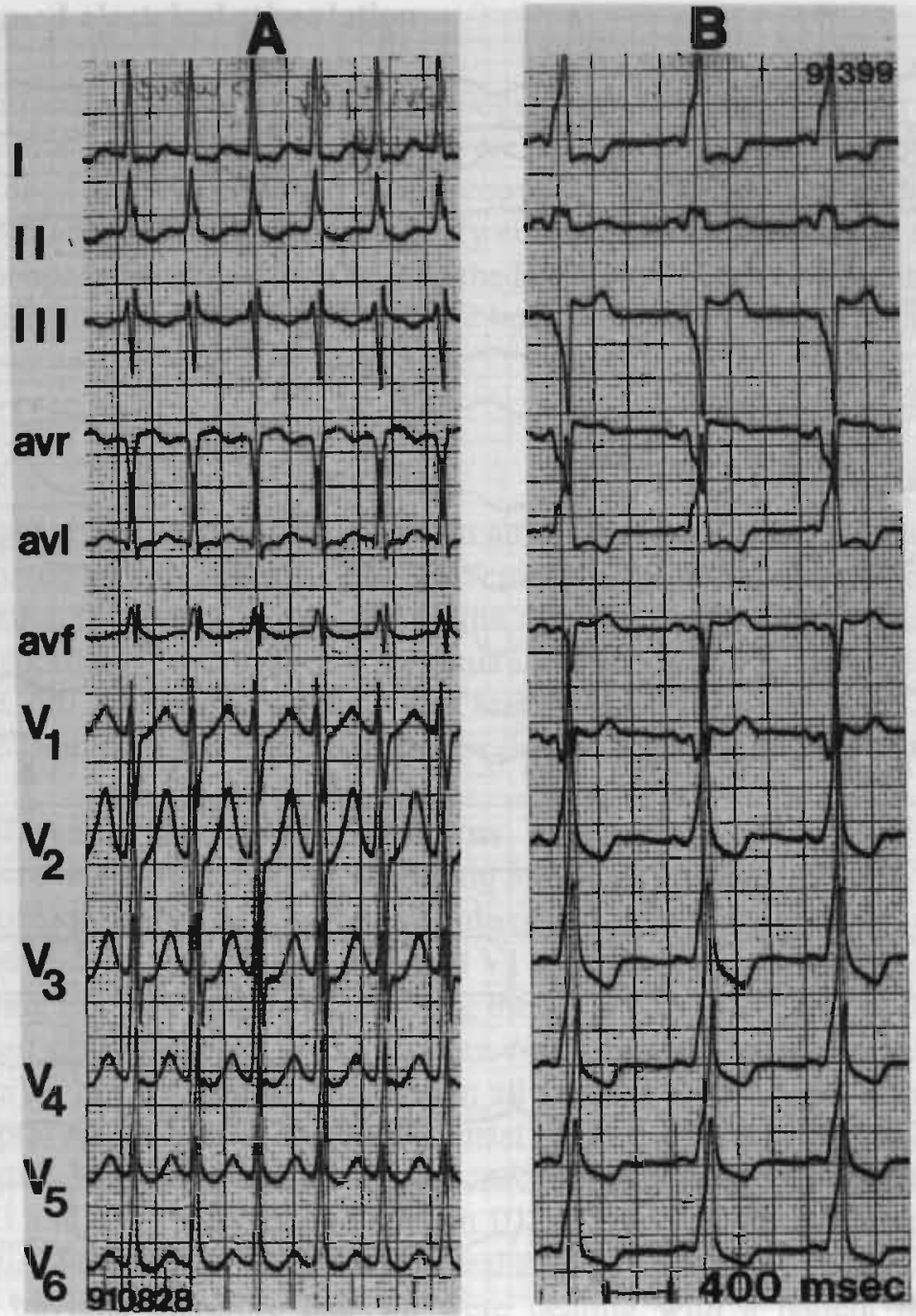

Figure 1: 12-lead ECG during sinus rhythm (panel B) and supraventricular tachycardia (panel A).

ECG during sinus rhythm (Fig $1 \mathrm{~B}$ ) showed a P-delta interval of $0.12 \mathrm{sec}$. with a negative delta wave in leads III, aVF and V1 suggestive for a right posteroseptal accessory pathway (AP). The echocardiogram was normal. 


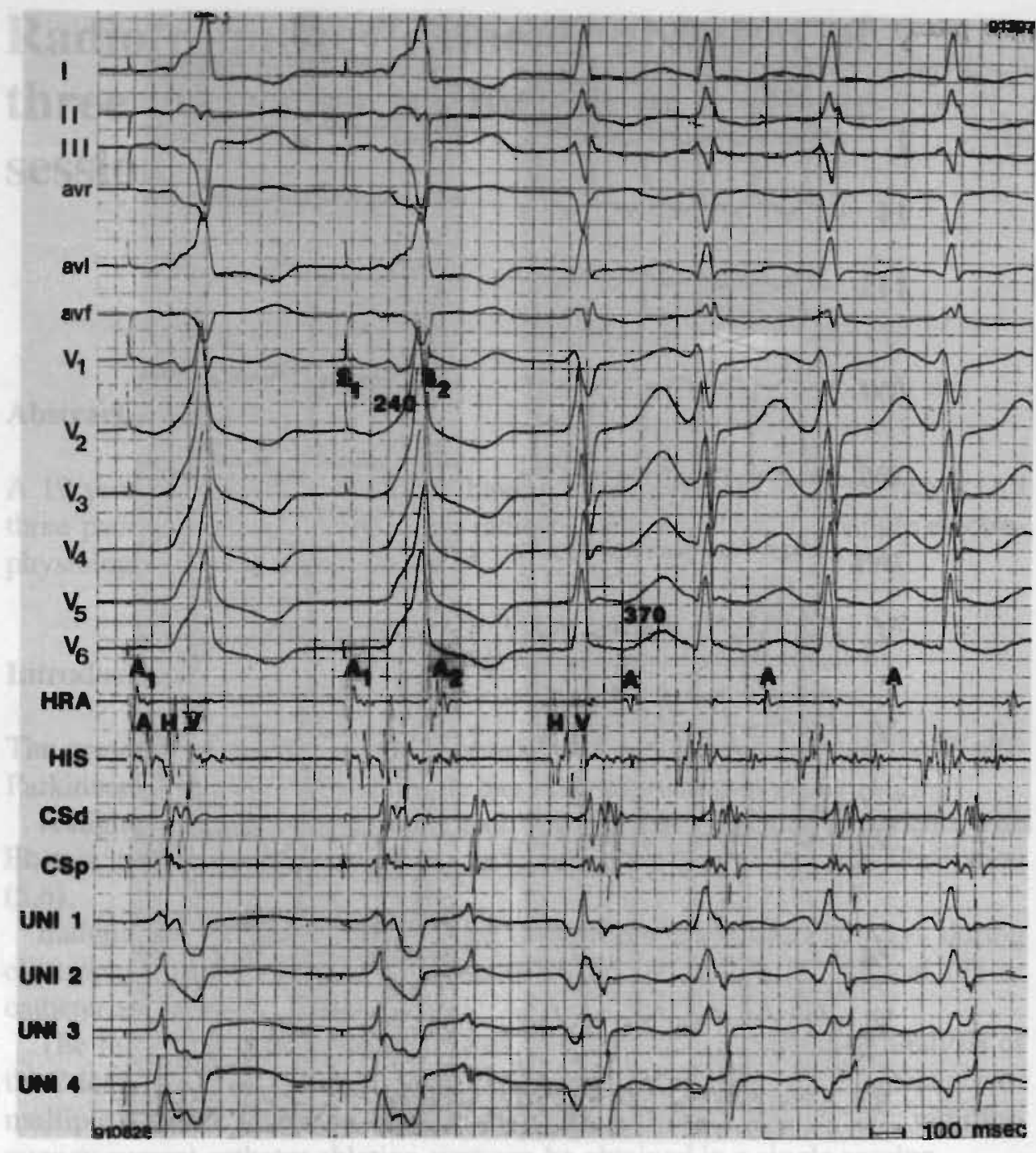

Figure 2: Initiation of an orthodromic circusmovement tachycardia by one atrial premature beat given after $240 \mathrm{msec}$. during right atrial pacing at $600 \mathrm{msec}$. Abbreviations: A1- = atrial electrogram during atrial pacing at $600 \mathrm{msec} . \mathrm{A} 2=$ atrial electrogram at a coupling interval of $240 \mathrm{msec} . \mathrm{A}=$ atrial activation during orthodromic circusmovement tachycardia. CSD = coronary sinus distal, CSP = coronary sinus proximal, $\mathrm{H}=$ His bundle electrogram, HRA = high right atrium, $\mathrm{V}=$ ventricular electrogram, UNI 1,2,3,4, = coronary sinus unipolar recordings from distal to proximal. (paper speed $100 \mathrm{~mm} / \mathrm{sec}$.) 


\section{Programmed electrical stimulation}

After informed consent an electrophysiologic study was performed in the postabsortive, non-sedated state. Catheters were passed through both femoral veins and positioned in the heart under fluoroscopy. This included quadripolar catheters in the high right atrium and coronary sinus, a bipolar catheter in the right ventricular apex and a bipolar catheter in the His region. Methods for stimulation and recording used in our laboratory have been described previously (8).

\section{Results}

During right atrial pacing at $600 \mathrm{msec}$ an atrial premature beat given after 240 $\mathrm{msec}$, initiated an orthodromic circus movement tachycardia. The earliest retrograde atrial activation was recorded in the distal coronary sinus (Fig 2). The unipolar recordings from the coronary sinus showed bracketing with the shortest V-A time ( $90 \mathrm{msec}$ ) measured in the second unipolar recording. This orthodromic tachycardia was the only tachycardia initiated during the study.

\section{Three different preexcited QRS patterns}

During incremental high right atrial pacing 3 different preexcited QRS patterns could be observed (Fig 3 ). On the left side of the figure preexcited complexes with negative delta waves in III, aVF and V1 are present. This pattern is similar to the resting ECG pattern. On decreasing the atrial pacing interval to $280 \mathrm{msec}$ (middle part of the figure) a second pattern emerged with a negative delta wave in II, III, aVF but positive delta waves in all precordial leads suggesting a left posteroseptal AP. A further decrease in atrial pacing interval to $220 \mathrm{msec}$ (right part of figure 3) resulted in a third preexcited QRS pattern, with negative delta waves in I and aVL and positive ones in III, aVF and all the precordial leads indicating AV conduction over a left lateral AP.

It was obvious therefore that we were dealing with a patient having 3 anterogradely conducting AP demonstrated by 3 different $\mathrm{QRS}$ patterns during atrial pacing. Only the left free wall AP was found to conduct retrogradely during orthodromic tachycardia and ventricular pacing.

After discussion with the patient an attempt to ablate the different AP's by radiofrequency $(\mathrm{RF})$ was undertaken in the same session. We decided to ablate first the left lateral AP because orthodromic tachycardia using the pathway retrogradely seemed to be his clinical problem. A 7 F Mansfield-Webster quadripolar ablation catheter with a $4 \mathrm{~mm}$ tip was introduced by way of the right femoral artery into the left ventricle and positioned against the lateral part of the mitral annulus facing the distal pole of the coronary sinus catheter. The shortest V-A time recorded during orthodromic tachycardia on the ablation catheter was 


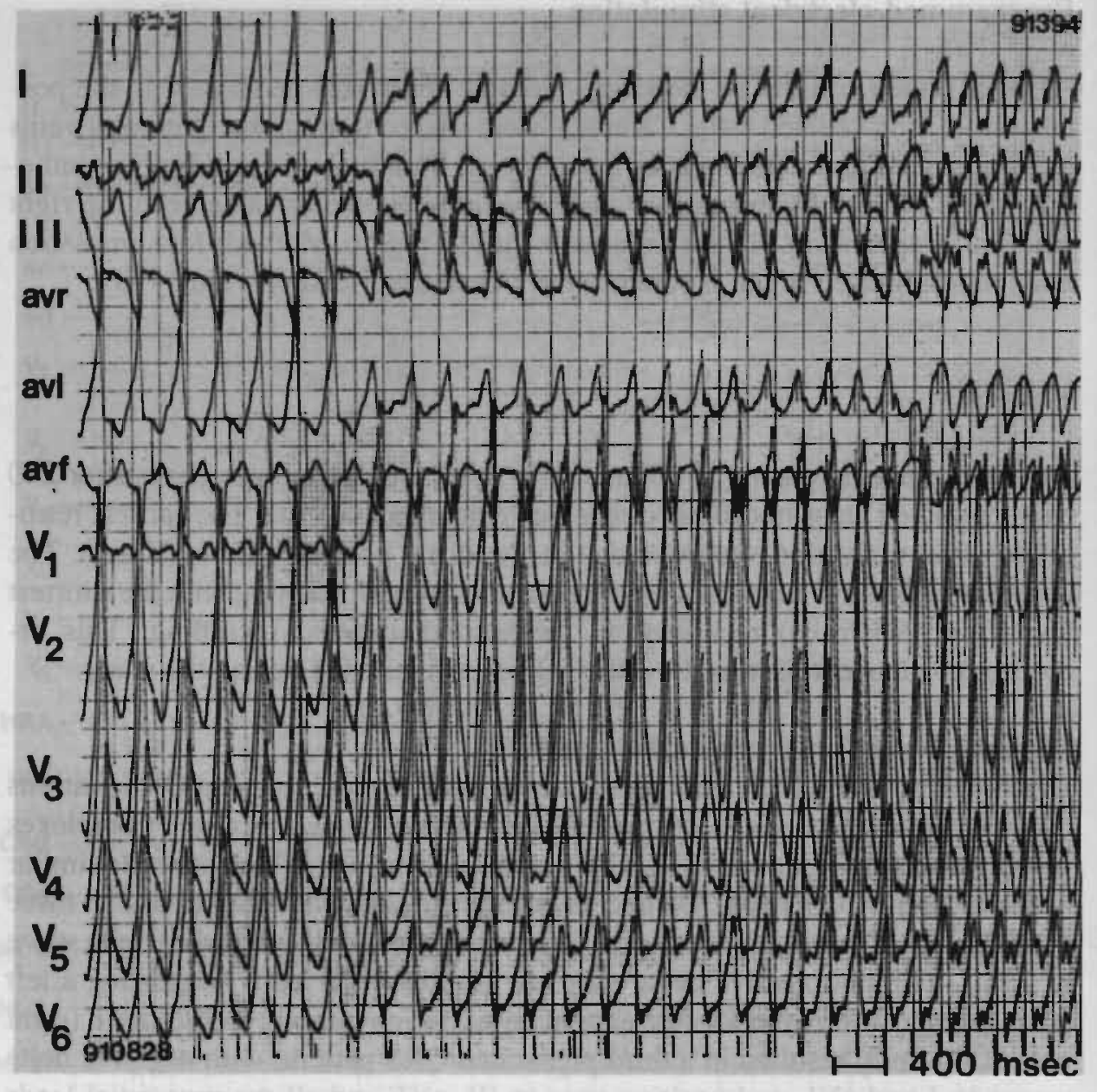

Figure 3: 12-lead ECG recording during incremental high right atrial pacing showing 3 different preexcited QRS patterns (see text).

$90 \mathrm{msec}$ which equalled the V-A time in the distal coronary sinus (Fig 4). RF application ( $40 \mathrm{~W}$ for $20 \mathrm{sec}$ ) terminated orthodromic tachycardia. This tachycardia was no longer inducible thereafter. It was also observed that after the ablation of the left lateral AP no V-A conduction was present during ventricular pacing.

Atrial pacing at increasing rates was again performed showing persistence of anterograde conduction over both the right and left posteroseptal AP followed by 1 to 1 conduction over the AV node without any evidence of conduction over the left lateral AP (Fig 5). 


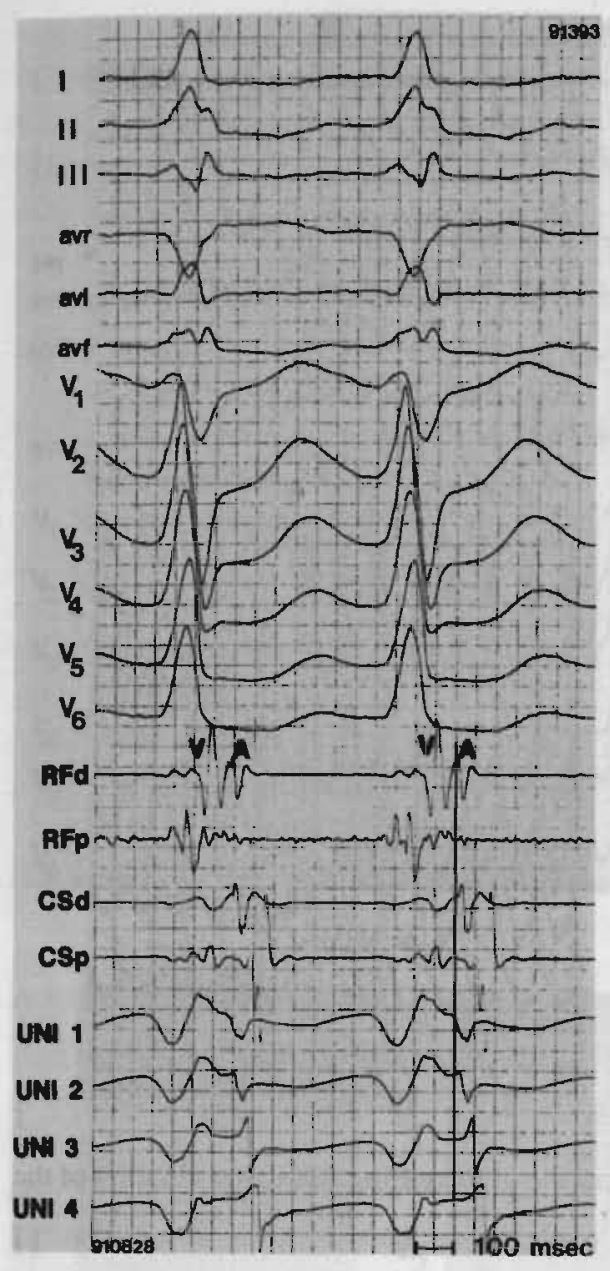

Figure 4: Electrogram during orthodromic circusmovement tachycardia showing a shortest V-A time of $90 \mathrm{msec}$ on the ablation catheter which equals the $\mathrm{V}$ - $\mathrm{A}$ time in the distal coronary sinus. (paper speed 100 $\mathrm{mm} / \mathrm{sec}$ ). Abbreviations: $\mathrm{RFd}=$ radiofrequency ablation catheter distal, RFp = proximal.

During sinus rhythm we started then from the left ventricle to apply RF energy to the left posteroseptal AP. Three RF applications (of $40 \mathrm{~W}$ during $20 \mathrm{sec}$ ) were needed to successfully ablate this second AP. Atrial pacing thereafter showed that preexcitation occurred over the right posteroseptal pathway only.

The ablation catheter was then moved from the left to the right ventricle. After mapping the right posterior area during sinus rhythm, RF ablation was attempted. Transient disappearance of anterograde conduction over the AP was noted after 4 applications (Fig 6). A total of 14 RF applications to this area were necessary to completely interrupt conduction over the remaining AP (Fig 7). 

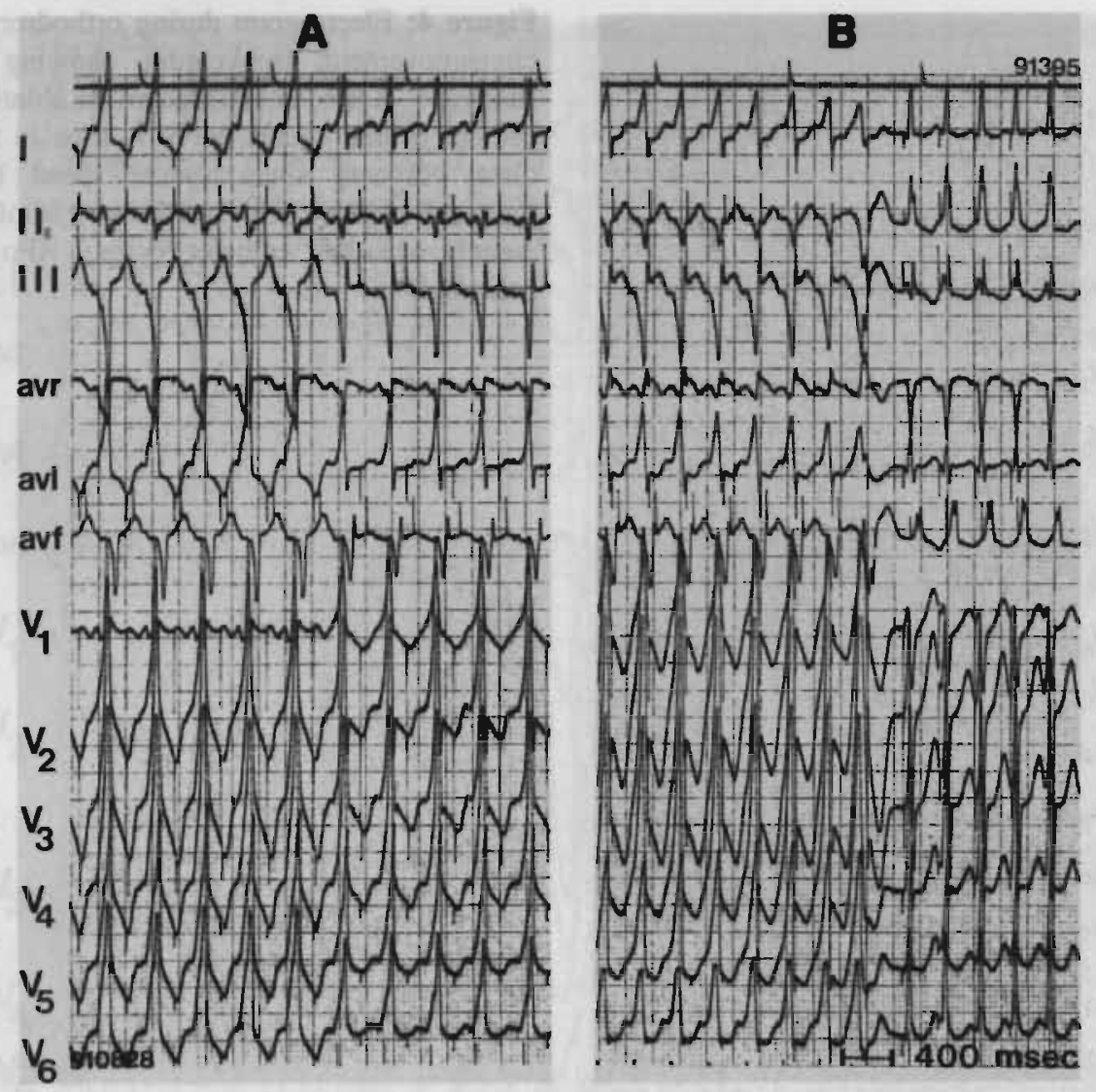

Figure 5: 12-lead ECG recording during atrial pacing at increasing rates after ablation of the left lateral AP (see text).

Forty minutes after the last RF application a control stimulation protocol showed absence of anterograde and retrograde conduction over an AP. AV conduction was by way of the AV node-His bundle only. The total time for the electrophysiological study was 3 hours and 50 minutes and the fluoroscopy time 1 hour and 50 minutes.

The ECG on discharge the following morning showed exclusive A-V conduction over the AV node with a normal PR interval. At follow-up after 3 months an intermittently occurring preexcitation pattern using the right posteroseptal accessory pathway was found. During further evaluation using holter recordings only non-sustained circus movement tachycardia were seen lasting 3-5 beats. Ventriculo-atrial conduction was over the right posteroseptal accessory pathway. The patient refused a second RF ablation because he considered his symptoms of no significance. No antiarrhythmic drug treatment was prescribed. 


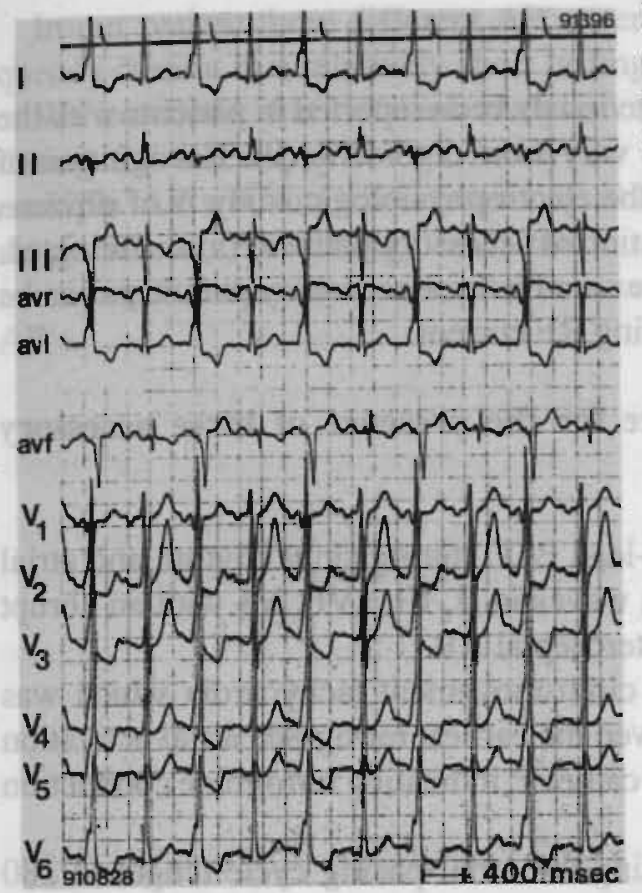

Figure 6: ECG recorded after several RF applications in to right posteroseptal region showing 2 to 1 conduction over the remaining right posteroseptal AP.
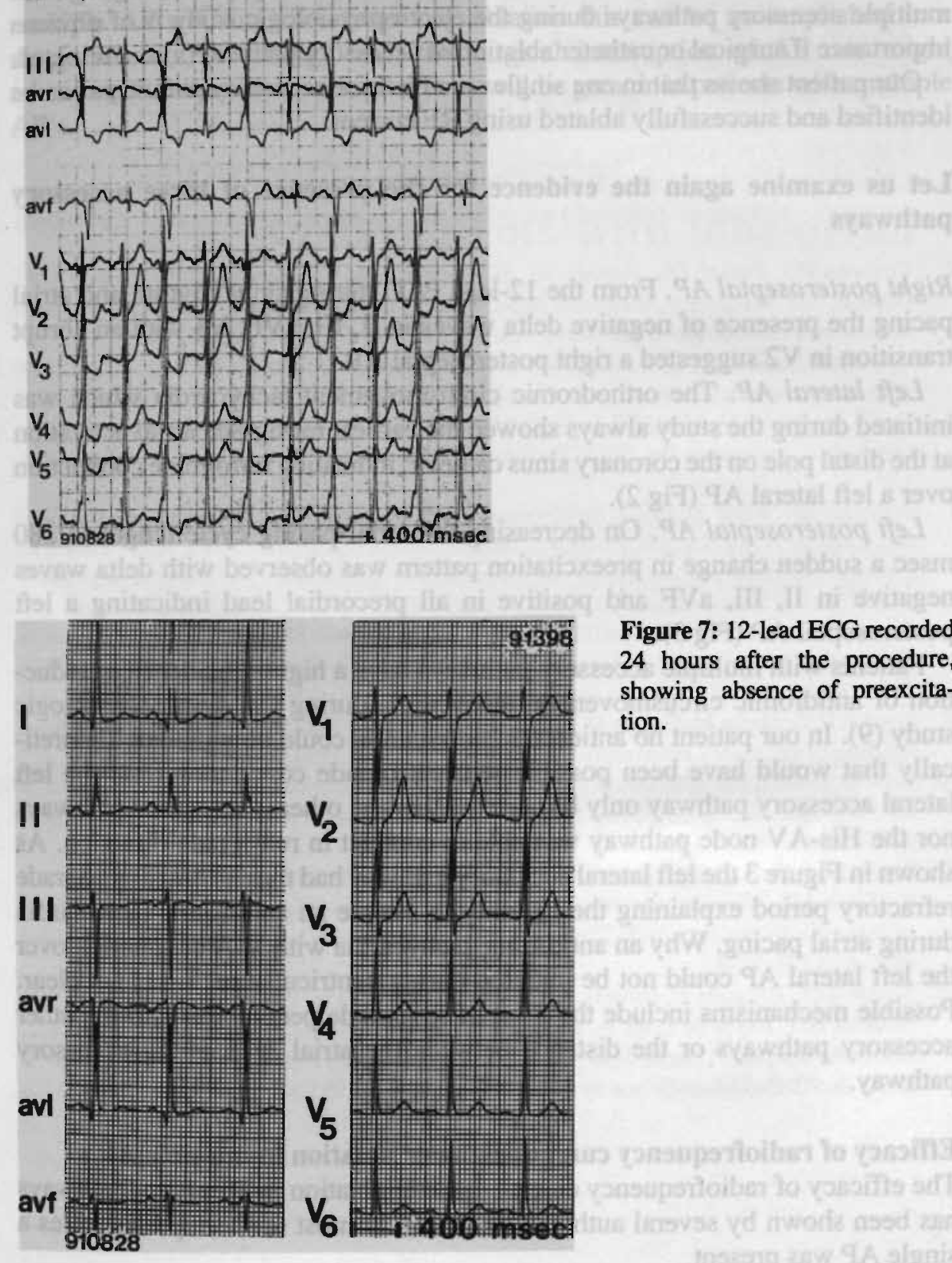

Figure 7: 12-lead ECG recorded 24 hours after the procedure, showing absence of preexcitation. 


\section{Discussion}

The incidence of multiple AP have previously been reported in patients with the Wolff-Parkinson-White syndrome to vary from 5 to $15 \%$ (9). Recognition of multiple accessory pathways during the electrophysiologic study is of obvious importance if surgical or catheter ablation of accessory pathway(s) is attempted.

Our patient shows that in one single session three accessory pathways can be identified and successfully ablated using RF current.

\section{Let us examine again the evidence for the presence of three accessory pathways}

Right posteroseptal AP. From the 12-lead ECG during sinus rhythm and atrial pacing the presence of negative delta waves in II, III, aVF, V1 with an abrupt transition in V2 suggested a right posteroseptal AP.

Left lateral AP. The orthodromic circusmovement tachycardia which was initiated during the study always showed the earliest retrograde atrial activation at the distal pole on the coronary sinus catheter, indicating retrograde conduction over a left lateral AP (Fig 2).

Left posteroseptal AP. On decreasing the atrial pacing cycle length to 280 msec a sudden change in preexcitation pattern was observed with delta waves negative in II, III, aVF and positive in all precordial lead indicating a left posteroseptal AP (Fig 3).

Patients with multiple accessory pathways have a higher incidence of induction of antidromic circusmovement tachycardia during the electrophysiologic study (9). In our patient no antidromic tachycardia could be initiated. Theoretically that would have been possible with retrograde conduction over the left lateral accessory pathway only because neither the other 2 accessory pathways nor the His-AV node pathway was able to conduct in retrograde direction. As shown in Figure 3 the left lateral accessory pathway had the shortest anterograde refractory period explaining the inability to initiate an antidromic tachycardia during atrial pacing. Why an antidromic tachycardia with V-A conduction over the left lateral AP could not be initiated during ventricular pacing is not clear. Possible mechanisms include the level of retrograde penetration into the other accessory pathways or the distance between the atrial ends of the accessory pathway.

\section{Efficacy of radiofrequency current catheter ablation in multiple AP's}

The efficacy of radiofrequency current catheter ablation in accessory pathways has been shown by several authors $(10,11,12)$. In most of the reported cases a single AP was present. 
In our patient three different AP's were diagnosed and ablated by radiofrequency current in a relatively short lasting procedure ( 3 hours $50 \mathrm{~min}$.)

We conclude that detailed analysis of the 12-lead ECG and the findings during the electrophysiologic study are essential for a cure in patients with multiple AP's. Using radiofrequency ablation this can be accomplished in a single session. In analogy with the surgical interruption of AP one might anticipate that the chance on recurrence will be greater in patients with multiple AP's. 


\section{References}

1. Atie J, Brugada P, Brugada J, Smeets JLRM, Cruz FES, Peres A, Roukens MR, Wellens HJJ. Clinical and electrophysiologic characteristics of patients with antidromic circusmovement tachycardia in the Wolff-Parkinson-White syndrome. Am J Cardiol 1990;66:1082-1091.

2. Calkins H, Sousa J, El-Altasi R, Rosenheck S, de Buitler M, Kou WH, Kadish AH, Langerb JJ, Morady F. Diagnosis and cure of the Wolff-Parkinson-White syndrome or paroxysmal supraventricular tachycardias during a single electrophysiologic test. NEngl J Med 1991;324:1612-1618.

3. Cinca J, Valle V, Gutierrez L, Figuras J, Ruiz J. Reciprocating tachycardia using bilateral accessory pathways: electrophysiological and clinical implications. Circulation 1980;62:657-661.

4. Colovita PG, Packer DL, Pressly JC, Ellenbogen KA, O'Callaghan WG, Gilbert MR, German LD. Frequency, diagnosis and clinical characteristics of patients with multiple accessory atrioventricular pathways. Am J Cardiol 1987;59:601-606.

5. Gallagher JJ, Sealy WC, Kassel J, Wallace AG. Multiple accessory pathways in patients with the pre-excitation syndrome. Circulation 1976;54:571-591.

6. Iwa T, Kawasuji M, Misaki T, IwaseT, Magara T. Location and interruption of accessory conduction pathway in the Wolff-Parkinson-White syndrome. J Thorac Cardiovasc Surg 1981;81-707-712.

7. Jackman W, Wang X, Friday KJ, Roman CA, Moulton KP, Beckman KJ, McClelland JH, Twidale N, Hazlitt AH, Prior MI, Margolis PD, Calame JD, Overholt E, Lazzara R. Catheter ablation of accessory atrioventricular pathways (Wolff-Parkinson-White syndrome) by radiofrequency current. N Engl J Med 1991; 324:1605-1611.

8. Klein GI, Bashore TM, Sellers TD, Pritchett ELC, Smith WM, Gallagher JJ. Ventricular fibrillation in the Wolff-Parkinson-White syndrome. N Engl J Med 1979;302:10801085.

9. Kuck KH, Schluter M, Geiger M, Siebels J, Duckeck W. Radiofrequency current catheter ablation of accessory atrioventricular pathways. Lancet 1991;337:1557-1561.

10. Ross D, Farré J, Bär FWHM, Wellens HJJ. Comprehensive electrophysiologic studies in the investigation of documented or suspected tachycardias. Problems and costs involved. Circulation 1980;61:1010-1016.

11. Smith WM, Gallagher JJ, Kerr CR, Sealy WC, Kasell JH, Benson DW, Reiter MJ, Sterba $\mathrm{R}$, Grant AO. The electrophysiologic basis and management of symptomatic recurrent tachycardia in patients with Ebstein's anomaly of the tricuspid valve. Am J Cardiol 1982;49:1223-1234.

12. Torner MP, Brugada P, Smeets J, Talajic M, Della Bella P, Lezaun R, v.d. Dool A, Wellens HJJ, Bayés de Luna A, Oter R, Breithardt G, Borgreffe M, Klein H, Kuck KH, Kunze A, Coumel P, Leclercq JF, Chouty F, Frank R, Fontaine G. Ventricular fibrillation in the Wolff-Parkinson-White syndrome. Eur Heart J. 1991;12:144-150. 


\section{Chapter 5}

\section{Improvement in left ventricular}

function by ablation of atrioventricular nodal conduction in selected patients with lone atrial fibrillation

Luz-Maria Rodriguez, MD, Joep LRM. Smeets, MD, Baiyan Xie, MD, Christian de Chillou, MD, Emile Cheriex, MD, Frans Pieters, MD, Jacques Metzger, MD, Karel den Dulk MD, Hein JJ Wellens, MD. 


\title{
Improvement in left ventricular function by ablation of atrioventricular nodal conduction in selected patients with lone atrial fibrillation
}

\begin{abstract}
Left ventricular function was studied in 30 patients with lone atrial fibrillation (AF) (paroxysmal $=27$, persistent $=3$ ) before and after ablation of atrioventricular conduction (AV). In all patients drug treatment failed to control ventricular rate during $\mathrm{AF}$ and /or to prevent recurrences of the arrhythmia. Left ventricular (LV) ejection fraction, LV end systolic, end diastolic and left atrial dimensions were measured by echocardiography before $(<1-37$, mean $7 \pm 10$ months) and after ablation (<1-77, mean $14 \pm 20$ months). Before ablation LV ejection fraction was $\leq 50 \%$ in 12 patients (group I) and $>50 \%$ in 18 patients (group II). Following ablation LV ejection fraction increased significantly after ablation in group I patients from $43 \pm 8 \%$ to $54 \pm 7 \%(p<0.0001)$. There were also significant decreases in the LV end systolic, LV end diastolic and left atrial dimensions. No changes in these parameters were observed in group II patients. Patients from group I and group II had a significant difference in duration of their arrhythmia, 8 to 28 , mean 11 years in group I, 2 to 14 , mean 5 years in group II $(p<0.05)$. No differences were present in age, sex, New York Heart Association functional class for dyspnea and type of ablation procedure. Thus, some patients with lone AF may show deterioration of LV function which seems to be related to the duration of the arrhythmia. In them, LV function may improve significantly after ventricular rate control is accomplished by ablation of $\mathrm{AV}$ conduction.
\end{abstract}

\section{Introduction}

Atrial fibrillation (AF) is a common arrhythmia (1-3). It may be paroxysmal or chronic, the paroxysmal type frequently preceding the chronic form. Most patients with AF have some form of underlying heart disease or hormonal abnormality but the arrhythmia can also occur as an independent arrhythmic 
entity, so called lone, primary or idiopathic AF (4). The occurrence of the high ventricular rate and loss of atrial contribution to ventricular filling during AF may lead not only to the unpleasant sensation of palpitations and complications like dizziness but also to cardiac dilatation and congestive failure even in the absence of an underlying cardiovascular abnormality (5). In 1982 Scheinman et al (6) and Gallagher et al (7) introduced high energy direct current ablation of the atrio-ventricular (AV) junction in patients with AF in whom the ventricular rate could not be controlled by drug therapy. In 1990 Brugada et al (8) used an injection of ethanol into the AV nodal coronary artery to interrupt AV junctional conduction in patients with AF. This report examines the effect of ventricular rate control by ablation of the AV conduction on left ventricular (LV) function in patients with lone AF in whom drugs had failed to control the ventricular rate during $\mathrm{AF}$ and to prevent recurrences of the arrhythmia.

\section{Patients and Methods}

From March 1985 to March 1991, 30 patients with lone AF underwent ablation of their AV conduction. There were 19 men and 11 women with an age range from 36-78, mean $59 \pm 10$ years at the time of ablation. In all patients the diagnosis of lone AF was reached after reviewing the medical history, physical examination, 12-lead electrocardiogram, and echocardiogram-Doppler studies. Coronary angiography was performed in $18 / 30$ patients, in 11 patients to exclude coronary artery disease and in 7 patients because ethanol injection into the AV nodal coronary artery was used for ablation of AV conduction. In all patients recurrences of atrial fibrillation could not be prevented and ventricular rate during AF not adequately controlled by drugs like digitalis, disopiramide, verapamil, sotalol, flecainide, amiodarone, $\beta$-blockers alone or in combination. The number of drugs per patient varied from 4 to 7 , mean 5 . The duration of the arrhythmia ranged from 2 to 28 years.

\section{Ablation procedure}

After informed consent patients underwent ablation of the atrioventricular junction. Interruption of AV conduction was accomplished by DC-shock (9) in 16 patients, by injection of ethanol into the AV nodal artery (8) in 7 patients, surgical cryoablation in 6 patients and radiofrequency energy in the remaining patient. Interruption of AV nodal conduction by cryoablation of His bundle was performed after failure of DC-Shock attempts. Following achievement of third degree AV block a temporary demand ventricular pacemaker was inserted and 
the patient monitored in the coronary care unit for 72 hours. Serial isoenzyme (lactic dehydrogenase, creatine phosphokinase, serum glutamic oxaloacetic transaminase, serum glutamic pyruvic transaminase were obtained for 48 hours. After 72 hours of complete AV block, a permanent cardiac pacemaker was implanted. Patients were thereafter followed-up at our out patient clinic.

\section{Echocardiographic measurements}

M-mode and 2-dimensional echocardiograms were obtained before $(<1-37$, mean $7 \pm 10$ months) and after ( $<1-77$, mean $14 \pm 19$ months) the ablation procedure.

The LV ejection fraction, end systolic, end diastolic diameter and left atrial size were measured according to the recommendations of the American Society of Echocardiography (10). All echocardiograms were performed by the same investigator. In patients with AF, LV ejection fraction and left heart dimensions were measured as the mean of five consecutive beats. In all patients the postablative follow-up echocardiograms were recorded during a pacemaker rhythm of 70 beats/min.

\section{Statistical analysis}

Continuous variables are expressed as mean \pm SD. Group of patients were compared with the Paired t-test. Non continuous variables were compared by use of the CHI-2 test. Statistical significance was assumed for $p$ values of $<0.05$.

\section{Results}

The population was divided according to a pre-ablation value of the LV ejection fraction of $\leq 50 \%$ (12 patients; Group I) and $>50 \%$ (18 patients; Group II).

No differences were present between group I and II patients in sex (men/women $10 / 8$ vs $9 / 3$ ), age ( $56 \pm 10$ vs $62 \pm 9$ years), ablation procedure (DC-shock: 9 vs 7; ethanol injection: 4 vs 3; surgical cryoablation: 5 vs 1 , and radiofrequency energy: 0 vs 1 ). All but one patient were in New York Heart Association functional class II. The type of AF was paroxysmal in 9/12 and $18 / 18$ in group I and II patients respectively. Persistent AF was present in 3 of 


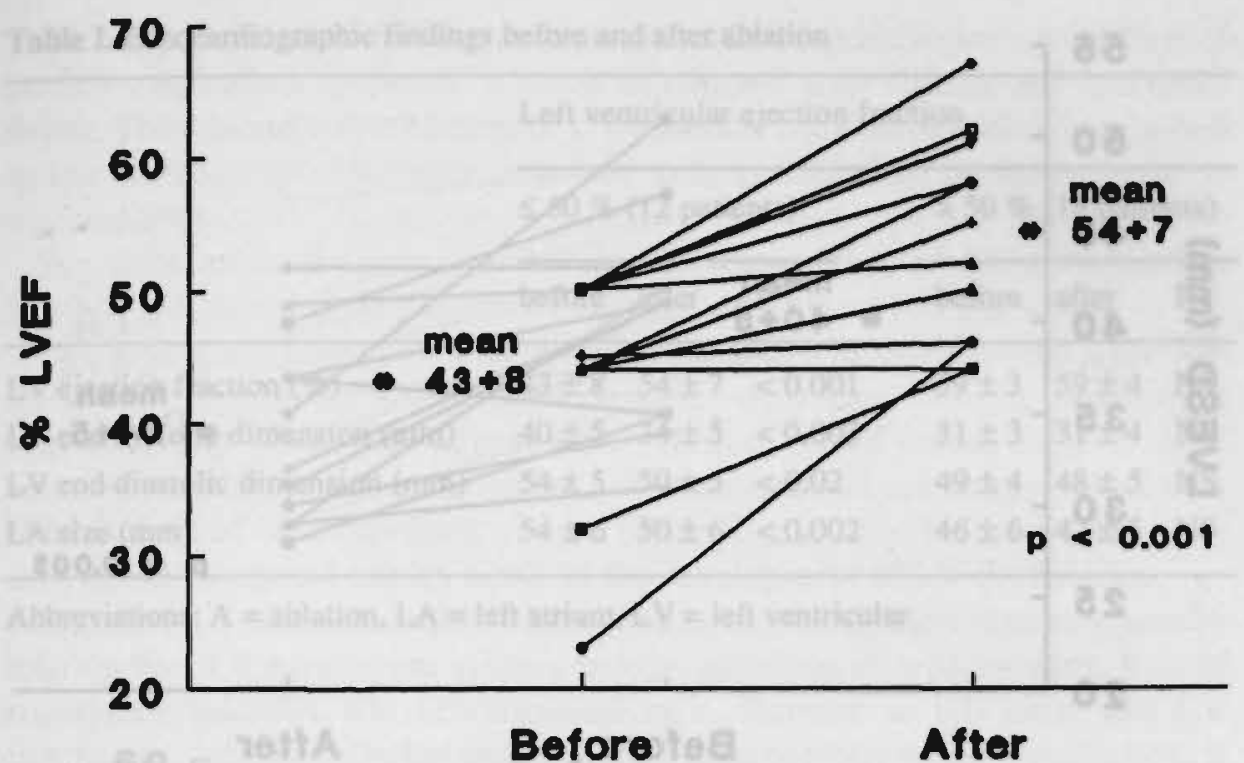

Figure 1: Individual representation of the left ventricular ejection fraction before and after ablation in group I patients.

the group I patients. The duration of AF was significantly longer in group I as compared to group II patients (8-28, mean 11 years vs $2-14$, mean 5 years respectively $(\mathrm{p}<0.05))$.

The heart rate at the preablation echocardiographic studies was similar in both groups (group I: $112 \pm 9 \mathrm{~b} / \mathrm{min}$ (100-130); group II; $109 \pm 11 \mathrm{~b} / \mathrm{min}$; (100-130)).

\section{Post-ablative pacing mode}

A VVIR pacing with rate response mode was used in $29 / 30$ patients. One patient of group I received a VVI pacemaker.

\section{Effect on left ventricular function}

\section{Left ventricular ejection fraction}

In group I patients the LV ejection fraction increased significantly by a mean of $22 \%$ of the pre-ablation value (before ablation $43 \pm 8$ and after ablation $54 \pm$ $7 \%)(\mathrm{p}<0.001)$ (Fig 1). No change in LV ejection fraction was found in group II patients ( $59 \pm 3 \%$ before and $59 \pm 4 \%$ after ablation). In 6 patients of group I 


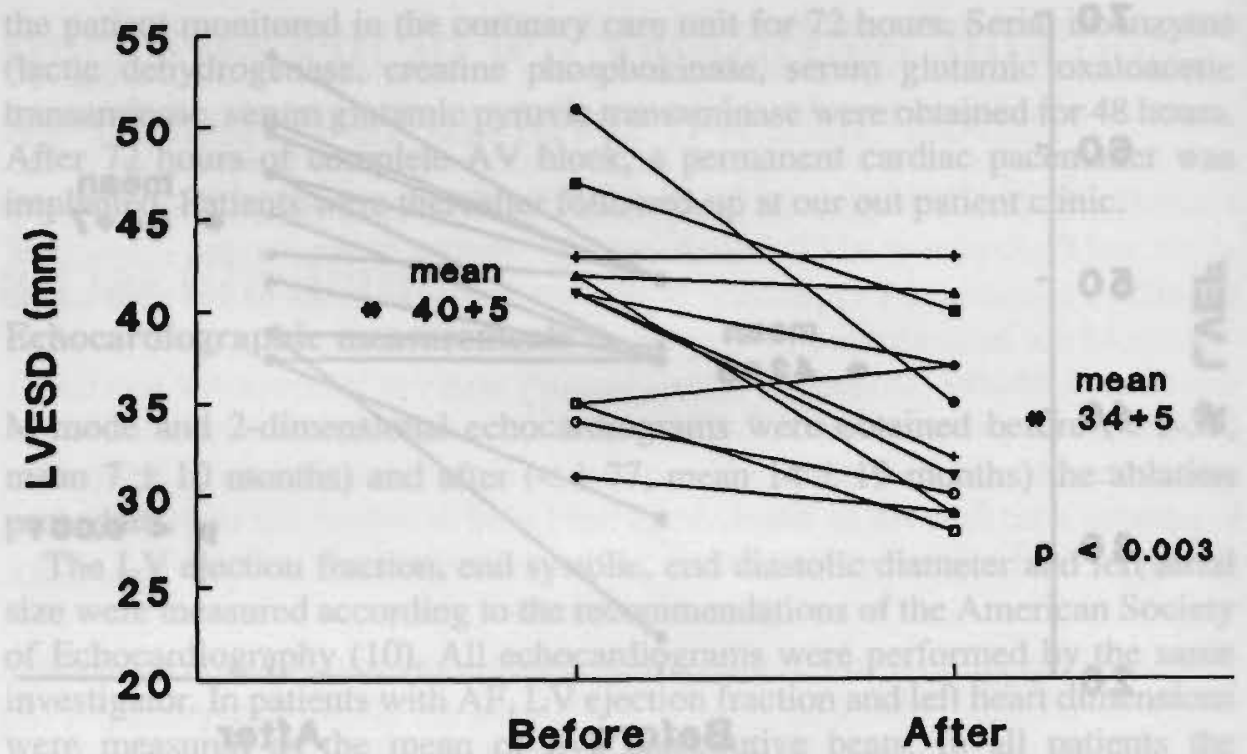

Figure 2: Pre-ablation (before) and post-ablation (after) values of left ventricular end systolic dimensions in group I patients.

the LV ejection fraction was measured within 6 months and in the other 6 patients more than 12 months after ablation. An increase in LV ejection fraction of $22 \%$ was found in both groups of patients.

In group I patients the mode of interruption of the AV conduction system (DC-shock, ethanol injection, surgical cryoablation and radiofrequency energy) did not affect the amount of improvement in LV ejection fraction after ablation.

The time of measuring the LV ejection fraction before and after the ablation procedure were comparable in group I and group II patients ( $<1$ to $36 \mathrm{vs}<1$ to 37 months and $<1$ to 65 vs $<1$ to 77 months) respectively.

Before ablation the echocardiographic measurements were made during sinus rhythm in 3 group I and 10 group II patients and during AF in 9 group I and 8 group II patients. After ablation 3 group I and 6 group II patients were in sinus rhythm and 9 group I and 12 group II patients in AF.

\section{Left ventricular end systolic dimensions}

The LV end systolic dimension decreased significantly by $15 \%$ (before: $40 \pm 5$ $\mathrm{mm}$ and after ablation $34 \pm 5 \mathrm{~mm})(\mathrm{p}<0.003)$ in group I patients (Fig 2). No change was observed in group II patients (before: $31 \pm 3 \mathrm{~mm}$, after: $31 \pm 4 \mathrm{~mm}$ ) (Table I). 
Table I. Echocardiographic findings before and after ablation

\begin{tabular}{|c|c|c|c|c|c|c|}
\hline \multirow{3}{*}{ 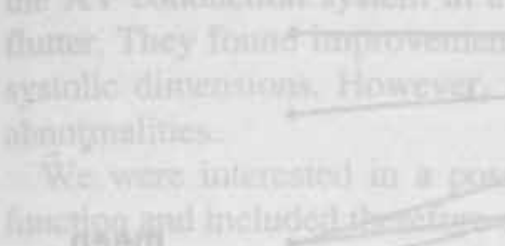 } & \multicolumn{4}{|c|}{ Left ventricular ejection fraction } & \multicolumn{2}{|c|}{ 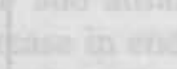 } \\
\hline & \multicolumn{3}{|c|}{$\leq 50 \%$ (12 patients) } & \multicolumn{3}{|c|}{$>50 \%$ (18 patients) } \\
\hline & before & after & $\mathbf{P}$ & before & after & $\mathbf{P}$ \\
\hline LV ejection fraction (\%) & $43 \pm 8$ & $54 \pm 7$ & $<0.001$ & $59 \pm 3$ & $59 \pm 4$ & NS \\
\hline LV end systolic dimension ( $\mathrm{mm})$ & $40 \pm 5$ & $34 \pm 5$ & $<0.003$ & $31 \pm 3$ & $31 \pm 4$ & NS \\
\hline LV end diastolic dimension (mm) & $54 \pm 5$ & $50 \pm 5$ & $<0.02$ & $49 \pm 4$ & $48 \pm 5$ & NS \\
\hline LA size $(\mathrm{mm})$ & $54 \pm 6$ & $50 \pm 6$ & $<0.002$ & $46 \pm 6$ & $47 \pm 5$ & NS \\
\hline
\end{tabular}

Abbreviations: $\mathrm{A}=$ ablation, $\mathrm{LA}=$ left atrium, $\mathrm{LV}=$ left ventricular

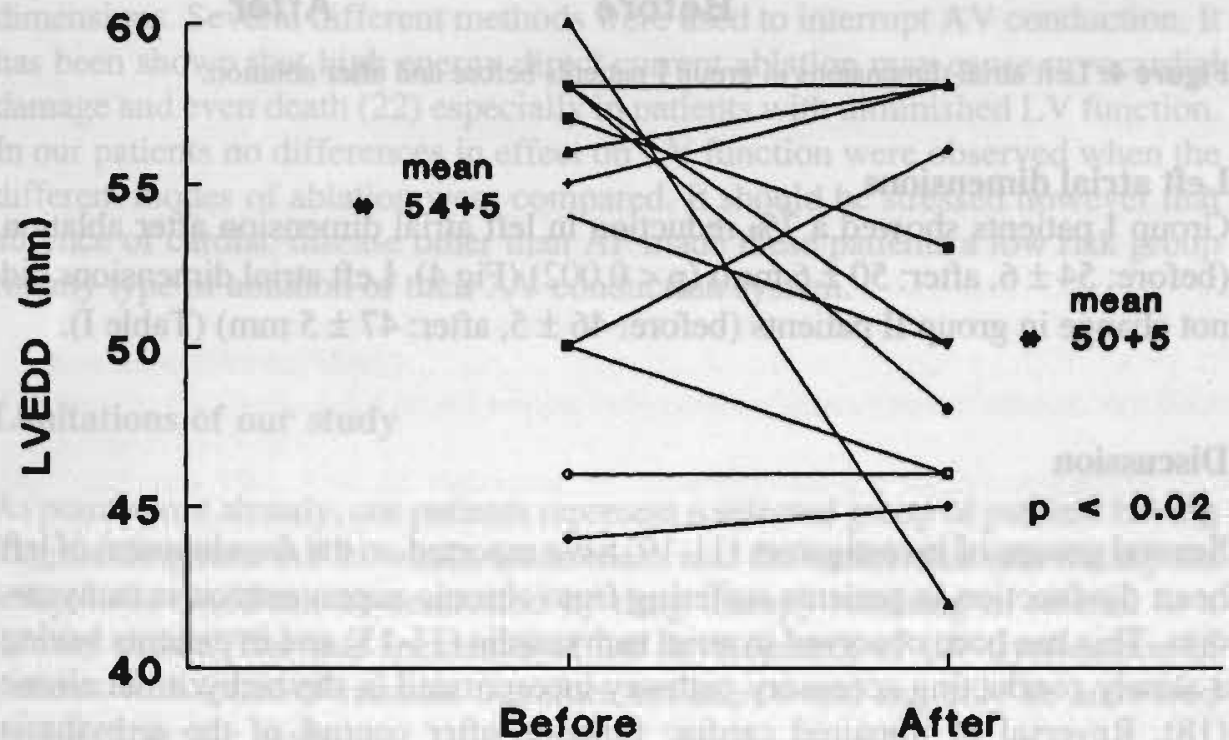

Figure 3: Left ventricular end diastolic dimensions in group I patients before and after ablation.

\section{Left ventricular end diastolic dimensions}

The LV end diastolic dimension decreased by $7 \%$ after ablation in group I patients (before: $54 \pm 5$, after: $50 \pm 5 \mathrm{~mm}$ ) $(\mathrm{p}<0.02)$ (Fig 3). No change occurred in group II patients (before: $49 \pm 4$, after: $48 \pm 5 \mathrm{~mm}$ ) (Table I). 


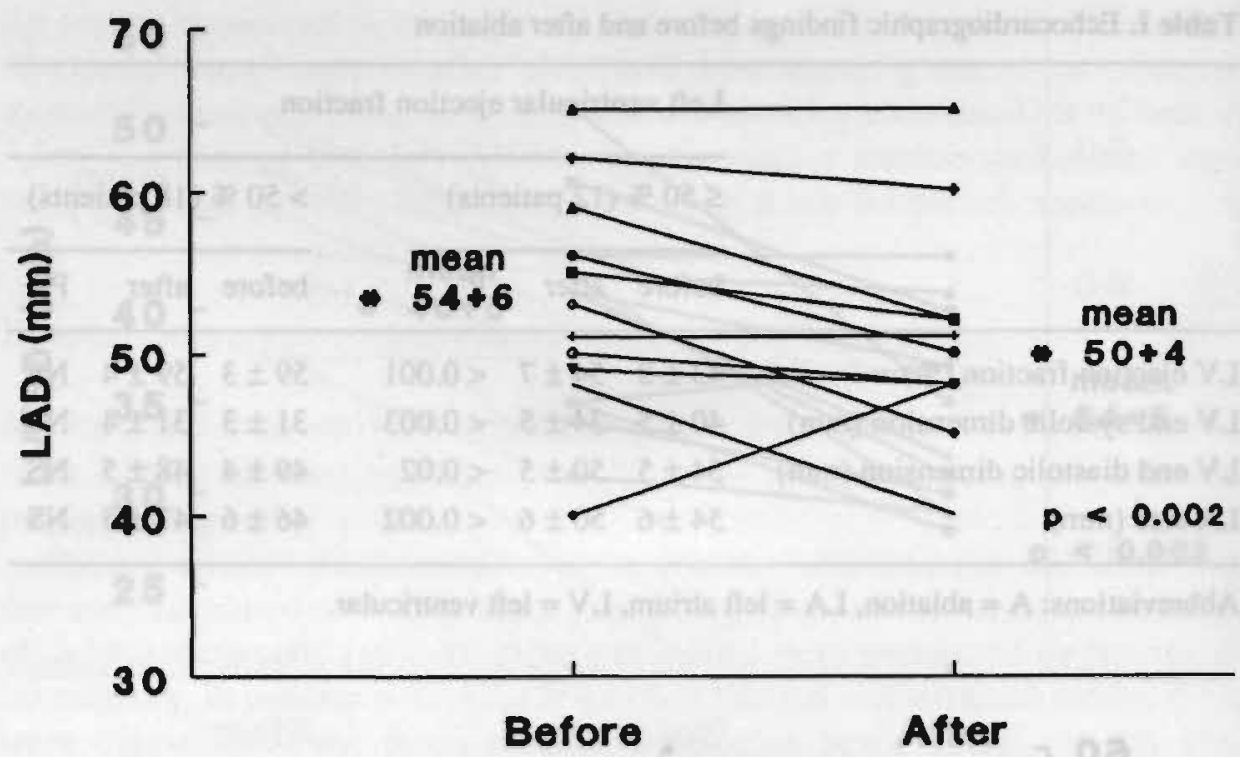

Figure 4: Left atrial dimensions in group I patients before and after ablation.

\section{Left atrial dimensions}

Group I patients showed a $7 \%$ reduction in left atrial dimension after ablation (before: $54 \pm 6$, after: $50 \pm 6 \mathrm{~mm}$ ) ( $p<0.002$ ) (Fig 4). Left atrial dimensions did not change in group II patients (before: $46 \pm 5$, after: $47 \pm 5 \mathrm{~mm}$ ) (Table I).

\section{Discussion}

Several groups of investigators (11-19) have reported on the development of left heart dysfunction in patients suffering from chronic supraventricular tachycardias. This has been observed in atrial tachycardia (11-13) and in patients having a slowly conducting accessory pathway incorporated in the tachycardia circuit (18). Reversal of impaired cardiac function after control of the arrhythmia suggests that even in the absence of additional cardiac disease, a chronically accelerated cardiac rhythm may lead to a dilated cardiomyopathy (so called tachy-cardiomyopathy).

In 1987 Lemery et al (20) described a patient with AF and congestive failure who showed marked improvement in pump function after DC-shock ablation of the AV conduction system. 
Recently Heinz et al (21) reported on the effect of radiofrequency ablation of the AV conduction system in a series of patients with chronic AF and atrial flutter. They found improvement of LV function because of a decrease in end systolic dimensions. However, many of their patients had additional cardiac abnormalities.

We were interested in a possible deteriorating effect of AF perse on LV function and included therefore only patients with lone AF in our study.

Our observations suggest that in some patients with long lasting lone AF, chronic impairment of LV function develops over time. This is obviously a selected group of patients. They were referred to our center because their frequently occurring and long-lasting arrhythmias could not be controlled by a wide variety of antiarrhythmic drugs. Interestingly, only the duration of the arrhythmia was found to play a role in the development of LV dysfunction.

Impaired LV function could be improved by control of the ventricular rate by ablating the AV conduction system and the insertion of a pacemaker. It is of importance that this was accompanied by a decrease in left atrial and LV dimensions. Several different methods were used to interrupt AV conduction. It has been shown that high energy direct current ablation may cause myocardial damage and even death (22) especially in patients with diminished LV function. In our patients no differences in effect on LV function were observed when the different modes of ablation were compared. It should be stressed however that absence of cardiac disease other than AF made these patients a low risk group for any type of ablation of their AV conduction system.

\section{Limitations of our study}

As pointed out already, our patients represent a selected group of patients having longstanding lone $\mathrm{AF}$ in whom recurrences and the ventricular rate during the arrhythmia could not be controlled by drug therapy resulting in referral to a tertiary center. The true incidence of the development of LV dysfunction in patients with lone AF remains therefore not known and can only be answered by a prospective study.

The retrospective nature of our study led to other limitations like absence of standardization of the preablation antiarrhythmic drug regimen and differences in duration of AF. Different modes of ablation of AV conduction were used and the negative inotropic effects of drugs given may have contributed to impairment of LV function. Also the time of the echocardiographic measurements before and after ablation was not standardized. The atrial rhythm (sinus rhythm or AF) during our studies may not have been the same before and after ablation and post ablation measurements were made during ventricular pacing. Never- 
theless in contrast to the patients with normal LV function all patients having depressed LV function showed improvement after ventricular rate control by AV ablation.

Twenty nine out of the 30 patients had a VVIR pacemaker implanted. It is likely that in the future, because several of these patients had paroxysmal AF, more pacing devices will be implanted allowing atrial contribution to ventricular filling. This may result in even greater improvement of LV function after ablation. Echocardiogram-Doppler measurements could be useful in selecting the most appropriate pacing mode in each patient. 


\section{References}

1. Ostrander LD Jr, Brands RL, Kjelsberg MO, Epstein FK. Electrocardiographic findings among the adult population of a total natural community. Tecumseh, Michigan. Circulation 1965;31:888-898.

2. Petersen P, Godtfredsen J,. Atrial fibrillation. A review of course and prognosis. Acta Med Scand 1984;216:5-9.

3. Kannel WB, Abbott RD, Savage DD, Mc Namara PM. Epidemiologic features of chronic atrial fibrillation: The Framingham study. New Engl Med 1982;306:1018-1022.

4. Evans W, Swan P. Lone atrial fibrillation. Brit Heart J 1954;16:189-194.

5. Gajewski J, Singer RB. Mortality in an insured population with atrial fibrillation. JAMA 1981;245:1540-1544.

6. Scheinman MM, Morady F, Hess DS, Gonzalez R.Catheter induced ablation of the atrioventricular junction to control refractory supraventricular arrhythmias. JAMA 1982;248:851-855.

7. Gallagher JJ, Svenson RH, Kasell JH, German LD, Bardy GH, Broughton A, Crittelli G. Catheter technique for closed-chest ablation of the atrioventricular conduction system. New Engl Med 1982;306:194-200.

8. Brugada P, de Swart H, Smeets JLRM, Wellens HJJ. Transcoronary chemical ablation of atrioventricular conduction. Circulation 1990;81:757-761.

9. Lemery R, Brugada P, Della Bella P, Dughernier T, Wellens HJJ. Predictors of long-term success during closed-chest catheter ablation of the atrioventricular junction. Eur Heart J 1989;10:826-832.

10. Sciller, Shah PM, Crawford M, DeMaria A, Devereux R, Feigenbaum H,Gutgesell H, Reichek N, Sahn D, Schnittger I, Silverman NH, Tajik AJ. Recommendations for quantification of the left ventricle by two-dimensional echocardiography. Committee on standards. Subcommittee on quantification of two-dimensional echocardiograms. J Am Soc Echo 1989;6:358-367

11. Morgan CL, Nadas AS. Chronic ectopic tachycardia of infancy and childhood. Am Heart J 1964;67:617-627.

12. Scheinman MM, Basu D, Holenberg M. Electrophysiologic studies in patients with persistent atrial tachycardia. Circulation 1974;50:266-273.

13. Gillette PC, Garson A. Electrophysiological and pharmacologic characteristics of automatic ectopic atrial tachycardia. Circulation 1977;56:571-584.

14. Engel TR, Bush CA, Schael SF. Tachycardia aggravated heart disease. Ann Int Med 1974;80:384-388.

15. McLaren CJ, Gersh BT, Sugrue DD, Hammil SC, Seward JB, Holmes DR. Tachycardia induced myocardial dysfunction, a reversible phenomenon ?. Br Heart J 1985;53:323327.

16. Packer DL, Bardy GH, Worly SJ, Smith MS, Cobb FR, Coleman RE, Gallagher JJ, German LD. Tachycardia-induced cardiomyopathy: a reversible form of the left ventricular dysfunction. Am J Cardiol 1986;57:563-570.

17. Damiano RJ, Tripp HF, Asano T, Small KW, Jones RH, Lowe JE. Left ventricular dysfunction and dilatation resulting from chronic supraventricular tachycardia. J Thorac Cardiovasc Surg 1987;94:135-143. 
18. Cruz FES, Cheriex EC, Smeets JLRM, Atie J, Peres AK, Penn OCKM, Brugada P, Wellens HJJ. Reversibility of tachycardia induced cardiomyopathy after cure of incessant supraventricular tachycardia. J Am Coll Cardiol 1990;16:739-744.

19. Rabbani L, Wang PL, Couper GL, Friedman PL. Time course of improvement in ventricular function after ablation of incessant automatic atrial tachycardia. Am Heart J 1991;121:816-819.

20. Lemery R, Brugada P, Cheriex E, Wellens HJJ. Reversibility of tachycardia induced left ventricular dysfunction after closed-chest catheter ablation of the atrio-ventricular junction for intractable atrial fibrillation. Am J Cardiol 1987;60:1406-1408.

21. Heinz G, Siostrzonek P, Kreiner G, Gössinger H. Improvement in left ventricular systolic function after successful radiofrequency his bundle ablation for drug refractory, chronic atrial fibrillation and recurrent atrial flutter. Am J Cardiol 1992;69:489-492.

22. Evans GT, Scheinman MM, Bardy G. Predictors of in-hospital mortality after DC catheter ablation of atrioventricular junction: Results of a prospective international multicenter study. Circulation 1991;84:1924-1937. 
Secand Part 


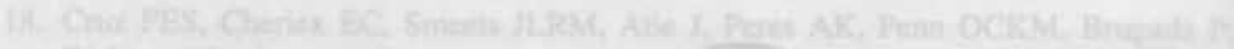

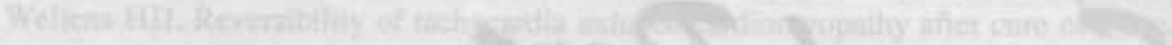

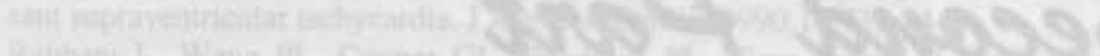

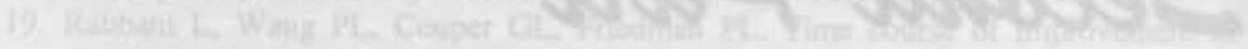

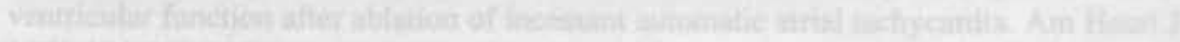

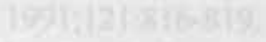

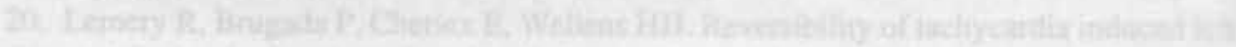

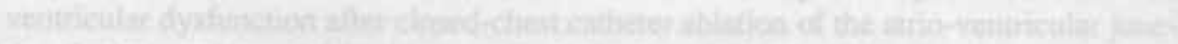

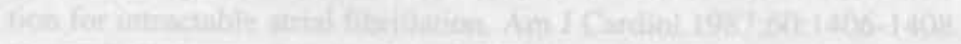

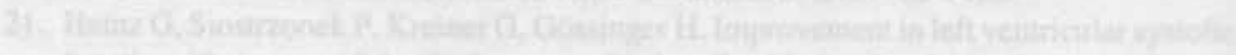

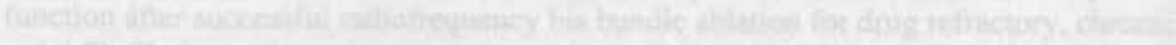

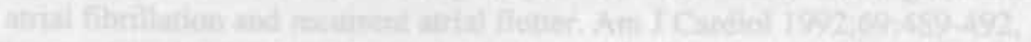

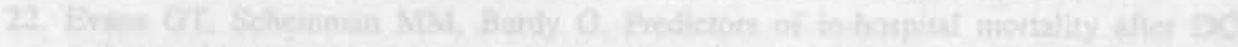

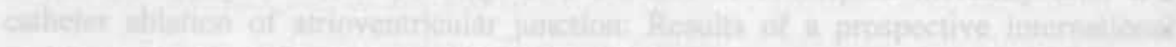

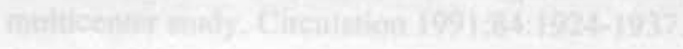




\section{Chapter 6}

\section{Time course and prognostic}

significance of serial signal averaged electrocardiograms after a first acute myocardial infarction

Luz-Maria Rodriguez, MD, Ruud Krijne, MD, Adri van den Dool, BS, Pedro Brugada, MD, Joep Smeets, MD, and Hein J.J Wellens, MD. 


\section{Time course and prognostic significance of serial signal averaged electrocardiograms after a first acute myocardial infarction}

\section{Abstract}

The prognostic significance of serial signal averaged electrocardiograms performed during the first 3 days (period 1), in the second week (period 2) after a first acute myocardial infarction (AMI) and 6 months later (period 3) was prospectively assessed in 190 patients. No patients were treated with thrombolytic therapy. Patients with conduction disturbances were excluded. The mean age of the 190 patients was 57 (range 34 to 74) years and their mean left ventricular ejection fraction $40 \% \pm 6 \%$ (range $12-70 \%$ ). Eighty-four patients had an anterior wall AMI and the remaining 106 patients an inferior wall AMI. After a mean follow-up of 24 months, 16 patients had developed sustained symptomatic monomorphic ventricular tachycardia, 7 patients were resuscitated from an episode of ventricular fibrillation, and 10 patients died suddenly. Multivariate regression analysis using continuous variables showed that the strongest predictor of sustained ventricular tachycardia and ventricular fibrillation was the left ventricular ejection fraction ( $p<0.0001$ ) followed by the duration of $Q R S$ complex on the signal averaged electrocardiogram recorded during the first 3 days after AMI $(\mathrm{p}<0.0005)$. Sudden death was only predicted by the left ventricular ejection fraction $(p<0.02)$.

\section{Introduction}

In patients surviving acute myocardial infarction (AMI), recognition of those at high risk of developing life-threatening arrhythmias and sudden death is of obvious importance. Size of infarction as reflected in left ventricular ejection fraction and also complex ventricular arrhythmias have been identified as important factors in this risk stratification (1). Recently, increasing attention has been given to the signal averaged electrocardiogram as another screening 
method alone or in combination with other parameters (2). Most of these studies have been retrospective. Recordings have been obtained at varying time intervals after AMI. Our study using serially recorded signal averaged electrocardiograms in 190 patients was performed to (1) obtain prospective data on the value of this technique, and (2) get an insight into the most appropriate time of recording the signal averaged electrocardiogram after AMI.

\section{Patients and methods}

All patients admitted to our coronary care unit in 1983 with the diagnosis of AMI were considered candidates to prospectively enter the study. Patients were excluded if (1) the diagnosis of AMI could not be confirmed even after the first recording had been obtained; (2) conduction disturbances were present at the time of recruitment; (3) technical or practical problems impeded the necessary recordings; (4) the patient was taking antiarrhythmic drugs at the time of admission with AMI or, (5) the patient had a previous AMI, had undergone bypass surgery or other associated cardiac or non-cardiac conditions (e.g., electrolyte disturbances) that could influence the results of the signal averaged electrocardiogram. Of the 320 patients with a first AMI, 190 had no exclusion criteria and could prospectively be included in the study. No patient was treated with thrombolytic therapy. A signal averaged electrocardiogram using Simson's method (3) was recorded during one of the first 3 days (period 1) after the onset of symptoms. The study was repeated in the second week (period 2) and, if the patient was alive, after 6 months in the outpatient clinic (period 3). Full electrical isolation during the recording was guaranteed by a specially prepared room next to the coronary care unit where no other electrical devices were present. The duration of the QRS complex and the voltage of the terminal $40 \mathrm{~ms}$ of the QRS complex were calculated according to the methods defined by Simson (3). Although filters for 25 and $50 \mathrm{~Hz}$ were used only data using $25 \mathrm{~Hz}$ filters will be presented because results were identical.

In our study the voltage of the terminal $40 \mathrm{~ms}$ of the QRS complex (V40) was analyzed as a continuous variable and dichotomized as well. When the amplitude of signals in the last $40 \mathrm{msec}$ of the filtered QRS were dichotomized, late potentials were considered present if case low-amplitude voltage $<25$ microV.

Late potentials were also categorized as normal ( $>25$ microV) or abnormal $(<25$ microV).

In all patients information was available on age, gender, location of AMI, maximal enzyme increase, cause of death and incidence spontaneously occurring sustained ventricular tachycardia during follow-up. Left ventricular ejection fraction was measured before discharge using 2-dimensional echocardiography, left ventricular contrast angiography or nuclear techniques. In 
patients in whom left ventricular ejection fraction had been measured with several of these techniques the average value was used for calculation. As previously reported in our institution correlation between echocardiographic and angiographic left ventricular ejection fraction and between nuclear and angiographic left ventricular ejection fraction is 0.96 and 0.94 , respectively (4).

Statistical analysis was performed using univariate and multivariate analysis with the Cox proportional Hazard model using continuous variables with a univariate predictor value of $<0.10$. One-way analysis of variance and simultaneous confidence intervals were used to compare the continuous variables between groups. All values are expressed as a mean \pm standard deviation.

The mean follow-up at time of analysis was 25 months (range 1 to 33 ).

\section{Results}

Of the 190 patients, $37(19 \%)$ had late potentials (V40 $<25$ microV) during the first 3 days (period 1 ) after myocardial infarction.

The incidence decreased to $15 \%$ ( 30 of 190 patients) during the second period ( 2 weeks after AMI) and was 12\% (23 patients) in the 178 survivors after 6 months (period 3) (table I). There were 12 death: 10 patients died suddenly and 2 patients died because of pump failure.

Of 142 patients with a left ventricular ejection fraction $>40 \%, 25$ patients $(18 \%)$ had late potentials during $>1$ of the 3 postinfarction periods in contrast to 19 of 48 patients $(39 \%)$ with left ventricular ejection fraction $<40 \%(p=0.003)$.

When comparing the patients without arrhythmic events to patients with arrhythmic events (sudden death, ventricular fibrillation, ventricular tachycardia), we noted some differences among the 4 groups. The peak of creatine kinase and oxaloacetic transferase were higher in patients with ventricular tachycardia $(p<0.0001)$. The left ventricular ejection fraction was lower in patients having ventricular fibrillation and in those who died suddenly $(\mathrm{p}<0.0001)$. Mean duration of QRS in period 1 was $108 \mathrm{~ms}$ (range 88 to 120) in patients developing sustained ventricular tachycardia during follow-up, $120 \mathrm{~ms}$ (range 66 to 120 ) in patients with ventricular fibrillation, and $106 \mathrm{~ms}$ in those who died suddenly. In patients without arrhythmic events mean duration of QRS was $90 \mathrm{~ms}$ ( $p<0.0001)($ table II).

Mean voltage of the terminal $40 \mathrm{~ms}$ of the QRS complex (V40) in the first period after myocardial infarction was lower in patients developing ventricular tachycardia ( $\mathrm{p}<0.0001$ ). In contrast patients having ventricular fibrillation had a lower voltage during the second and third period after myocardial infarction $(\mathrm{p}<0.0001)$. 
Table I. Presence of late potentials and arrhythmic events in relation to left ventricular ejection fraction

\begin{tabular}{|c|c|c|c|c|c|c|c|}
\hline \multicolumn{3}{|c|}{ Periods after AMI } & \multicolumn{2}{|c|}{$E F>40 \%$} & \multicolumn{2}{|c|}{$E F<40 \%$} & \multirow[b]{2}{*}{$p$ value } \\
\hline 1 & 2 & 3 & LP & $\mathrm{AE}$ & LP & $\mathrm{AE}$ & \\
\hline+ & - & - & 6 & 1 & 2 & 1 & NS \\
\hline+ & + & - & 6 & 0 & 4 & 0 & NS \\
\hline+ & - & + & 0 & 1 & 2 & 0 & NS \\
\hline - & - & + & 0 & 0 & 4 & 1 & NS \\
\hline+ & + & + & 13 & 5 & 4 & 7 & $0.02 *$ \\
\hline - & + & - & 0 & 0 & 3 & 0 & NS \\
\hline - & + & + & 0 & 1 & 0 & 0 & NS \\
\hline - & - & & 117 & 7 & 29 & 9 & NS \\
\hline
\end{tabular}

Abbreviations: $\mathrm{AMI}=$ Acute myocardial infarction; $\mathrm{AE}=$ Arrhythmic event; $\mathrm{EF}=$ Left ventricular ejection fraction; $\mathrm{LP}=$ late potentials; $-(\mathrm{V} 40>25 \mathrm{microV})=$ No $\mathrm{LP},+(\mathrm{V} 40<$ 25 microV) $=$ Presence of LP. period 1 = first 3 days after AMI, period $2=$ week 2 after AMI, period $3=6$ months after AMI.

After a mean follow-up of 25 months there were 33 arrhythmic events, 16 patients $(8.8 \%)$ presented symptomatic sustained monomorphic ventricular tachycardia. In 4 patients this arrhythmia was observed around the twenty-fifth day after AMI, in 4 patients approximately 1 month after AMI and in the remaining 8 patients after $>13$ months (range 13 to 32 ). Seven patients $(3.8 \%)$ were resuscitated from ventricular fibrillation. Four patients had ventricular fibrillation < 1 month after AMI and 3 at 1 month after AMI. Ten patients (5.5\%) died suddenly. Two patients died with documented ventricular tachycardia/ventricular fibrillation after 1 month of AMI. The remaining 8 patients died suddenly and without electrocardiographic documentation before the third signal averaged electrocardiogram was recorded (1-5.5 months). Two patients died because of pump failure approximately 15 months after AMI. Arrhythmic events occurred more often in patients with left ventricular ejection fraction $<40 \%$ (15 in 48 vs 18 in 142) ( $<<0.01)$. The combination of persistent late potentials during the 3 postinfarction periods and the occurrence of arrhythmic events was also seen more often in patients with low left ventricular ejection fraction ( 5 in 142 vs 7 in 42) ( $p<0.01$ ) (Table I). 
Table II. Clinical characteristics of patients with ventricular tachycardia, ventricular fibrillation and sudden death.

\begin{tabular}{lllll}
\hline & No events & VT & VF & SD \\
\hline No. of Pts. & 157 & 16 & 7 & 10 \\
Age (years) & $57 \pm 3$ & $62 \pm 2$ & $55 \pm 1$ & $57 \pm 3$ \\
Site of MI & & & & \\
Anterior & 60 & 13 & 6 & 5 \\
Inferior & 97 & 3 & 1 & 5 \\
Peak CK (U/) & $2331 \pm 30$ & $2879 \pm 181^{*}$ & $2563 \pm 92$ & $2553 \pm 90$ \\
Peak OT (U/l) & $260 \pm 20$ & $325 \pm 15 *$ & $292 \pm 13$ & $272 \pm 20$ \\
LVEF \% & $47 \pm 3$ & $39 \pm 2$ & $30 \pm 4^{*}$ & $30 \pm 5^{*}$ \\
Mean duration QRS period 1 (ms) & $90 \pm 3$ & $108 \pm 2$ & $120 \pm 1^{*}$ & $106 \pm 2$ \\
Mean duration QRS period 2(ms) & $99 \pm 3$ & $112 \pm 2^{*}$ & $112 \pm 1^{*}$ & $106 \pm 2$ \\
Mean duration QRS period 3(ms) & $95 \pm 3$ & $96 \pm 2$ & $96 \pm 1$ & $96 \pm 2$ \\
Mean V40 period 1 (mv) & $65 \pm 3$ & $45 \pm 3^{*}$ & $48 \pm 2$ & $52 \pm 3$ \\
Mean V40 period 2 (mv) & $52 \pm 2$ & $43 \pm 3$ & $34 \pm 2^{*}$ & $62 \pm 2$ \\
Mean V40 period 3 (mv) & $53 \pm 2$ & $46 \pm 3$ & $36 \pm 2^{*}$ & $66 \pm 2$ \\
\hline
\end{tabular}

Abbreviations: $\mathrm{CK}=$ creatine kinase; $\mathrm{LVEF}=$ left ventricular ejection fraction; $\mathrm{MI}=$ myocardial infarction; OT = oxala-cetic transferase; Pts = patients; period $1=$ first 3 days after AMI, period 2 = week 2 after AMI, period $3=6$ months after AMI, V40 = amplitude last $40 \mathrm{~ms}$ of $\mathrm{QRS} ;{ }^{*} \mathrm{P}$ value $<0.0001$

With use of continuous variables (Cox Proportional Hazard), the strongest predictor of sustained ventricular tachycardia and ventricular fibrillation was found to be left ventricular ejection fraction $(p<0.0001$ ) followed by the duration of the $\mathrm{QRS}$ complex in the signal averaged electrogram recorded during the 3 days of infarction $(p<0.0005)$.

Sudden death was only predicted by the left ventricular ejection fraction $(p<0.02)$. When sudden death, ventricular fibrillation and ventricular tachycardia were taken together and the same continuous variables applied, left ventricular ejection fraction remained the strongest predictor for arrhythmic events $(p<0.0001)$ with the duration of the QRS complex from the signal averaged electrogram recorded during the first 3 days after myocardial infarction as the second most powerful predictor. 


\section{Discussion}

In recent years several investigators have recorded late potentials after an AMI. $(2,3,5-10)$. Our results suggest that the left ventricular ejection fraction was the most important predictor of sudden death and the occurrence of sustained ventricular arrhythmias during follow-up. The duration of the QRS complex on the signal averaged electrocardiogram during the first period (3 days) after AMI was an independent predictor $(p<0.0005)$. Serial signal averaged electrocardiograms at the second period ( 2 weeks) and third period (6 months after AMI) did not add additional information.

Gomes et al (5) found good specificity ( $80 \%$ ) and sensitivity ( $88 \%$ ) of the duration of QRS complex in the "acute" phase of AMI but the signal averaged electrocardiograms were not recorded during the late phase of AMI. The same group (6) found that the left ventricular ejection fraction had an independent value from the late potentials to predict arrhythmic events. They also described that the predictive value of the signal averaged electrocardiogram in patients with anterior wall AMI was better than left ventricular ejection fraction. Pollak et al (7) reported that the predictive value of late potentials was independent of left ventricular ejection fraction in patients with and without ventricular tachycardia.

El-Sherif et al (8) described that an abnormal signal averaged electrocardiograms and a low ejection fraction had independent value for predicting late arrhythmic events after the acute phase of myocardial infarction. In their study an abnormal signal averaged electrocardiogram was considered a low-amplitude signal $(<25 \mathrm{mV})$ in the last $40 \mathrm{msec}$ of the QRS, a total filtered QRS duration $>120$, or both. In our patients left ventricular ejection fraction was the strongest predictor of prognosis. Late potentials were not an independent variable in terms of prognosis.

Few studies have paid attention to the value of serial and prospectively recorded signal averaged electrocardiograms (8-10). Serial signal averaged electrocardiograms showed that the most important prognostic information was recorded during the first period ( 3 days) after AMI. This observation is of interest both pathophysiologically and in terms of the practical application of the technique.

From the pathophysiologic point of view one can only speculate on the serial changes observed in the signal averaged electrocardiogram. The incidence of late potentials (as here defined) decreased from the first to the second period after AMI with a further decrease in the survivors 6 months later. Progressive cell death may have caused the changes from the first to second period and 6 months later but also slowing in conduction during the phase of acute ischemia. Because sudden death after AMI can be the result of other causes than a 
sustained ventricular arrhythmia, it cannot be expected that either the signal averaged electrocardiogram or the left ventricular ejection fraction will reach a sensitivity or specificity of $100 \%$.

With regard to the practical application of the technique, serially recorded signal averaged electrocardiograms demonstrate that the best prognostic value can be obtained when recordings are made early after AMI (9). Interestingly, our findings suggest that this is true for the duration of the QRS complex, but not for the presence of a late potential. A widened QRS on the signal averaged electrocardiogram during the first 3 day after AMI probably indicates a large area at risk.

Our patients were admitted to the hospital at a time that thrombolytic therapy was not given. It is well known now that thrombolytic therapy after AMI leads to a reduced incidence of abnormal signal averaged electrocardiograms $(11,12)$. It appears unlikely, however, that the presence of an abnormal signal averaged electrocardiogram after thrombolytic therapy will be of different significance as compared to an abnormal signal averaged electrocardiogram without thrombolytic therapy. 


\section{References}

1. Moss AJ. Bigger TJ, Case RB. The multicenter postinfarction Research Group: Risk stratification and survival after myocardial infarction. N Engl J Med 1983;309:331-336,

2. Deniss AR, Richards DA. Cody DV, Russell PA, Young AA, Cooper MJ, Ross DL, Uther JB. Prognostic significance of ventricular tachycardia and fibrillation induced at programmed stimulation and delayed potentials detected on the signal-averaged electrocardiograms of survivors of acute myocardial infarction.Circulation 1986;74: 731-745

3. Simson MB. Use of signals in the terminal QRS complex to identify patients with ventricular tachycardia after myocardial infarction. Circulation 1981;64: 235-242

4. Braat SHJG. Right ventricular infarction. Its detection by electrocardiography and its effect on right ventricular ejection fraction. Maastricht, Leiter Nypels, 1984:1-1 15-18

5. Gomes AJ, Winters S, Stewart D, Horowitz S, Milner M, Barreca P. A new non-invasive index to predict sustained ventricular tachycardia and sudden death in the first year after myocardial infarction: Based on signal-averaged electrocardiogram, radionuclide ejection fraction and holter monitoring. J Am Coll Cardiol 1987; 10: 349-357

6. Gomes AJ, Winters SL, Martison M, Machac J, Stewart D, Targonski A. The prognostic significance of quantitative signal-averaged variables relative to clinical variables, site of myocardial infarction, ejection fraction and ventricular premature beats: A prospective study. J Am Coll Cardiol 1989;13: 377-384

7. Pollak SJ, Kestes PJ, Bredlau CE, Walter PF. Influence of left ventricular ejection fraction on signal averaged late potentials in patients with coronary artery disease with and without ventricular tachycardia. Am Heart J 1985;110: 747-752

8. El-Sherif N, Ursell SN, Bekheit S, Fontaine J, Turitto G, Henkin R, Caref E. Prognostic significance of the signal-averaged ECG depends on the time of recording in the posinfarction period. Am Heart J 1989;118:256-264

9. McGuire M, Kuchar D, Ganis J, Sammel N, Thorbum C. Natural history of late potentials in the first ten days after myocardial infarction and relation to early ventricular arrhythmias. Am J Cardiol 1988;61:1187-1190

10. Turitto G, Caref E, Macina G, Fontaine JM, Ursell SN, El-Sherif N. Time course of ventricular arrhythmias and the signal averaged electrocardiogram in the postinfarction period: a prospective study of correlation. Br Heart J 1988;60: 17-22

11. Gang E, Lew A, Hong M, Wang F, Siebert C, Peter T. Decreased incidence of ventricular late potentials after successful thrombolytic therapy for myocardial infarction. $\mathrm{N}$ Engl $\mathrm{J}$ Med 1989;321:712-716

12. Lange RA, Cigarroa RG, Wells PJ, Kremers MS, Hillis LD. Influence of anterograde flow in the infarct artery on the incidence of late potentials after acute myocardial infarction.Am J Cardiol 1990;65:554-558. 


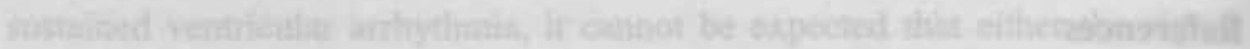

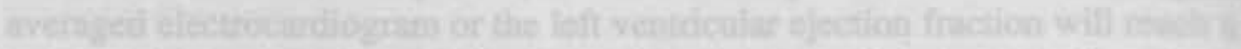

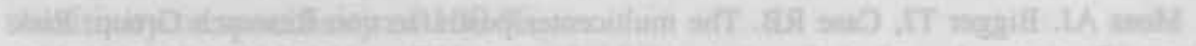
agkilk

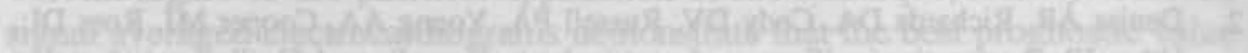

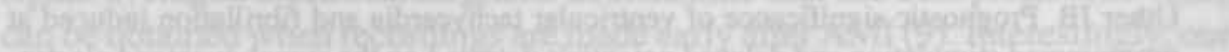

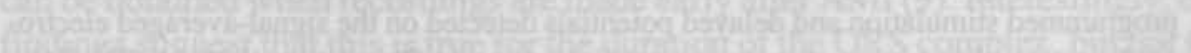

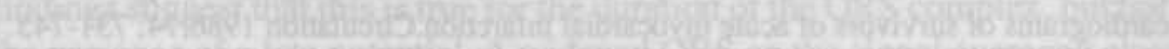

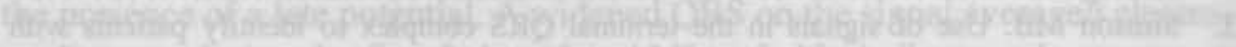

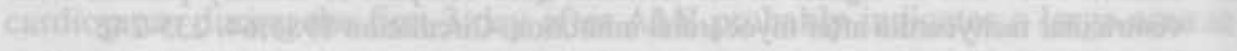

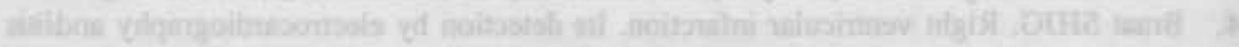

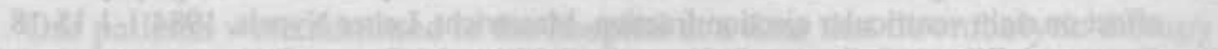

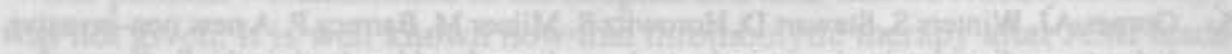

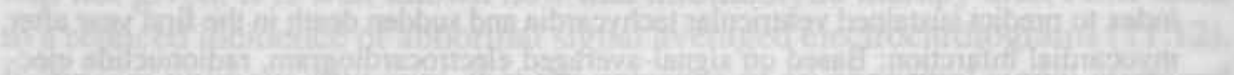

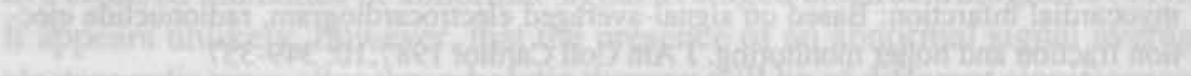

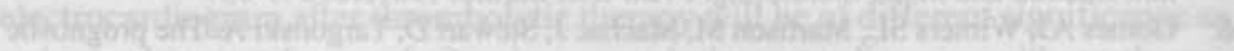

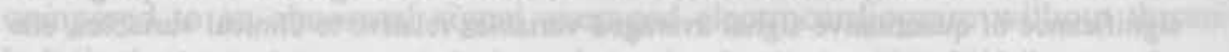

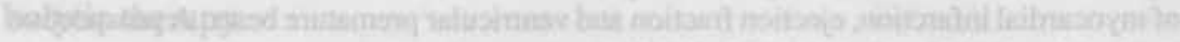

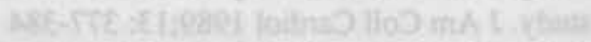

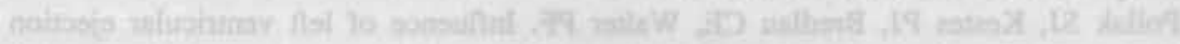

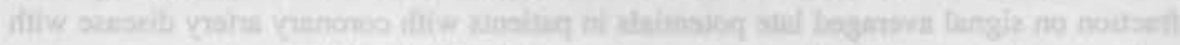

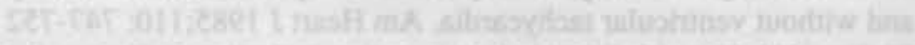

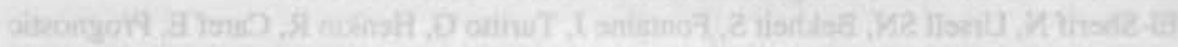

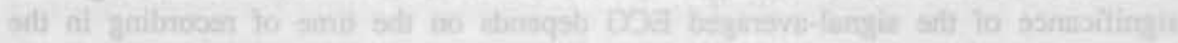

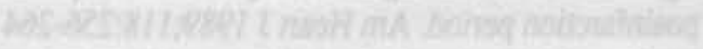

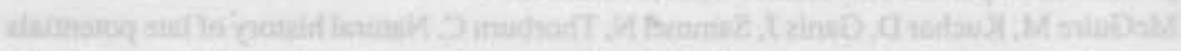

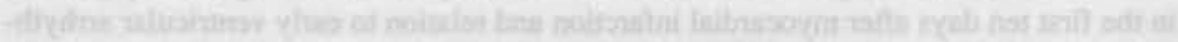

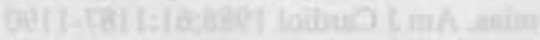

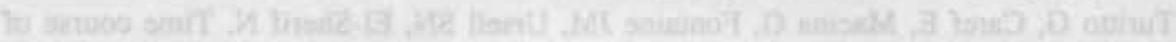

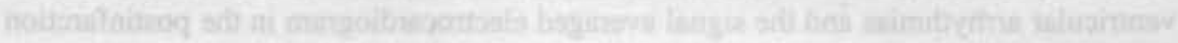

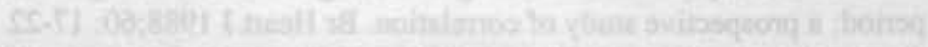

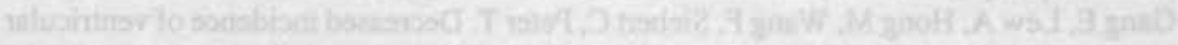

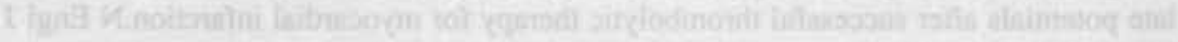
altsictegener balk

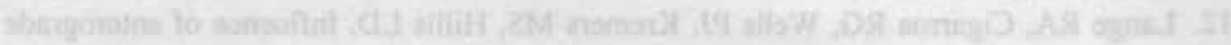

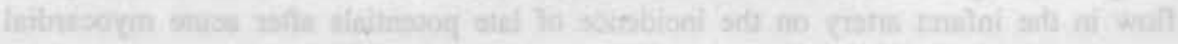

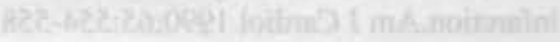




\section{Chapter 7}

\section{Observations on the QRS complex in postinfarction and non-ischemic ventricular tachycardias}

Luz-Maria Rodriguez, M.D, Joep L.R.M, Smeets, M.D. Jürg Schläpfer,M.D, Barbara Dijkman, M.D. Apostolos Katsivas, M.D, Christian de Chillou, M.D, Hein J.J. Wellens, M.D.

Presented at the American Heart Association.

Circulation 1991;84:-650

(Submitted for publication) 


\title{
Observations on the QRS complex in postinfarction and non-ischemic ventricular tachycardias
}

\begin{abstract}
The twelve lead electrocardiogram characteristics during tachycardia were compared in 73 patients with a postinfarction (group A) and 73 patients with a non-ischemic etiology of their ventricular tachycardia (VT) (group B). Seventy five tracings were available in the group B patients ( 8 right ventricular dysplasia, 24 idiopathic ventricular tachycardia and 43 preexcited tachycardia). Correct diagnosis was based on electrophysiologic and angiographic study. Presence of a $\mathrm{qR}$ or $\mathrm{QR}$ pattern (with a QR ratio of $25 \%$ or more) in any lead except aVR was found to be the most helpful parameter in differentiating postinfarction from non-ischemic ventricular tachycardia. This sign was found in $65 / 73(89 \%)$ and $0 / 75$ of postinfarction and non-ischemic ventricular tachycardia respectively. The specificity and sensitivity of this sign was $100 \%$ and $90 \%$ respectively ( $p<0.0001)$. In right bundle branch block VT morphology,(44/73 group A, $44 / 75$ group B) a total $R$ wave amplitude in all precordial leads of more than $80 \mathrm{~mm}$ was of help in differentiating postinfarction from non-ischemic VT. Forty out of forty four ( $91 \%$ ) of postinfarction VT and 4/44 (9\%) of non-ischemic VT had an amplitude of $\leq 80 \mathrm{~mm}(\mathrm{p}<0.0001)$. The specificity and sensitivity of this finding was $90 \%$ and $90 \%$ respectively. In right bundle branch block VT morphology, the distance between onset to summit of $R$ wave in lead V1 was $100 \pm 50$ (mean) msec vs $87 \pm 38$ (mean) $\operatorname{msec}(\mathrm{p}<0.01)$ and the distance between the onset to nadir of $S$ wave in V6 was $89 \pm 27$ (mean) msec vs $71 \pm 18$ (mean) msec $(p<0.001)$ in group A and group B patients respectively. In left bundle branch block VT morphology, the total $R$ wave amplitude in the extremity leads was higher $(41 \pm 23 \mathrm{~mm})$ in non-ischemic VT than postinfarction VT $(29 \pm 12 \mathrm{~mm})(\mathrm{p}<0.001)$.
\end{abstract}




\section{Conclusions}

Certain findings on the 12-lead electrocardiogram during ventricular tachycardia can be of help in differentiating between an postinfarction or a non-ischemic origin. 1) $\mathrm{A} q R$ or $\mathrm{QR}$ pattern in any lead except aVR suggests postinfarction VT, 2) In right bundle branch block VT morphology a total $R$ wave amplitude in all precordial leads $\leq 80 \mathrm{~mm}$ suggests postinfarction VT. 3 ) In right bundle branch block VT morphology a distance from onset to summit of the R wave in lead V1 of $\geq 120 \mathrm{msec}$ and a distance from onset to nadir of S wave in lead V6 of $\geq 90$ msec suggests postinfarction VT. 4) In left bundle branch block VT morphology a total $R$ wave amplitude in extremity leads of $>40 \mathrm{~mm}$ suggests non-ischemic VT.

\section{Introduction}

Several studies have focused on establishing criteria to differentiate a supraventricular from a ventricular origin in patients with a wide QRS tachycardia (1-10).

Less attention has been given to the possibility to diagnose a postinfarction from a non-ischemic cause when analyzing a wide QRS tachycardia (11).

The purpose of this study was therefore, to study the value of the 12-lead electrocardiogram to differentiate postinfarction from non-ischemic ventricular tachycardia. In this study preexcited tachycardias (exclusive atrioventricular conduction over the accessory pathway) were considered as a form of ventricular tachycardia.

\section{Methods and Patients}

Our nonblinded retrospective study included 73 consecutive patients with 73 twelve lead electrocardiogram recordings of sustained monomorphic ventricular tachycardia after an old myocardial infarction (group A). There were 55 males and 18 females with a mean age of $59 \pm 10$ years. The myocardial infarction location was anterior in 31 patients, inferior: 26 patients, lateral: 5 patients, anterior + inferior: 8 and anterior + lateral: 3 patients. Also seventy-five 12 lead electrocardiograms were available from 73 consecutive patients with non-ischemic VT, 56 males and 17 females (group B). The mean age was $32 \pm 14$ (range 12-67) years. As shown in Table 2 forty three preexcited tachycardias with exclusive atrio-ventricular conduction over an accessory atrioventricular pathway were present in 41 patients (antidromic tachycardia $=27$, atrial flutter 
Table 1. QRS axis in postinfarction and non-ischemic VT

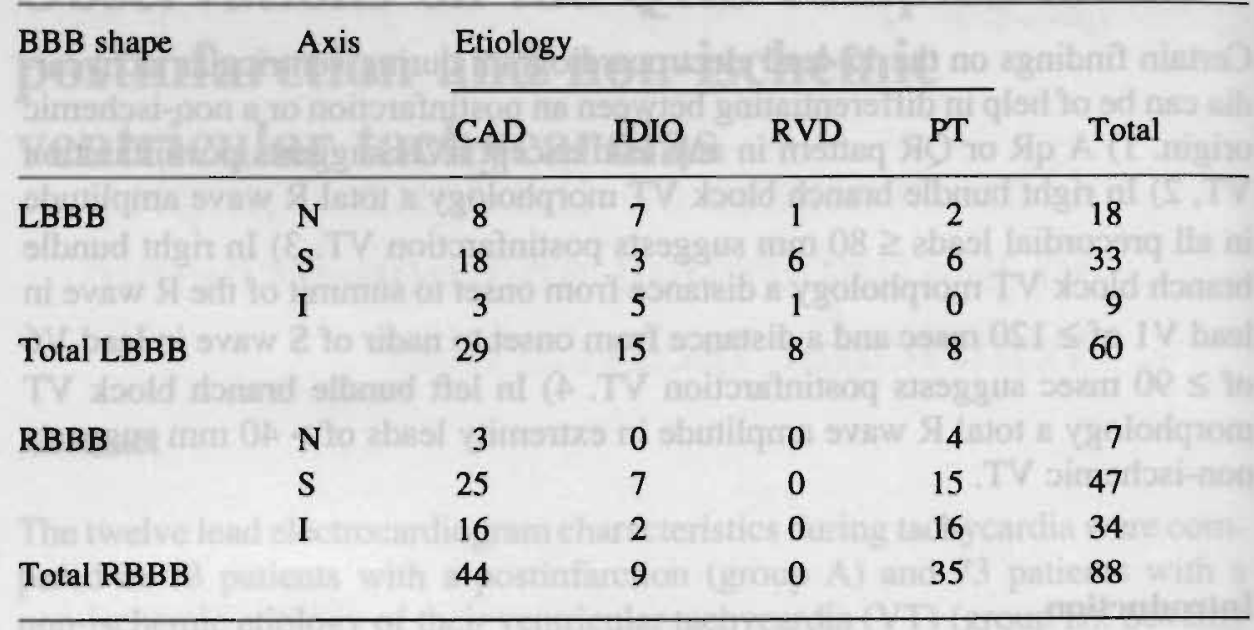

Abbreviations: $\mathrm{BBB}=$ bundle branch block, $\mathrm{CAD}=$ coronary artery disease, IDIO = idiopathic ventricular tachycardia, $\mathrm{I}=$ inferior, $\mathrm{L}=$ left, $\mathrm{N}=$ normal, $\mathrm{PT}=$ preexcited tachycardia, $\mathbf{R}=$, right, $\mathrm{RVD}=$ right ventricular dysplasia, $\mathrm{S}=$ superior, $\mathrm{VT}=$ ventricular tachycardia.

$=14$, atrial tachycardia $=2$ ). In these patients accessory pathway location was left free wall in 29 cases, $(67 \%)$, right free wall in 7 cases (16\%), posteroseptal in $5(12 \%)$, anteroseptal in 1 and mid-septal in $1(5 \%)$. Twenty four patients had idiopathic ventricular tachycardia, and 8 patients had right ventricular dysplasia ventricular tachycardia. A complete 12-lead electrocardiogram during tachycardia was available in all patients. All tachycardias occurred spontaneously except the preexcited tachycardias which were induced during electrophysiologic study. VT's from patients with dilated cardiomyopathy were not included in this study because of the few cases available. The etiology of ventricular tachycardia was based on non-invasive and invasive tests including echocardiography, cardiac catheterization with ventricular and coronary angiography and an electrophysiologic study. In patients with left bundle branch block like VT special attention was given to the echocardiographic examination to exclude right ventricular dysplasia. The preexcited tachycardias were included in the study after the electrophysiologic study showed that ventricular activation occurred exclusively over the accessory atrio-ventricular pathway.

Electrocardiograms were analyzed at a paper speed of $25 \mathrm{~mm} / \mathrm{sec}$ and standardization $1 \mathrm{mV}=10 \mathrm{~mm}$ and graded by four independent observers for: 1) right or left bundle branch block morphology; 2) frontal QRS axis; 3) QRS width; 4) the total $R$ wave amplitude in the precordial leads; 5 ) the total $R$ wave amplitude 
in the extremity leads; 6) total QRS amplitude in all 12 leads by adding each $\mathrm{QRS}$ component (i.e., $\mathrm{Q}+\mathrm{R}+\mathrm{S}$ amplitude) from all extremity and precordial leads; 7) Total S wave amplitude in the precordial leads, and 8) in the extremity leads, 9) the presence of $q R$ or $Q R$ pattern in any lead except aVR; 10) the distance between onset to summit of the R wave in V1 and from the onset to nadir of the S wave in lead V6 in right bundle branch block shaped VT; 11) the distance between onset to nadir of the S wave in V1 and onset to summit of the $R$ wave in V6 in left bundle branch block shaped VT.

In all patients electrocardiograms were recorded in the absence of antiarrhythmic drug therapy or after antiarrhythmic drugs had been stopped for at least 5 elimination half lives.

\section{Statistical analysis}

Continuous variables were analyzed using a paired $t$ test. The means are reported with the standard deviation. Categorical variables were analyzed with chi-square and Fisher's exact test. Statistical significance was assumed for $p$ values of $<0.05$.

\section{Definitions}

Frontal $Q R S$ axis: Normal ranging from $-30^{\circ}$ to $+75^{\circ}$

Superior ranging from $-30^{\circ}$ to $-180^{\circ}$

Inferior ranging from $+75^{\circ}$ to $-180^{\circ}$

$Q$ wave: $T$ o be classified as a $\mathrm{qR}$ or $\mathrm{QR}$ complex, the $\mathrm{q}$ wave had to have a width of at least 0.04 seconds and the downstroke of the $q$ wave had to be rapid to avoid misclassification of a negative delta wave as a $\mathrm{qR}$ complex. Apart from a width of 0.04 seconds the $\mathrm{Q} / \mathrm{R}$ ratio had to be at least $25 \%$.

Right bundle branch block morphology: R, qR, QR or R/S complex in lead V1; $\mathrm{qR}, \mathrm{qRS}, \mathrm{QS}, \mathrm{R} / \mathrm{S}$ or R complex in V6.

Left bundle branch block morphology: QS or $\mathrm{rS}$ complex in $\mathrm{V} 1 ; \mathrm{R}$ or $\mathrm{R} / \mathrm{S}$ complex in V6. 
Table 2 A. Electrocardiographic findings in postinfarction and non-ischemic VT

\begin{tabular}{|c|c|c|c|c|c|c|}
\hline \multirow[t]{2}{*}{ Parameters } & \multirow{2}{*}{ 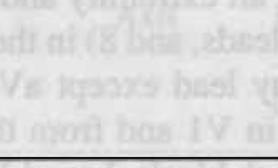 } & \multirow{2}{*}{$\underline{\text { Group A }}$} & \multicolumn{3}{|l|}{ Group B } & \multirow{2}{*}{$\begin{array}{l}\mathrm{P} \\
\text { value }\end{array}$} \\
\hline & & & IDIO & RVD & PT & \\
\hline QR pattem & & $89 \%$ & $0 \%$ & $0 \%$ & $0 \%$ & $<0.001$ \\
\hline \multicolumn{7}{|c|}{ QRS width (ms) } \\
\hline & LBBB VT & $174 \pm 20$ & $147 \pm 22$ & $180 \pm 19$ & $140 \pm 15$ & $<0.0001$ \\
\hline & RBBB VT & $166 \pm 19$ & $152 \pm 16$ & - & $165 \pm 18$ & $=0.02$ \\
\hline \multicolumn{7}{|c|}{ Total QRS amplitude (mm) } \\
\hline & LBBB VT & $154 \pm 42$ & $222 \pm 68$ & $166 \pm 38$ & $205 \pm 08$ & $<0.0001$ \\
\hline & RBBB VT & $155 \pm 56$ & $176 \pm 32$ & - & $198 \pm 40$ & $<0.0001$ \\
\hline \multicolumn{7}{|c|}{ Total S wave amplitude precordial leads (mm) } \\
\hline & LBBB VT & $67 \pm 45$ & $105 \pm 52$ & $74 \pm 39$ & $86 \pm 39$ & $=0.07$ \\
\hline & RBBB VT & $43 \pm 31$ & $47 \pm 22$ & & $32 \pm 23$ & NS \\
\hline \multicolumn{7}{|c|}{ Total S waves amplitude in extremity leads (mm) } \\
\hline & LBBB VT & $29 \pm 18$ & $36 \pm 12$ & $40 \pm 19$ & $27 \pm 17$ & NS \\
\hline & RBBB VT & $27 \pm 15$ & $38 \pm 7$ & - & $25 \pm 17$ & $=0.08$ \\
\hline \multicolumn{7}{|c|}{ Total $\mathbf{R}$ waves amplitude precordial leads (mm) } \\
\hline & LBBB VT & $29 \pm 12$ & $34 \pm 34$ & $32 \pm 22$ & $43 \pm 35$ & NS \\
\hline & RBBB VT & $51 \pm 40$ & $74 \pm 41$ & - & $117 \pm 35$ & $<0.0001$ \\
\hline \multicolumn{7}{|c|}{ Total $\mathbf{R}$ wave amplitude extremity leads (mm) } \\
\hline & LBBB VT & $29 \pm 12$ & $51 \pm 27$ & $23 \pm 07$ & $39 \pm 23$ & $<0.0001$ \\
\hline & RBBB VT & $25 \pm 11$ & $29 \pm 17$ & - & $26 \pm 13$ & NS \\
\hline
\end{tabular}

Results (Tables 1, 2A and 2B)

\section{1) QRS morphology}

Right bundle branch block morphology was observed in 44 out of $73(60 \%)$ of postinfarction and 44 out of $75(58 \%)$ (NS) of non-ischemic VT. Left bundle branch block shape was found in 29 out of $73(40 \%)$ and 31 out of $75(42 \%)$ (NS) of postinfarction and non-ischemic VT respectively.

As shown in table 3 a right bundle branch block morphology was seen in patients with a left free wall or posteroseptal accessory pathway and 9/24 of idiopathic VT. Left bundle branch block shape was found in all 8 patients with right ventricular dysplasia, 15/24 patients with idiopathic VT and $7 / 7$ with a right free wall and $1 / 1$ with an anteroseptal accessory pathway. 
Table 2 B. Electrocardiographic findings in postinfarction andnon-ischemic VT

\begin{tabular}{lllllll}
\hline Parameters & Group A & Group B & & P \\
\cline { 2 - 5 } \cline { 4 - 6 } & & IDIO & RVD & PT & value \\
\hline
\end{tabular}

Patients with RBBB VT and when

$\mathrm{R}$ wave in precordial leads

$\begin{array}{lrrr}\leq 80 \mathrm{~mm} & 40 / 44 & 4 / 44 & <0.0001 \\ >80 \mathrm{~mm} & 4 / 44 & 40 / 44 & <0.0001\end{array}$

Distance from onset-summit

(R wave) in V1 (ms)

$100 \pm 50 \quad 97 \pm 30 \quad-\quad 85 \pm 16 \quad$ NS

Distance from onset-nadir

(S wave) in V6 (ms)

$89 \pm 27 \quad 73 \pm 25 \quad-\quad 70 \pm 18<0.002$

Distance from onset-nadir

(S wave) in V1 (ms)

$86 \pm 18 \quad 75 \pm 20 \quad 96 \pm 22 \quad 76 \pm 17 \quad$ NS

Distance from onset-summit

( $R$ wave) in V6 (ms)

$$
98 \pm 34 \quad 71 \pm 15 \quad 98 \pm 26 \quad 80 \pm 21=0.06
$$

Abbreviations: See Table 1.

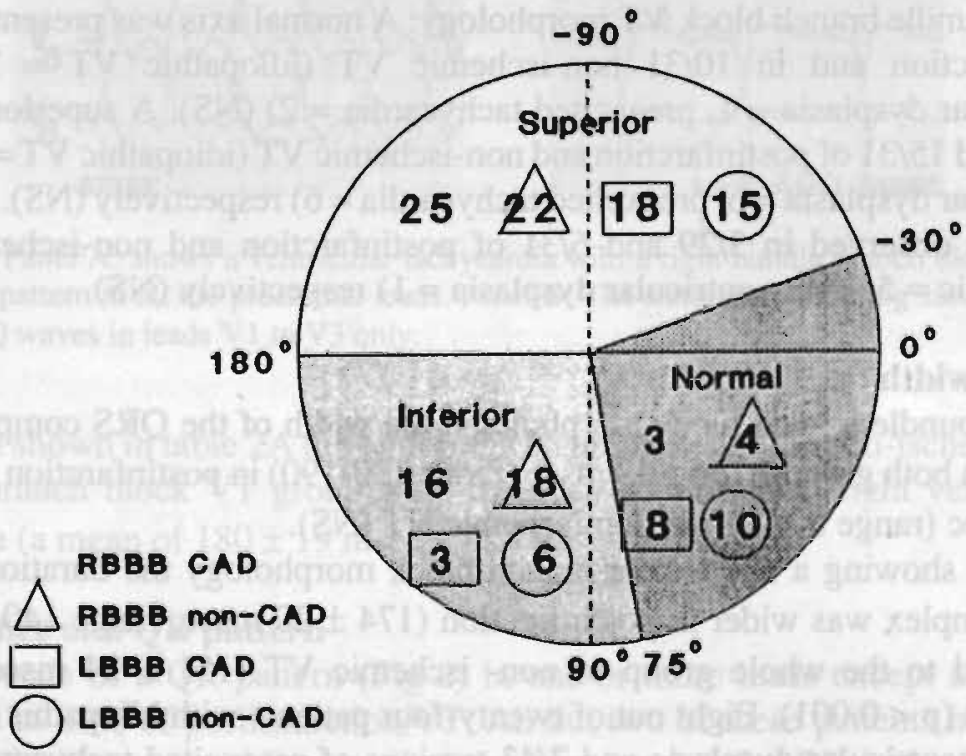

Figure 1: The QRS axis in postinfarction and non-ischemic ventricular tachycardia. The numbers represent: a) patients with coronary artery disease with right or left bundle branch block (open squares) shaped ventricular tachycardia; b) patients without coronary artery disease and right (open triangle) or left bundle branch block (open circle) shaped ventricular tachycardia. 
Table 3. Findings of help in the differential diagnosis of postinfarction from non-ischemic ventricular tachycardias

\begin{tabular}{lcc}
\hline & RBBB & LBBB \\
\hline $\begin{array}{l}\text { 1. Presence of } Q R \text { pattem in any lead except aVR } \\
\text { 2. Total } R \text { wave amplitude in the extremity leads }<40 \mathrm{~mm}\end{array}$ & yes & yes \\
3. Total $R$ wave amplitude in all precordial leads $\leq 80 \mathrm{~mm}$ & yes & yes \\
4. Distance from onset to summit of $R$ wave in lead V1 & \\
$\geq 120 \mathrm{msec}$ and the distance from onset to nadir of $S$ & \\
wave $\geq 90$ msec in lead V6 & yes & \\
\hline
\end{tabular}

\section{2) QRS axis in the frontal plane (Fig 1)}

Right bundle branch block morphology: A normal axis was observed in 3/44 postinfarction and in 4/44 non-ischemic VT (all preexcited tachycardia). A superior axis was found in 25/44 of postinfarction and 22/44 of non-ischemic VT (idiopathic VT $=7$, preexcited tachycardia $=15$ ) $(\mathrm{NS})$. An inferior axis was present in 16/44 and 18/44 of postinfarction and non-ischemic VT (idiopathic $\mathrm{VT}=2$, preexcited tachycardia $=16$ ) respectively (NS).

Left bundle branch block VT morphology: A normal axis was present in 8/29 postinfarction and in 10/31 non-ischemic VT (idiopathic VT $=7$, right ventricular dysplasia $=1$, preexcited tachycardia $=2$ ) $(\mathrm{NS})$. A superior axis in $18 / 29$ and $15 / 31$ of postinfarction and non-ischemic VT (idiopathic VT $=3$, right ventricular dysplasia $=6$, preexcited tachycardia $=6$ ) respectively $(\mathrm{NS})$. Inferior axis was observed in $3 / 29$ and $6 / 31$ of postinfarction and non-ischemic VT (idiopathic $=5$, right ventricular dysplasia $=1$ ) respectively (NS).

\section{3) QRS width}

In right bundle branch block morphology, the width of the QRS complex was similar in both groups: $166 \pm 19 \mathrm{msec}$ (range 130-190) in postinfarction and 161 $\pm 24 \mathrm{msec}$ (range 80-200) in non-ischemic VT (NS).

In VT showing a left bundle branch block morphology the duration of the QRS complex was wider in postinfarction (174 $\pm 20 \mathrm{msec}$, range 140-200) as compared to the whole group of non- ischemic VT $(151 \pm 24 \mathrm{msec}$, range $120-200)(p<0.001)$. Eight out of twenty-four patients with idiopathic VT, 0/8 of right ventricular dysplasia and 7/43 tracings of preexcited tachycardias (all with a septal location of their accessory pathway) had a QRS width of $<140$ 

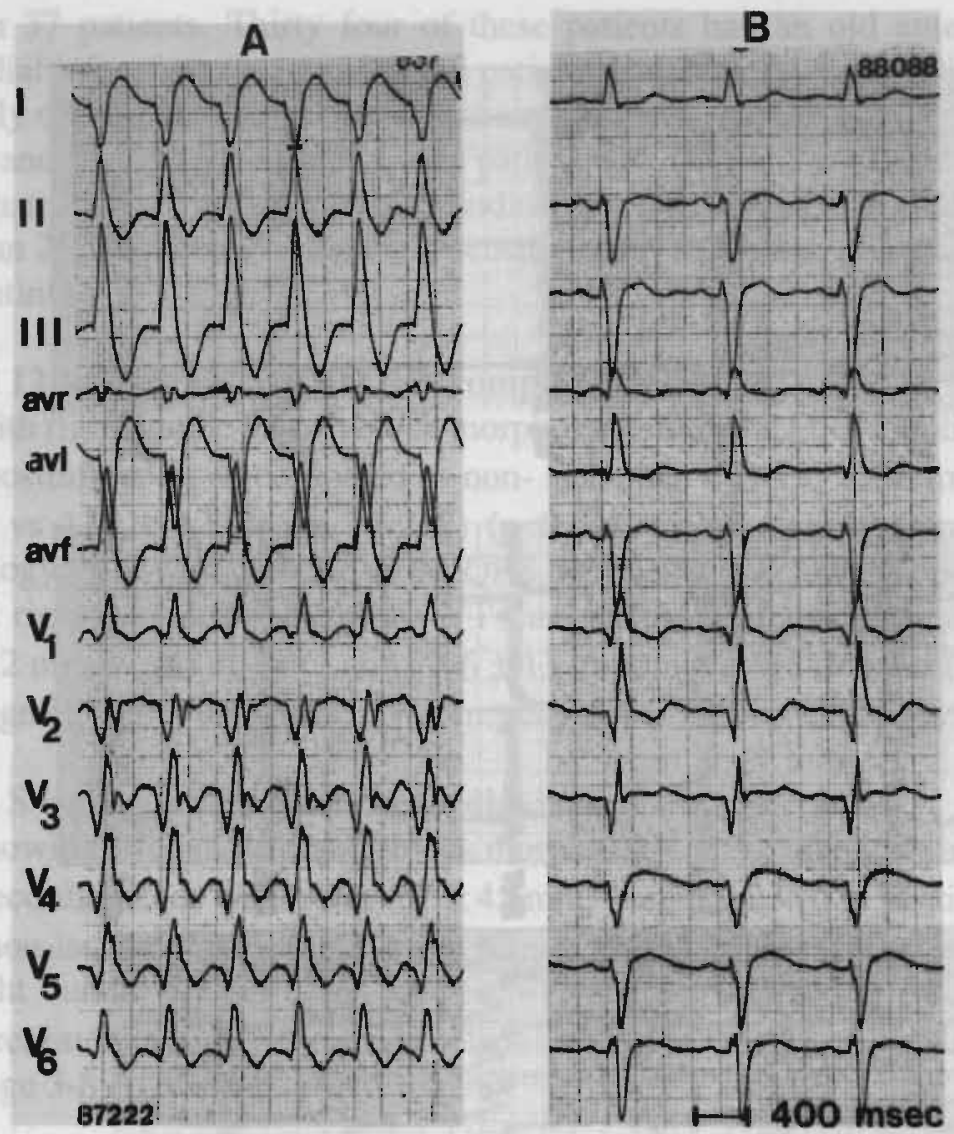

Figure 2: Panel A: shows a ventricular tachycardia with a right bundle branch block shape and $\mathrm{a} Q \mathrm{QR}$ pattem in all the precordial leads. Panel $\mathrm{B}$ : The same patient during sinus rhythm showing $Q$ waves in leads V1 to V3 only.

msec. As shown in table 2A the widest QRS complexes in the non-ischemic left bundle branch block VT group were found in patients with right ventricular dysplasia (a mean of $180 \pm 19 \mathrm{msec}$ ).

\section{4) Presence of a $Q R$ pattern}

The presence of a QR pattern (Fig 2) in one or more leads except aVR was observed in $89 \%$ of postinfarction VT. All but two of these patients had more than one lead showing this pattern. As shown in table 3 a QR in lead III was present in 17 patients. Fifteen of these patients had an old inferior-posterior myocardial infarction and the remaining two patients had inferior-anterior myocardial infarction. A QR in lead I and AVL and or the precordial leads was 

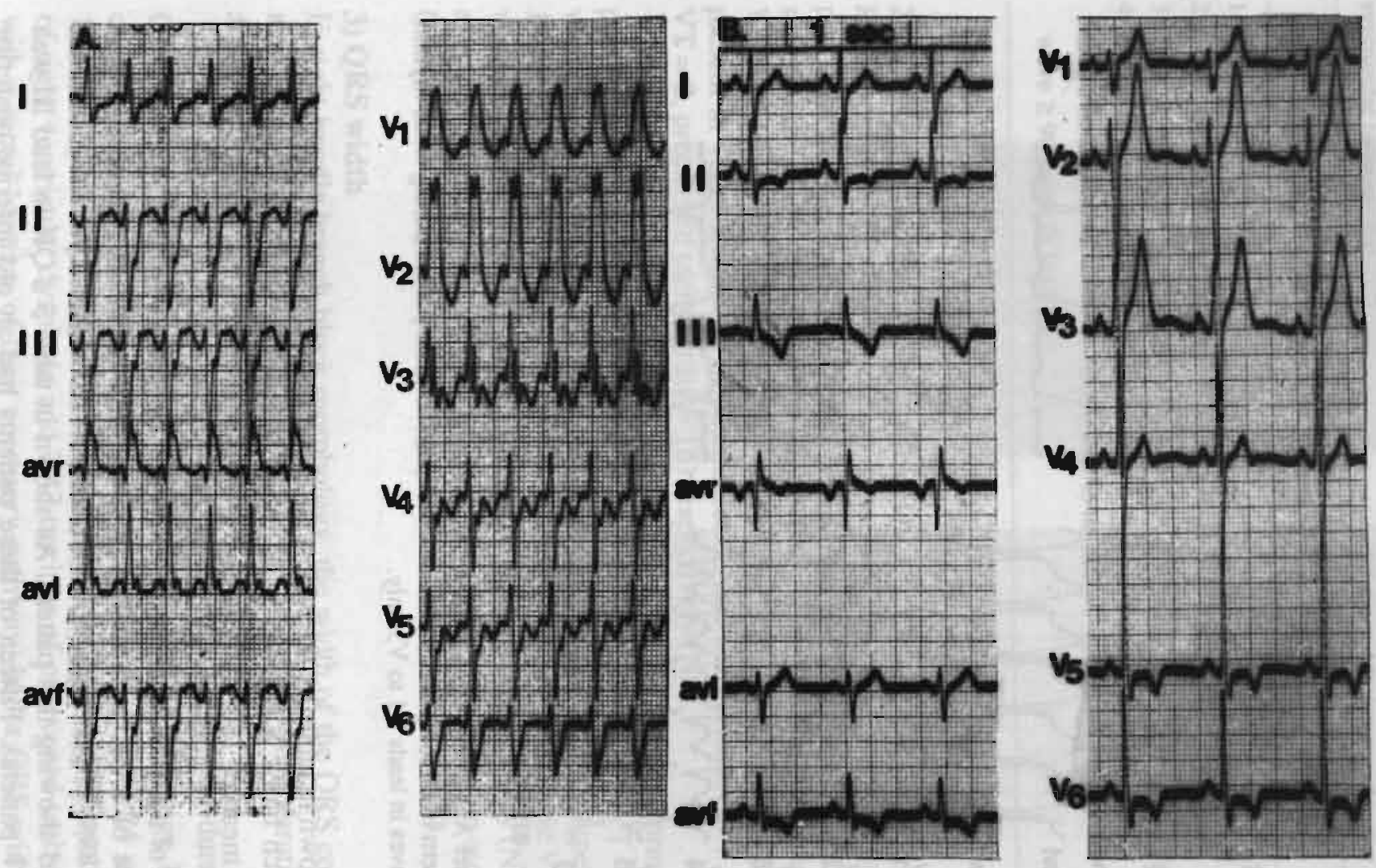

Figure 3: Panel A shows the 12-lead electrocardiogram of an idiopathic ventricular tachycardia. Note a presence of a $q R$ pattern with a $\mathrm{qR}$ ratio of less than $25 \%$ in lead V1 and V2. Panel B shows the same patient during sinus rhythm. This was one of the 2 patients with a verapamil sensitive right bundle branch block shaped, left axis VT. 
found in 37 patients. Thirty four of these patients had an old anterior wall myocardial infarction, the remaining 3 patients had a lateral myocardial infarction. Only one patient from the non-ischemic VT group showed a $\mathrm{qR}$ pattern in lead V1 and V2 (Fig 3). However, this patient with idiopathic VT had a q wave of less than $25 \%$ of the $\mathrm{R}$ wave. The finding of a $\mathrm{QR}$ pattern with a $\mathrm{QR}$ ratio of more than $25 \%$ had a specificity and sensitivity of $100 \%$ and $90 \%$ respectively for a postinfarction origin of VT.

\section{5) Total 12-lead amplitude of QRS complexes}

In VT with right bundle branch block morphology, the total QRS amplitude was less in postinfarction as compared to non- ischemic VT: $155 \pm 56 \mathrm{~mm}$ (range 77-355) vs $174 \pm 12$ (range 77-212) ( $<<0.01$ ). In left bundle branch block morphology the total amplitude of the QRS complexes was lower in postinfarction and right ventricular dysplasia VT than in idiopathic and preexcited VT (154 $\pm 42 \mathrm{~mm}$; range 76-246) and (166 $\pm 13 \mathrm{~mm}$; range $118-245)$ vs (222 \pm 68 $\mathrm{mm}$; range 107-350) and (205 $\pm 08 \mathrm{~mm}$; range 131-360) $(\mathrm{p}<0.0001)$.

\section{6) Total $S$ wave amplitude in precordial leads}

In VT showing left bundle branch block morphology, the total $\mathrm{S}$ wave amplitude in all precordial leads was lower (67 $\pm 45 \mathrm{~mm}$, (range 0-235)) in postinfarction than in non-ischemic VT $(91 \pm 47 \mathrm{~mm}$ (range 22-235)) $(\mathrm{p}<0.04)$.

In right bundle branch block shaped VT, this sum tended to be higher in postinfarction than in non-ischemic VT ( $43 \pm 31 \mathrm{~mm}$ (range $2-139)$ vs $32 \pm 23$ mm (range 3-89)) respectively $(p=0.09)$.

\section{7) Total S wave amplitude in extremity leads}

The total S waves amplitude in extremity leads in VT with left bundle branch block morphology was not different between postinfarction and non-ischemic VT (29 $\pm 18 \mathrm{~mm}$ (range 6-63) vs $33 \pm 16 \mathrm{~mm}$ (range 5-61)) (NS). In right bundle branch block VT morphology, this was similar in postinfarction $(27 \pm 15 \mathrm{~mm}$, range 3-64) and non-ischemic VT (25 $\pm 17 \mathrm{~mm}$, range 7-109) (NS).

\section{8) Distance from onset to nadir of the $S$ wave in lead V1 and from onset to summit of $R$ wave in V6}

In patients with left bundle branch block morphology the distance from onset to nadir of S wave in lead V1 did not differ in postinfarction and non-ischemic VT ( $86 \pm 18 \mathrm{msec}$ (range $60-120$ ) vs $81 \pm 5 \mathrm{msec}$, (range 40-120)) (NS). Distance from the onset to summit of $R$ wave in lead V6 was longer in postinfarction as 
B

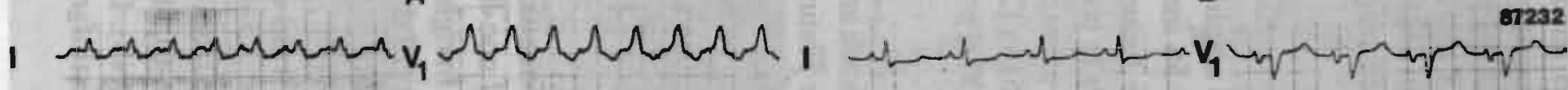

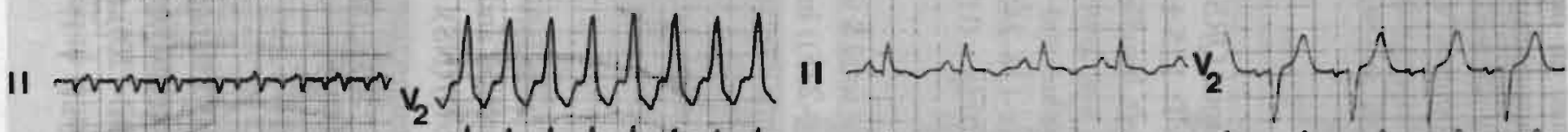

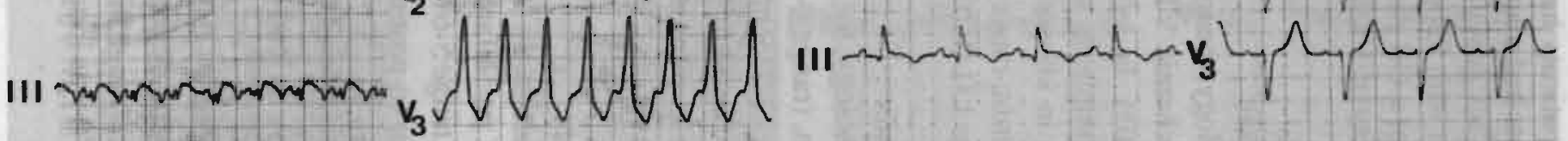

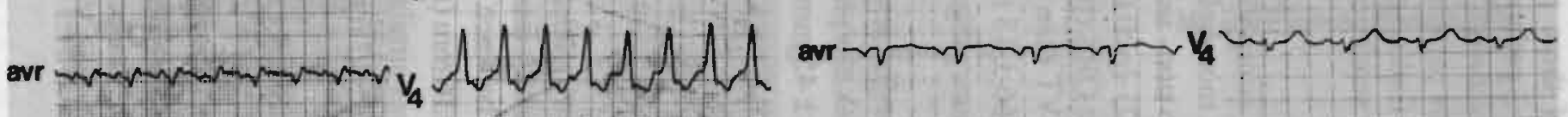

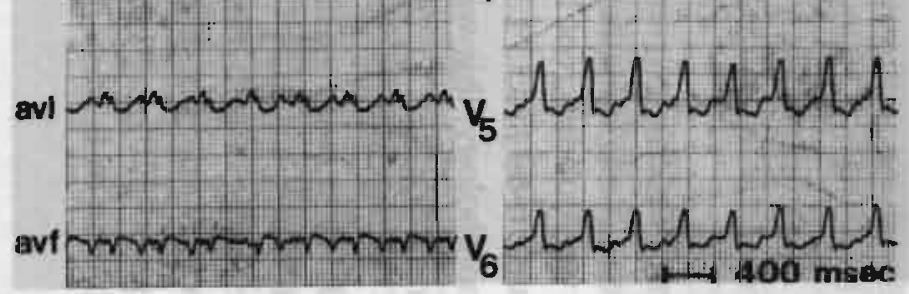
ant avf

Figure 4: Ventricular tachycardia (panel A) in a patient with an old inferior myocardial infarction (panel B) showing a positive concordant pattern with a total $R$ wave amplitude of more than $80 \mathrm{~mm}$. 
compared to non-ischemic VT $(98 \pm 34 \mathrm{msec}$. (range $50-170)$ vs $79 \pm 19 \mathrm{msec}$. (range 40-120)) $(\mathrm{p}=0.06)$. Only patients with postinfarction VT had an onsetsummit $R$ interval in V6 of more than 120 msec ( $6 / 29$ patients).

\section{9) Distance from onset to summit of $R$ wave in V1 and from onset to nadir of S wave in lead V6}

In right bundle branch block shaped VT, the distance from onset to summit of $R$ wave in lead V1 was longer in postinfarction (100 $\pm 50 \mathrm{msec}$, (range 40-160) than in non-ischemic VT $(87 \pm 38 \mathrm{msec}$, (range 50-140)) but this difference was not significant. In lead V6 the distance from onset to the nadir of S wave was also significantly longer in postinfarction than non-ischemic VT $(89 \pm 27 \mathrm{msec}$ (range 50-160) vs $71 \pm 18 \mathrm{msec}$ (range $40-100$ ), $\mathrm{p}<0.002$ ). Only patients with postinfarction VT had an interval of more than $100 \mathrm{msec}$ (15/44 patients).

\section{0) Total $R$ wave amplitude in precordial leads}

In the presence of a right bundle branch block shaped VT, the total amplitude of $\mathrm{R}$ waves in all precordial leads was lower in postinfarction as compared to non-ischemic VT $(51 \pm 40 \mathrm{~mm}$ (range $2-151)$ vs $106 \pm 10 \mathrm{~mm}$ (range 29-189)) $(\mathrm{p}<0.0001)$. When the total $\mathrm{R}$ wave amplitude was divided into those with $\leq 80$ $\mathrm{mm}$ and $>80 \mathrm{~mm}$ the specificity and sensitivity, positive predictive value and negative predictive value was $90 \%, 90 \%, 90 \%$ and $90 \%$ respectively for postinfarction and non-ischemic VT ( $\leq 80 \mathrm{~mm} 40 / 44$ of postinfarction VT and $4 / 44$ of non-ischemic VT $>80 \mathrm{~mm} \mathrm{4/44}$ postinfarction VT and 40/44 of non-ischemic VT). Only in the four patients with an old infero-posterior myocardial infarction and who showed a positive concordant pattern during VT, the total R wave amplitude was found to be $>80 \mathrm{~mm}$. An example is given in figure 4 .

\section{1) Total $R$ wave amplitude in extremity leads}

Only in left bundle branch block VT morphology, the total $\mathrm{R}$ wave amplitude in the extremity leads was higher in non-ischemic as compared to postinfarction VT (41 $\pm 23 \mathrm{~mm}$ (range $8-60$ ) vs $29 \pm 12 \mathrm{~mm}$, (range 12-59), p < 0.001).

\section{Discussion}

In this study we found that 4 out of 10 electrocardiographic parameters analyzed were helpful in differentiating postinfarction from non-ischemic VT: 1) a QR pattern in any lead except aVR, favors postinfarction VT, 2) In left bundle branch block shaped VT a total R wave amplitude in the extremity leads $\geq 40$ $\mathrm{mm}$, favors non-ischemic VT. 3) In right bundle branch block shaped VT a total $R$ wave amplitude in all precordial leads $\leq 80 \mathrm{~mm}$, favors postinfarction VT. 4) 
A distance from onset to summit of $R$ wave in lead $V 1 \geq 120 \mathrm{msec}$ and a distance from onset to nadir of $S$ wave in lead V6 $\geq 90 \mathrm{msec}$, favors postinfarction VT. (Table 3)

\section{QR pattern}

Coumel et al (11) have reported that the presence of $\mathrm{QR}$ ( $\mathrm{qR}, \mathrm{Qr}$ ) or $\mathrm{QS}$ (especially in leads V5 and V6) complexes during a wide QRS VT strongly suggests an postinfarction origin. Bisteni et al (12) have previously shown in a dog model that ventricular premature beats with a $Q R$ pattem only occurred after myocardial infarction, but that beats with a QS pattern could also be produced in normal hearts. Our observations are in agreement with Bisteni. QS complexes were observed both in postinfarction and non-ischemic VT. Our patients with non-ischemic VT did not include patients with cardiomyopathy or infectious or infiltrative myocardial diseases like sarcoidosis and amyloidosis. Pathologic Q waves may be present in these patients during sinus rhythm (13). It is likely that some of these patients will show QR complexes during VT.

Dash et al (14) found a low sensitivity (29\%) but a high specificity (97\%) for a $Q R$ pattern of ventricular premature beats as indicative for scarring after a myocardial infarction. In our study $89 \%$ of postinfarction VT had at least one lead with a $Q R$ pattern. It is of interest that in only $60 \%$ of these patients the $Q R$ pattern during VT was seen in the same leads showing pathologic $Q$ waves during sinus rhythm. This is in agreement with the findings of Coumel et al (11).

However, under some circumstances there may be other reasons for a discrepancy between a $Q R$ pattern during ventricular tachycardia and absence of a $\mathrm{Q}$ wave during sinus rhythm like disappearance of a $\mathrm{Q}$ wave in an old myocardial infarction or the presence of complete left bundle branch block in sinus rhythm.

QRS amplitude: Several factors play a role in the amplitude of the QRS complexes like normal or abnormal spread of activation through the ventricle, thickness of the ventricular wall and cancellation from ventricular activation running in opposite directions. In ventricular tachycardia this process is further complicated by the abnormal site of origin of ventricular activation and (as in postinfarction VT or right ventricular dysplasia) loss of ventricular muscular tissue.

Coumel et al (11) noted a higher total QRS amplitude in the extremity leads in patients with idiopathic VT and observed an inverse relation between QRS amplitude and QRS width. In our patients we found a higher total QRS amplitude in non-ischemic VT both in right and left bundle branch block shaped VT with the exception of patients with right ventricular dysplasia. Interestingly, 
and in agreement with the inverse relation between amplitude and QRS width observed by Coumel (11), the right ventricular dysplasia patients had the widest QRS complexes of the non-ischemic VT group.

In our patients with a left bundle branch block shaped VT, those with a non-ischemic etiology had a higher total $R$ amplitude in the extremity leads than those with postinfarction VT. This was not caused (as shown in Fig 1) by a higher incidence of a normal or inferior axis in the non-ischemic VT group.

Total $\mathbf{R}$ wave amplitude in the precordial leads was found to be helpful in making the distinction between postinfarction and non-ischemic VT. In the non-ischemic VT population this finding was primarily caused by the patients having ventricular activation starting at the ventricular insertion of a left free wall or posteroseptal accessory atrio-ventricular pathway. Under those circumstances the ventricular activation front moves towards the anterior chest leading to a positive concordant QRS pattern in the precordial leads. In postinfarction VT this is only seen if the VT site of origin is located in the posterobasal wall of the left ventricle. This was present in four of our postinfarction VT patients. It is of interest that in these four patients the total $R$ wave amplitude measured $130 \pm 30$ (range 103-151) $\mathrm{mm}$. In the accessory pathway patients with positive concordant pattern in the precordial leads the total $\mathbf{R}$ wave amplitude measured $143 \pm 32 \mathrm{~mm}$ (range 101-189) (NS).

\section{Local activation times.}

Several authors $(5,9,10)$ found that in precordial leads showing initial positivity the time interval from the beginning of QRS to the peak of the $\mathrm{R}$ wave is longer in VT than in aberrant conduction.

It is of interest that In right bundle branch block shaped VT the time from onset QRS to summit R wave in lead V1 did not differ significantly between postinfarction and non-ischemic VT.

However in lead V6 there was a longer interval from onset QRS to nadir of S wave in postinfarction as compared to non-ischemic VT. In fact a distance of more than $100 \mathrm{msec}$ was only found in postinfarction VT (in 15/44 patients). This finding reflects longer conduction times from the left to the right ventricle in postinfarction VT, which can be explained by scarring post- myocardial infarction.

In left bundle branch block shaped VT the interval from onset QRS to summit $R$ wave in lead V6 was significantly longer in postinfarction than non-ischemic VT. A distance of more than $120 \mathrm{msec}$ was only found in patients with postinfarction VT. 


\section{Limitations of the study}

In our study we included patients with preexcited tachycardia with atrioventricular conduction over an accessory pathway. Most people would not call these tachycardias a ventricular tachycardia because the origin of the tachycardia is not in the ventricle but either in the atrium (as in atrial flutter or atrial tachycardia) or the tachycardia is based upon a circus movement tachycardia with atrioventricular conduction over the accessory pathway (antidromic circus movement tachycardia). We did include them because like in true ventricular tachycardia, ventricular activation starts in the ventricle outside the specific conduction system. Only those patients were accepted if the electrophysiological study showed that ventricular activation started at the ventricular end of the accessory pathway only, without contribution to ventricular activation from atrio- ventricular conduction over the AV-node-His bundle axis.

In 34 patients with preexcited tachycardia ( 29 with left free wall and 5 with posteroseptal accessory pathways) ventricular activation started in the postero basal or postero-lateral portion of the left ventricle. These patients played an important role in the finding of a total precordial $\mathrm{R}$ wave amplitude of more than $80 \mathrm{~mm}$ as pointing to a non-ischemic VT. We considered of importance to include antidromic tachycardias especially those arising from the posteriorbasal portion of the left ventricle because can be difficult to differentiate them from ventricular tachycardias originate from the same region.

Only patients were included if they were not receiving antiarrhythmic drugs at the time of the registration of their VT electrocardiogram. Drugs that slow conduction, for example class IA and IC drugs, will obviously affect some of the parameters that were analyzed, for example the time interval from the beginning of the $Q R S$ to the summit of the $R$ wave or to the nadir of the $S$ wave. This should be considered when VT electrocardiograms are analyzed.

As already mentioned in discussing the significance of a $Q R$ pattern during VT, another limitation of our study is that our non-ischemic VT patients did not include patients with cardiomyopathy or infiltrative or infectious myocardial disorders.

In conclusion: the electrocardiogram during ventricular tachycardia may show features that suggest an postinfarction or non-ischemic etiology. With the exception of the QR pattern the other parameters show significant overlap indicating that only their presence can be used as suggestive for an postinfarction or non-ischemic etiology of VT. 


\section{References}

1. Marriot HJL: Differential diagnosis of supraventricular and ventricular tachycardia. Geriatrics 1970;25:91-100.

2. Wellens HJJ, Bär FWH, Lie KI: The value of the electrocardiogram in the differential diagnosis of a tachycardia with a widened QRS complex. Am J Cardiol 1978;64:27-33.

3. Wellens HJJ, Brugada P: Diagnosis of ventricular tachycardia from the 12-lead electrocardiogram. Cardiology Clinics 1987;5: 511-25.

4. Kindwall KE, Brown J, Josephson ME: Electrocardiographic criteria for ventricular tachycardia in wide complex left bundle branch morphology tachycardias. Am J Cardiol 1988; 61:1279-83.

5. Dongas J, Lehmann MH, Mahmud R, Denker S, Soni J, Akhtar M: Value of preexisting bundle branch block in the electrocardiographic differentiation of supraventricular from ventricular origin of wide QRS tachycardia. Am J Cardiol 1985;55:717-21.

6. Kremers MS, Black WH, Wells P, Solodyna M: Effect of preexisting bundle branch block on the electrocardiographic diagnosis of ventricular tachycardia. Am J Cardiol 1988;62:1208-12.

7. Kremers MS, Wells P, Black W, Solo M: Differentiation of the origin of wide QRS complexes by the net amplitude of the QRS in lead V6. Am J Cardiol 1989;64:1053-56.

8. Griffith MJ, de Belder MA, Linker NJ, Ward DE, Camm AJ: Multivariate analysis to simplify differential diagnosis of broad complex tachycardia. Brit Heart J 1991;66:16674.

9. Brugada P, Brugada J, Mont L, Smeets J, Andries EW: A new approach to the differential diagnosis of a regular tachycardia with a wide QRS complex. Circulation 1991;83:164959.

10. Drew BJ, Scheinman MM, Value of electrocardiographic leads MCL1, MCL6 and other selected leads in the diagnosis of wide QRS complex tachycardia. J Am Coll Cardiol 1991;18:1025-33.

11. Coumel Ph, Leclercq JF, Attuel P, Slama R. The QRS morphology in post-myocardial infarction ventricular tachycardias. A study of 100 tracing compared with 70 cases of idiopathic ventricular tachycardia. Eur Heart J 1984;5:792-99.

12. Bisteni A, Sodi-Pallares D, Medrano GA, Pileggi F: A new approach for the recognition of ventricular premature beats. Am J Cardiol 1960;5:358-69.

13. Mandel WJ, Peter CT, Hoffman I. Electrocardiographic diagnostic dilemmas in myocardial ischemia and infarction. In What's new in electrocardiography. Wellens HJJ , Kulbertus HE (eds) Martinus Nijhoff, The Hague, 1981, pp 58-78.

14. Dash $\mathrm{H}$, Ciotola TJ: Morphology of ventricular premature beats as an aid in the electrocardiographic diagnosis of myocardial infarction. Am J Cardiol 1983;52:458-61. 


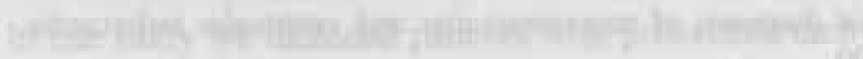

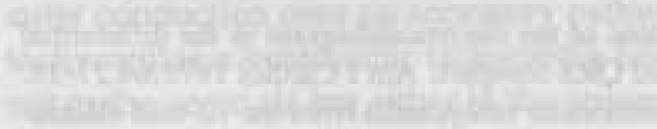

3a)

Cant

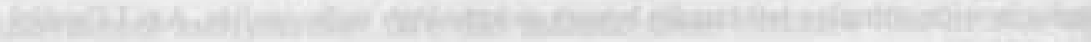

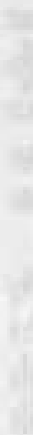

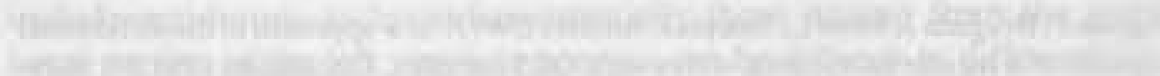

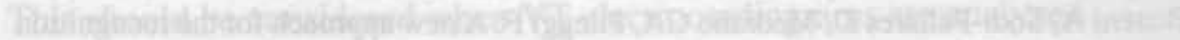

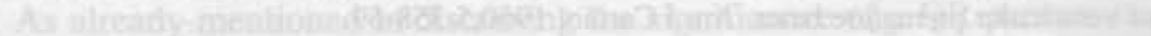

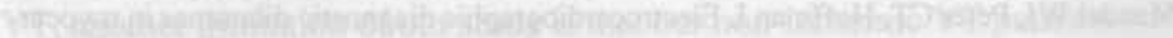

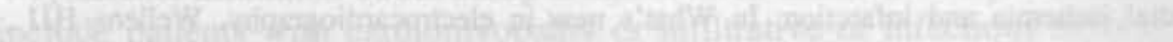

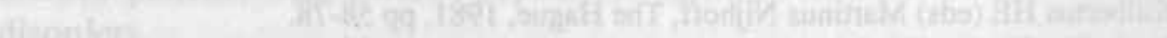

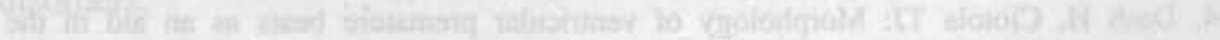

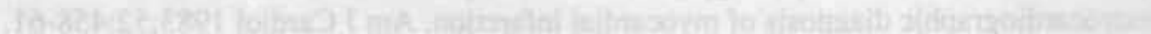

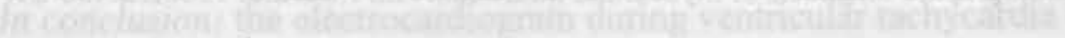




\section{Chapter 8}

\section{Identification of patients at high risk for recurrence of sustained ventricular tachycardia after healing of acute myocardial infarction}

Luz-Maria Rodriguez, MD, Rodulfo Oyarzun, MD, Joep Smeets, MD, Johannes Brachmann, MD, Claus Schmitt, MD, Pedro Brugada, MD, Peter Geelen, MD, Györgyi Lipcsei, MD, Adelin Albert, PhD, Hein J.J. Wellens, MD. 


\section{Identification of patients at high risk for recurrence of sustained ventricular tachycardia after healing of acute myocardial infarction}

\section{Abstract}

A prognostic index for non-fatal VT recurrences was developed using a retrospective analysis in a group of 206 patients with sustained monomorphic VT or ventricular fibrillation (VF) after healing of acute myocardial infarction. 74/206 (36\%) (64 VT patients and 10 VF patients) had recurrences of sustained monomorphic VT during $3.4 \pm 9$ years of follow-up. Three clinical variables were selected and weighted by stepwise logistic discriminant analysis of the study group. They were coded as follows: interval myocardial infarction-arrhythmia ( $<2$ months $=1,2$ to 6 months $=2,>6$ months $=3$ ), drug therapy: sotalol, or no sotalol (sotalol $=1$, no sotalol $=2$ ), and VT or VF as the presenting arrhythmia $(\mathrm{VT}=1, \mathrm{VF}=2)$. The prognostic index was: $3.41-(0.56 \mathrm{x}$ interval $)-(1.94 \mathrm{x}$ therapy $)+(0.86 x$ arrhythmia $)$. This prognostic index was validated prospectively in a test group of 158 consecutive patients with VT or VF after healing of acute myocardial infarction. Patients were allocated into different classes with decreasing prognostic index values, associated with increasing risk for VT recurrences. In the test group 27/158 (17\%) (22 VT patients and 5 VF patients) had recurrences (follow-up $2 \pm 2$ years). Two risk classes of patients were identified: one with high risk for VT recurrences $(61 \%)$ corresponding to patients with negative index, and one of low risk (4\% of recurrences) consisting of patients with a positive index. Thus, using 0 as cut-off point the sensitivity, specificity, and positive and negative predictive values were respectively: $81 \%$, $89 \%, 62 \%$, and $96 \%$. This prognostic index my be used in selecting treatment of patients with severe ventricular arrhythmias, after healing of acute myocardial infarction 


\section{Introduction}

Electrophysiologic testing has been reported to be of value to predict survival in patients with ventricular tachyarrhythmias (1) and of patients resuscitated from out-of-hospital cardiac arrest (2-4). Less attention has been given to the identification of patients at high risk of recurrences of non-fatal VT after healing of acute myocardial infarction (5). The present study was precisely aimed at evaluating clinical information likely to discriminate between patients at low risk and those at high risk of developing recurrences of VT after healing of acute myocardial infarction. By retrospective analysis of VT/VF patients with and without VT recurrences a prognostic index was developed to be used for identifying patients with VT/VF after healing of acute myocardial infarction at high risk of developing VT recurrences in the future. The value of this prognostic index was tested thereafter in a different group of patients with the same clinical problem.

\section{Patients and Methods}

The study group (Maastricht) comprised 206 consecutive patients with a healed myocardial infarction: 154 patients had had electrocardiographically documented sustained monomorphic VT and 52 patients from VF. In all patients the first episode of their arrhythmia occurred $>3$ days after infarction. The mean age was $59 \pm 9(38-79)$ years, 172 were men and 34 women. The test group consisted of 158 consecutive patients, 80 with sustained monomorphic VT and 78 patients with VF. They were admitted to the University Hospital of Heidelberg during the same time period as the Maastricht patients. The mean age in this group was $59 \pm 8$ (27-81 years). 149 were men. Apart from the history and the physical examination data were available on exercise testing, coronary and left ventricular angiography and programmed electrical stimulation. Left ventricular ejection fraction was measured either invasively $(85 \%)$ or non-invasively $(15 \%)$ (echocardiography or nuclear). As previously reported from our institution, there is a good correlation between the echocardiographic, angiographic and nuclear determination of the ejection fraction (6). Left ventricular aneurysm was defined as one or more circumscribed segments of dyskinesia identified either by contrast ventriculography or echocardiography.

All patients received antiarrhythmic drug therapy. No patient was treated with arrhythmia surgery or an implantable defibrillator. In the study group therapy was given while the "Parallel approach" was followed. This approach has been described in detail elsewhere (7). Briefly, patients admitted with an episode of VT or VF were continuously monitored in the coronary care unit. After washout 
Table I. Characteristics of the two groups of patients

\begin{tabular}{llll}
\hline & Study group & Test group & p Value \\
\hline No. Patients & 206 & 158 & \\
Age (mean) & 59 & 59 & NS \\
Male / Female & $172 / 34$ & $149 / 9$ & $<0.003$ \\
Anterior MI & $73(35 \%)$ & $86(54 \%)$ & $<0.001$ \\
Multiple MI & $45(22 \%)$ & $50(31 \%)$ & NS \\
LV Aneurysm & $99(48 \%)$ & $64(40 \%)$ & NS \\
LV ejection fraction (mean) & $35 \pm 11$ & $38 \pm 10$ & $<0.02$ \\
3 vessel disease & $51(24 \%)$ & $39(24 \%)$ & NS \\
VT & $154(74 \%)$ & $81(51 \%)$ & $<0.001$ \\
VF & $52(25 \%)$ & $77(48 \%)$ & $<0.0001$ \\
Sotalol & $15(7 \%)$ & $34(21 \%)$ & $<0.001$ \\
Interval MI-Arrhythmia & & & $<0.04$ \\
$<2$ months & $98(47 \%)$ & $58(37 \%)$ & NS \\
$>2$ months & $108(52 \%)$ & $100(63 \%)$ & NS \\
\hline Exercise related arrhythmia & $17(8 \%)$ & $21(13 \%)$ & \\
\hline
\end{tabular}

Abbreviations: $\mathrm{MI}=$ myocardial infarction, $\mathrm{VF}=$ ventricular fibrillation, $\mathrm{VT}=$ ventricular tachycardia.

of antiarrhythmic drug therapy (if present) patients underwent baseline studies including: exercise testing, echocardiography and programmed electrical stimulation. These tests were repeated after institution of antiarrhythmic drug therapy which was selected empirically. Antiarrhythmic therapy was continued until a spontaneous recurrence of the ventricular arrhythmia was observed. Inducibility of an arrhythmia during programmed electrical stimulation did not influence the antiarrhythmic drug regimen. Only spontaneous recurrences of the VT/VF during the treatment period was reason to change the antiarrhythmic drug regimen. In the test group antiarrhythmic drug selection was based upon serial drug testing (8).

\section{Statistical analysis}

Seven clinical and 4 non-clinical variables were coded. They were: age, history of $>1$ myocardial infarction, NYHA class for angina, anterior location of myocardial infarction, time interval from myocardial infarction to the first spontaneous arrhythmia (sustained VT or VF) coded from 1 to 3 (if the arrhyth- 
mia was present before 2 months $=1,2$ to 6 months $=2$ and after 6 months $=3$ ), type of arrhythmia (VT or VF) (VT=1, VF =2) and antiarrhythmic drug therapy given (amiodarone, propafenone, sotalol, procainamide) (sotalol =1, no sotalol $=2$ ), left ventricular ejection fraction, number of coronary arteries involved, presence or absence of left ventricular aneurysm and finally existence of an exercise related arrhythmia.

The study group (206 patients) was used to select the most discriminating variables and to establish a prognostic index. The performance of this index was validated thereafter on the test group (158 patients). Age and left ventricular ejection fraction were analyzed as continuous variables. Data were first screened by univariate analysis for differences between patients with and without recurrences of VT. Quantitative variables were tested by $t$ test and nominal findings by the chi-square test. To discriminate between patients with and without recurrences of VT on a multivariate level the multiple group logistic discrimination method was applied (9). Variables were selected in a stepwise manner using a likelihood ratio criterion distributed as a chi-square test on 1 degree of freedom. All results were considered to be significant at the $5 \%$ level.

\section{Results}

Of the 206 patients in the study group, 74 patients (36\%) (64 patients and 10 patients from the sustained VT and VF group respectively) had recurrences of VT after a mean follow-up of $3.4 \pm 9$ years. In the test group $27 / 158$ patients (17\%) (22 patients and 5 patients from sustained the VT and VF group respectively) had recurrences of VT after a mean follow-up of $2.4 \pm 2$ years. In the study group 15 of 206 patients (7\%) and in the test group 34 of 158 patients $(21 \%)$ were on oral sotalol $(80-420 \mathrm{mg}$ ). In patients receiving sotalol, recurrences of sustained monomorphic VT were observed in $2 / 15$ patients $(13 \%)$ in the study group and $4 / 34$ patients (12\%) in the test group. A comparison of the clinical and non-clinical variables in the two patient populations is given in Table I.

Prognostic value of the clinical variables: In the study group the stepwise variable selection procedure was applied to the 7 clinical and 4 non-clinical variables. Using this approach 3 clinical variables were retained as the most predictive of recurrences of VT after healing of acute myocardial infarction. The time interval from myocardial infarction to first episode of VT or VF was selected first, having the most powerful prognostic value $(<2$ months $=1,2$ to 6 months $=2,>6$ months $=3),(p<0.001)$. It was followed by sotalol as antiarrhythmic drug used, (sotalol $=1$, no sotalol $=2),(p<0.007)$, and VT as 
the presenting arrhythmia, $(\mathrm{VT}=1, \mathrm{VF}=2), \mathrm{p}<0.002$ ). From these 3 clinical variables a risk index was derived using the following equation: $3.41-(0.56 \mathrm{x}$ time interval myocardial infarction VT/VF $)-(1.94 \mathrm{x}$ sotalol yes or no $)+(0.86$ $x$ VT or VF). Negative values $(<0)$ were associated with a high risk of recurrences of VT whereas positive values $(>0)$ predicted a favorable evolution. For example if a patient has VT as presenting arrhythmia (code $=1) 6$ months after myocardial infarction (code $=3$ ) and receives another antiarrhythmic drug than sotalol (code $=2$ ), the prognostic index for developing VT recurrences is -1.29 (negative value, high risk for VT recurrences). None of the non-clinical variables were related to recurrences of VT.

Validation of the prognostic index: The index obtained in the study group was applied to the test group of 158 patients. Among the 36 patients (23\% of the population) with a negative index (high risk for VT recurrences), 22 patients $(61 \%)$ actually had recurrences of VT. Of the 122 patients $(77 \%)$ with a positive index (low risk for VT) only 5 patients (4\%) developed recurrences of VT. In terms of sensitivity, specificity, positive and negative predictive values, the index had the following results: $81 \%, 89 \%, 62 \%$ and $96 \%$ respectively.

\section{Discussion}

Several studies using invasive parameters have attempted to find predictors for death in patients with sustained ventricular tachyarrhythmias or cardiac arrest (1-4). The objective of our study was: 1) to establish a prognostic index for recurrences of sustained monomorphic ventricular tachycardia in patients with VT or VF after a previous myocardial infarction from clinical and laboratory findings, and 2) to validate this prognostic index in a test group.

In our study 3 clinical variables were selected from stepwise logistic discriminant analysis: 1) Time interval from myocardial infarction to sustained VT or VF, 2) Sotalol as antiarrhythmic drug, and 3) VT as the presenting arrhythmia. These clinical variables were found to be more predictive for recurrences of VT than invasive variables or the occurrence of a ventricular arrhythmia during exercise testing.

A prognostic index based on the variables selected was validated in a test group, allowing us to identify high risk patients with a predictive value of over $60 \%$.

Selection of antiarrhythmic drug treatment was different in the two groups of patients. The "Parallel approach" was used in the study group and serial drug testing in the test group. However irrespective of the approach used, the prognostic index was able to recognize patients at high and low risk for recurrences of sustained monomorphic VT in both the study and test group. 
Importance of the time interval between myocardial in farction and the first episode of arrhythmia. The interval from myocardial infarction to the first episode of a sustained ventricular arrhythmia was the best indicator of recurrence of sustained monomorphic VT. Our group has previously shown that a time interval of $<2$ months between myocardial infarction and the appearance of a sustained ventricular arrhythmia is a good predictor for identifying patients having a high mortality after a myocardial infarction (10). In another study (5) we have indicated that the value of this variable to detect patients at high risk of sudden death after myocardial infarction can be further augmented by adding other clinical variables such as: the occurrence of circulatory arrest during the first episode of sustained spontaneous ventricular arrhythmia, a NYHA functional class III for dyspnea and the presence of $>1$ previous myocardial infarction.

Value of sotalol as antiarrhythmic drug used. Sotalol, a beta blocking agent with class III antiarrhythmic properties, has been shown to be of short-and long term benefit in the management of life-threatening ventricular arrhythmias (11-14). Nadamanee et al (11) have observed that both the prevention of reinduction of VT/VF by intravenous sotalol and suppression of spontaneously occurring arrhythmias by the oral drug were predictive of long term drug efficacy.

Ruder et al (12) have studied 65 patients with symptomatic previously drug refractory sustained VT/VF treated with oral sotalol $(80-420 \mathrm{mg}$ ) and found an arrhythmia free incidence at 6 and 12 months follow-up of $54 \%$ and $47 \%$, respectively.

$V T$ as the presenting arrhythmia. This variable augmented the ability to recognize risk for recurrences of sustained VT. In our population, patients who had VT (154 patients) as the presenting arrhythmia had a higher incidence of recurrences of VT $(41 \%)$ than patients with VF (52 patients) $(19 \%)(\mathrm{p}<0.03)$.

In the VT group 14 patients were on sotalol and only $2 / 14$ patients had VT recurrences. In VF group only 1 patient was on sotalol and this patient did not develop VT recurrences. 


\section{References}

1. Swerdlow CD, Winkle RA, Mason JW. Determinants of survival in patients with ventricular tachyarrhythmias. N Engl J Med 1983; 308: 1436-1442.

2. Skale BT, Miles WM, Heger JJ, Zipes DP, Prystowsky EN. Survivors of cardiac arrest: Prevention of recurrences by drug therapy as predicted by electrophysiologic testing or electrocardiographic monitoring. Am J Cardiol 1986; 57: 113-119

3. Wilber DJ, Garan H, Finkelstein D, Kelly E, Newell J, McGovern B, Ruskin J. Out-ofhospital cardiac arrest. Use of electrophysiologic testing in prediction of longterm outcome. N Engl J Med 1988; 318: 19-24.

4. Morady F, Scheinman MM, Hess DS, Sung RJ, Shen E, Shapiro W. Electrophysiologic testing in the management of survivors of out-of hospital cardiac arrest. Am J Cardiol $1983 ; 51: 85-89$.

5. Brugada P, Talajic M, Smeets J, Mulleneers R, Wellens HJJ. Risk stratification of patients with ventricular tachycardia or ventricular fibrillation after myocardial infarction. The value of the clinical history. Eur Heart J 1989:10;747-752

6. Braat SHJG. Right ventricular infarction. Its detection by electrocardiography and its effect on right ventricular ejection fraction. Maastricht, Netherlans: Leiter Nypels, 1984:15-18

7. Brugada P, Wellens HJJ. Need and design of a prospective study to assess the value of different strategy approaches for management of ventricular tachycardia or fibrillation. Am J Cardiol 1986; 57: 1180-1184

8. Horowitz LN, Josephson ME, Farsshidi A, Spielman SR, Michelson EL, Greenspan AM,. Recurrent sustained ventricular tachycardia 3. Role of the electrophysiologic study in selection of antiarrhythmic regimens. Circulation 1978; 58: 986-997.

9. Albert A, Lesaffre E. Multiple group logistic discrimination. Comput Math Appl 1986; 12A: 209-224

10. Wellens HJJ, Bär FWHM, Vanagt EJDM, Brugada P. Medical treatment of ventricular tachycardia: Considerations in the selection of patients for surgical treatment. Am J Cardiol 1982;49:186-193

11. Nademanee, MD, Feld G, Hendrickson J, Singh PN, Phil D. Electrophysiologic and antiarthythmic effects of sotalol in patients with life-threatening ventricular tachyarrhythmias. Circulation 1985; 72: 555-564.

12. Ruder MA, Ellis T, Lebsack C, Mead RH, Smith N, Winkle RA. Clinical experience with sotalol in patients with drug-refractory ventricular arrhythmias. J Am Coll Cardiol 1989;13:145-152

13. Senges J, Lengfelder W, Jauerning R, Czygan E, Brachmann J, Rizos J, Cobbe S, Kubler W. Electrophysiologic testing in assessment of therapy with sotalol for sustained ventricular tachycardia. Circulation 1984;69:577-584.

14. Steinbeck G, Bach P, Haberl R. Electrophysiologic and antiarrhythmic efficacy of oral sotalol for sustained ventricular tachyarthytmias: Evaluation by programmed stimulation and ambulatory electrocardiogram. J Am Coll Cardiol 1986;8:994-958. 


\section{Chapter 9}

Incidence and timing of recurrences of sudden death and ventricular tachycardia during antiarrhythmic drug treatment in patients with sudden death or ventricular tachycardia after myocardial infarction

Luz-Maria Rodriguez, MD, Joep Smeets, MD, Gilles E. O'Hara, MD, Peter Geelen, MD, Pedro Brugada, MD, Hein J.J.Wellens, MD. 


\title{
Incidence and timing of recurrences of sudden death and ventricular tachycardia during antiarrhythmic drug treatment in patients with sudden death or ventricular tachycardia after myocardial infarction
}

\begin{abstract}
Incidence and timing of recurrences of sustained ventricular tachycardia (VT) or sudden death were studied in 206 patients having survived their first episode of ventricular fibrillation (VF:52 patients) or sustained VT (154 patients) after myocardial infarction. All patients were treated with (empirically selected) antiarrhythmic drugs, with $49 \%$ receiving amiodarone. After a mean follow-up of 36 months, 64 patients in the VT group (41\%) and 10 patients $(19 \%)$ had non-fatal VT recurrences. Sudden death occurred in $22(14 \%)$ and 9 patients $(17 \%)$ in the VT and VF groups respectively.

Incidence of sudden death showed 2 peaks at around 3 and 12 months. Non-fatal VT recurrences were more frequent (most commonly occurring in the first 6 months) in the VT group as compared to the VF group. In only 10\% of patients having survived 1 year, sudden death occurred during the next 3 year. Comparison between patients having a left ventricular ejection fraction $\leq 40 \%$ to $>40 \%$ revealed a much higher incidence of sudden death in patients with left ventricular ejection fraction $\leq 40 \%(28 / 65$ vs $3 / 141 ; p<0.0001)$ but no relation between left ventricular ejection fraction and non-fatal VT recurrences.
\end{abstract}

\section{Introduction}

The long-term treatment of life-threatening ventricular arrhythmias outside the acute phase of myocardial infarction remains a major challenge. Follow-up of these patients reveals that many of them die suddenly or suffer from non-fatal arrhythmia recurrences. This has been well documented for patients with out-of hospital sudden death and patients known with sustained VT (1-7). Less is known about the time course of recurrences of sudden death and sustained VT in those patients. To obtain that information we retrospectively analyzed 206 
patients who had suffered from a well documented episode of sustained VT or ventricular fibrillation (VF) late after a myocardial infarction and who were treated with antiarrhythmic drugs only.

\section{Patients and Methods}

Two hundred and six consecutive patients, who had suffered from a myocardial infarction in the past and either developed a VT (154 patients) or resuscitated from VF (52 patients) were included in this study. The mean age of these patients was $59 \pm 9$ years and $58 \pm 12$ in the VT and VF group respectively. In the VT group 129 patients were men and 25 patients were women. In the VF group 43 patients were men.

Evaluation of these patients during their hospital admission included the clinical history, physical examination, 12-lead electrocardiogram, long-term electrocardiographic monitoring, exercise-testing and programmed electrical stimulation of the heart while off and on antiarrhythmic drug treatment. Left ventricular ejection fraction was obtained using various techniques including nuclear or contrast angiography and 2-dimensional echocardiography. Coronary angiography was either performed at our institution or done in the referring hospital.

Antiarrhythmic drug therapy was not selected by serial drug testing but empirically because patients were included in the "Parallel study". This approach has been described in detail elsewhere (8). Briefly, patients admitted with an episode of VT or VF were continuously monitored in the coronary care unit. After washout of antiarrhythmic drug therapy (if present) patients underwent baseline studies including: exercise testing, echocardiography and programmed electrical stimulation. These tests were repeted after institution of antiarrhythmic drug therapy which was selected empirically. Antiarrhythmic therapy was continued until a spontaneous recurrence of the ventricular arrhythmia was observed. Inducibility of an arrhythmia during programmed electrical stimulation did not influence the antiarrhythmic regimen. Only spontaneous recurrences of the VT/NF during the treatment period was reason to change the antiarrhythmic drug regimen. Patients were followed-up at our out-patient clinic at regular intervals. The mean follow-up was 36 (range 1-108) months.

\section{Definitions}

Sudden death: Sudden unexpected death occurring within 1 hour of onset of symptoms. 
Sudden arrhythmic death: Death caused by a recurrent arrhythmia, even when death occurred more than 1 hour, after the onset of arrhythmia.

Recurrent ventricular tachycardia: A sustained monomorphic ventricular tachycardia occurring spontaneously out-of-hospital during follow-up.

\section{Statistical analysis}

Continuous data are expressed as mean \pm standard deviation. Comparison of the clinical characteristics between subgroups were made by chi-square test using Yates correction when appropriate. Predictive values ( $p$ value) $\leq 0.05$ were considered significant. Kaplan Maier actuarial curves (9) for sudden death and non-fatal VT recurrences were constructed. Actuarial recurrences for sudden death and non-fatal VT recurrences for the VT and VF group were compared between groups using Wilcoxon and Logrank test.

\section{Results}

The clinical and angiographic characteristics of VT and VF patients groups are shown in tables I and II. Sustained VT while off antiarrhythmic drug therapy could be induced in 140/154 (91\%) in the VT group and in 43/52 (83\%) in the VF group.

\section{Antiarrhythmic drug therapy}

One hundred and one patients (49\%) were taking amiodarone (mean dose 260 $\mathrm{mg}$ ) alone or in combination, 15 patients (7\%) received sotalol (range 40 to 420 $\mathrm{mg} /$ day), 33 patients ( $16 \%$ ) propafenone (range 450 to $900 \mathrm{mg} /$ day), 10 patients (5\%) procainamide (range 750 to $3000 \mathrm{mg} /$ day), 1 patient quinidine (range 1200 to $1600 \mathrm{mg} /$ day), 4 patients disopyramide, (range 300 to $600 \mathrm{mg} /$ day), 10 patients (5\%) flecainide (range 100 to $200 \mathrm{mg}$ /day), 3 patients aprindine, (range 50 to $150 \mathrm{mg} /$ day), mexilitine (range 200 to $300 \mathrm{mg}$ ), 4 patients and 5 patients were on bepridil (range 200 to $600 \mathrm{mg}$ ). Nine patients (4\%) had no antiarrhythmic drug therapy and the remaining 11 patients $(5 \%)$ were taking a combination of antiarrhythmic drugs. (Table IIIa).

Non-fatal recurrences occurred in $36 / 101(36 \%)$ in patients treated with amiodarone and $38 / 105(36 \%)$ in patients treated with another antiarrhythmic drug (p NS). (Table IIIb) 
Table I. Clinical characteristics of the patients studied.

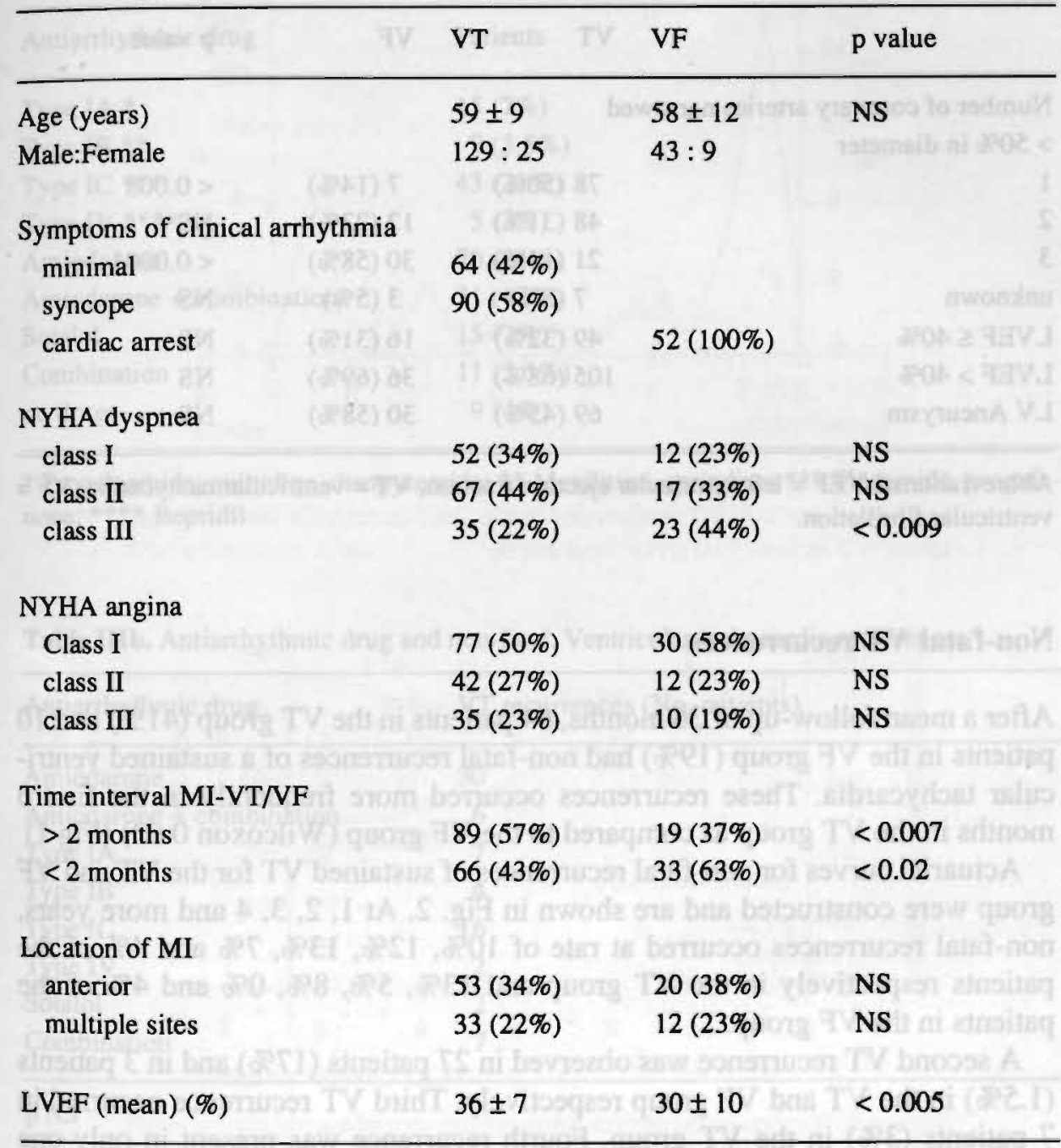

Abbreviations: $\mathbf{F}=$ female, $\mathrm{LVEF}=$ left ventricular ejection fraction, $\mathbf{M}=$ male, $\mathrm{MI}=$ myocardial infarction, VF = ventricular fibrillation, VT = ventricular tachycardia.

Of the 206 patients, 171 underwent programmed electrical stimulation while on antiarrhythmic drugs: $122 / 171(71 \%)$ were inducible and $49 / 171(29 \%)$ were not inducible. Non-fatal VT recurrences occurred in 49/122 (40\%) of inducible patients and $16 / 49(33 \%)$ in non-inducible patients (p NS). Sudden death occurred in 18/122 (17\%) of inducible patients and 8/49 (16\%) of non-inducible patients (p NS). 
Table II. Angiographic data

\begin{tabular}{lccl}
\hline \multicolumn{2}{l}{ VT } & VF & p value \\
\hline $\begin{array}{l}\text { Number of coronary arteries narrowed } \\
>50 \% \text { in diameter }\end{array}$ & & \\
1 & $78(50 \%)$ & $7(14 \%)$ & $<0.008$ \\
2 & $48(31 \%)$ & $12(23 \%)$ & NS \\
3 & $21(14 \%)$ & $30(58 \%)$ & $<0.0001$ \\
unknown & $7(5 \%)$ & $3(5 \%)$ & NS \\
LVEF $\leq 40 \%$ & $49(32 \%)$ & $16(31 \%)$ & NS \\
LVEF $>40 \%$ & $105(68 \%)$ & $36(69 \%)$ & NS \\
LV Aneurysm & $69(45 \%)$ & $30(58 \%)$ & NS \\
\hline
\end{tabular}

Abbreviations:LVEF = left ventricular ejection fraction, VT = ventricular tachycardia, VF = ventricular fibrillation.

\section{Non-fatal VT recurrences}

After a mean follow-up of 36 months, 64 patients in the VT group (41\%) and 10 patients in the VF group (19\%) had non-fatal recurrences of a sustained ventricular tachycardia. These recurrences occurred more frequently in the first 6 months in the VT group as compared to the VF group (Wilcoxon 0.03) (Fig 1)

Actuarial curves for non-fatal recurrences of sustained VT for the VT and VF group were constructed and are shown in Fig. 2. At 1, 2, 3, 4 and more years, non-fatal recurrences occurred at rate of $10 \%, 12 \%, 13 \%, 7 \%$ and $4 \%$ of the patients respectively in the VT group and $13 \%, 5 \%, 8 \%, 0 \%$ and $4 \%$ of the patients in the VF group.

A second VT recurrence was observed in 27 patients $(17 \%)$ and in 3 patients $(1.5 \%)$ in the VT and VF group respectively. Third VT recurrence occurred in 7 patients (3\%) in the VT group. Fourth recurrence was present in only one patient from the VT group. No patient from the VF had no more than 2 recurrences.

In regard to left ventricular ejection fraction, non-fatal VT recurrences were observed in 20 of 65 patients (31\%) with a left ventricular ejection fraction of $\leq 40 \%$ and in 54 of 141 patients (38\%) having a left ventricular ejection fraction $>40 \%$ (p NS). 
Table IIIa. Antiarrhythmic drug treatment

\begin{tabular}{lc}
\hline Antiarrhythmic drug & Patients \\
\hline Type IA * & $15(7 \%)$ \\
Type IB ** & $7(3.5 \%)$ \\
Type IC *** & $43(21 \%)$ \\
Type IV **** & $5(3 \%)$ \\
Amiodarone & $70(34 \%)$ \\
Amiodarone + combination & $31(15 \%)$ \\
Sotalol & $15(7 \%)$ \\
Combination & $11(5.5 \%)$ \\
no drugs & $9(4 \%)$ \\
\hline
\end{tabular}

* Procainamide, quinidine, disopyramide; ** Mexilitine, aprindine; *** Flecainide, propafenone; $* * * *$ Bepridil

Table IIIb. Antiarrhythmic drug and non-fatal. Ventricular tachycardia recurrences

\begin{tabular}{lc}
\hline Antiarrhythmic drug & VT recurrences (No. patients) \\
\hline Amiodarone & 30 \\
Amiodarone + combination & 6 \\
Type IA & 7 \\
Type IB & 4 \\
Type IC & 16 \\
Type IV & 2 \\
Sotalol & 2 \\
Combination & 7 \\
\hline
\end{tabular}

p NS

\section{Sudden death}

Twenty two patients (14\%) in the VT group and 9 patients in the VF group (17\%) (NS) died suddenly. The VT group showed 2 peaks at 3 and 12 months and the VF group at 3 months and around 18 months. In patients having survived 1 year, sudden death occurred in only $10 \%$ during the next 3 years.

Actuarial curves for sudden death in the VT and VF group are shown in figure 4. At $1,2,3,4$, and 5 years sudden death occurred at rates of $10 \%, 6 \%, 2 \%, 2 \%$, $0 \%$ respectively in the VT group. In the VF group these numbers were $12 \%, 6 \%$, 


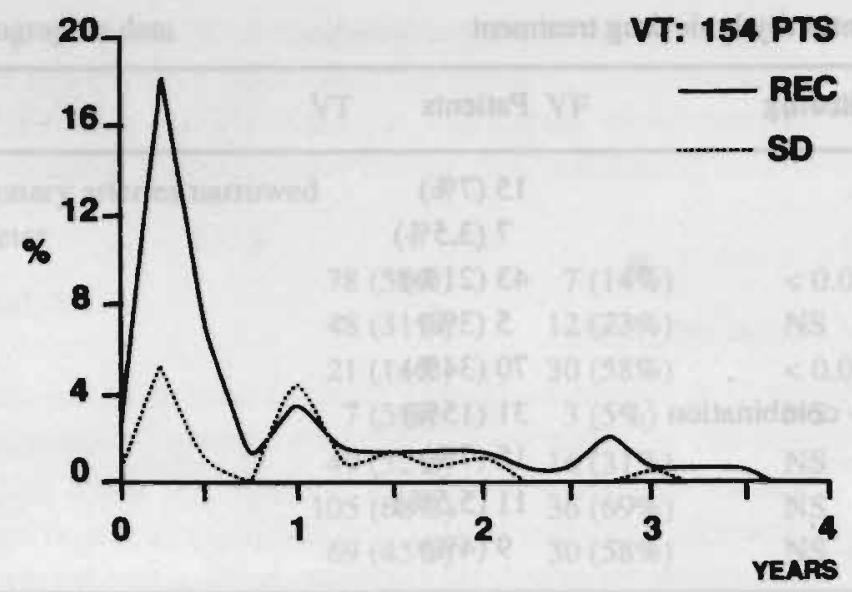

Figure 1: Curves representing the timing of sudden death (interrupted line) and non-fatal VT recurrences (solid line) in patients who had sustained VT as their first arrhythmic event.

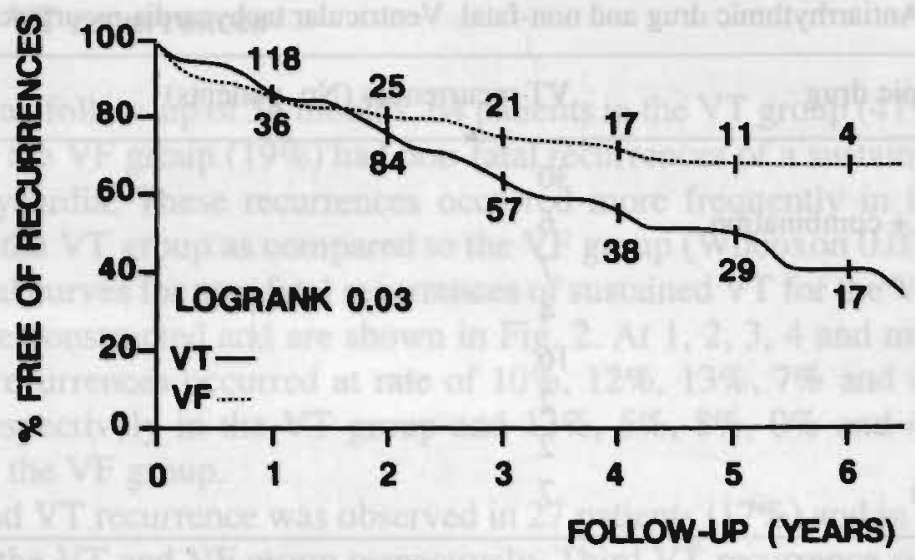

Figure 2: Kaplan-Meier curves for non-fatal recurrences in patients with VF (interrupted line) and VT patients (solid line).

$4 \%, 0 \%, 0 \%$. Although the incidence of sudden death was higher in the VF group there were no statistical significance with the VT group (Wilcoxon 0.10) (Fig 4).

According to the left ventricular ejection fraction, sudden death occurred more often in patients having an ejection fraction of $\leq$ than $40 \%(28 / 65=43 \%)$, than in patients with an ejection fraction $>40 \%(3 / 141=2 \%)(p<0.0001)$. 


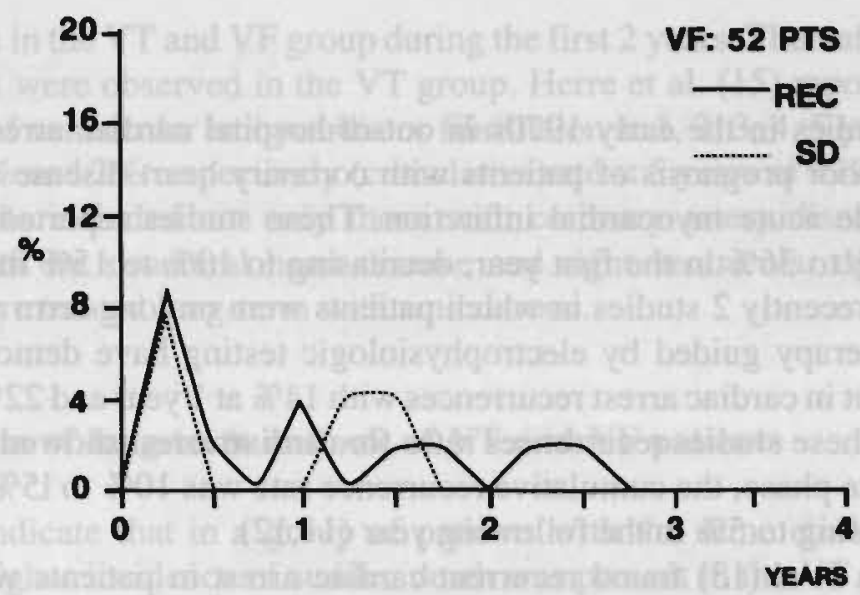

Figure 3: Curves showing the timing of sudden death (interrupted line) and non-fatal VT recurrences (solid line) in patients who had VF as their first arrhythmic event

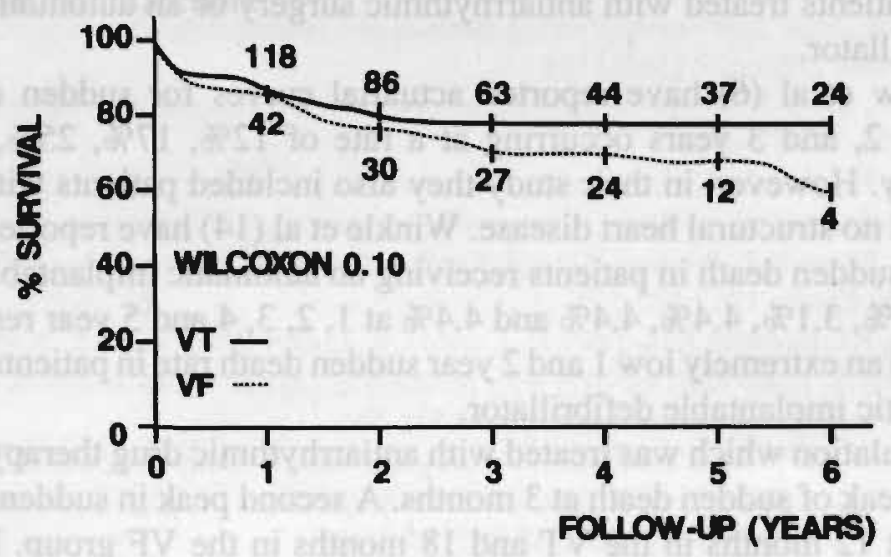

Figure 4: Kaplan-Meier curves for sudden death in patients with sustained VT (solid line) and VF (interrupted line)

Arrhythmic events (non-fatal VT recurrences and sudden death) were present in similar rates in responders (non-inducible or non-sustained VT during programmed electrical stimulation on drugs and no arrhythmic events) $16 / 33$ (48\%) than no responders (inducible and arrhythmic events) 29/54 (53\%) (p NS) treated with amiodarone. 


\section{Discussion}

The first studies in the early 1970s in out-of-hospital cardiac arrest survivors reflect the poor prognosis of patients with coronary heart disease and cardiac arrest outside acute myocardial infarction. These studies reported recurrence rates of $30 \%$ to $36 \%$ in the first year, decreasing to $10 \%$ to $15 \%$ in the second year. More recently 2 studies in which patients were on long-term antiarrhythmic drug therapy guided by electrophysiologic testing have demonstrated an improvement in cardiac arrest recurrences with $14 \%$ at 1 year and $22 \%$ at 3 years (10-12). In these studies recurrences rates for cardiac arrest showed 2 phases: a early and late phase, the cumulative recurrence rate was $10 \%$ to $15 \%$ in the first year, decreasing to $5 \%$ in the following year $(11,12)$.

Furukawa et al.(13) found recurrent cardiac arrest in patients with chronic coronary artery disease who had survived out-of-hospital cardiac arrest in the absence of acute myocardial infarction to have an incidence of $14 \%, 6.5 \%, 1.6 \%$ and $1.8 \%$ at $1,2,3$ and 4 years with an cumulative actuarial rate at 4 years of 24 $\pm 5 \%$. In that study most patients were on antiarrhythmic drugs with only a small group of patients treated with antiarrhythmic surgery or an automatic implantable defibrillator.

Swerdlow et al (6) have reported actuarial curves for sudden death at 6 months, 1, 2, and 3 years occurring at a rate of $12 \%, 17 \%, 25 \%$, and $36 \%$ respectively. However, in their study they also included patients with valvular disease and no structural heart disease. Winkle et al (14) have reported actuarial curves for sudden death in patients receiving an automatic implantable defibrillator of $0.9 \%, 3.1 \%, 4.4 \%, 4.4 \%$ and $4.4 \%$ at $1,2,3,4$ and 5 year respectively. They found an extremely low 1 and 2 year sudden death rate in patients receiving the automatic implantable defibrillator.

Our population which was treated with antiarrhythmic drug therapy only also showed a peak of sudden death at 3 months. A second peak in sudden death was observed at 12 months in the VT and 18 months in the VF group. In patients having survived 1 year sudden death occurred in only $10 \%$ during the next 3 years. Actuarial curves for sudden death showed rates of $10 \%, 6 \%, 2 \%, 0 \%, 0 \%$ in the VT group and $12 \%, 6 \%, 4 \%, 0 \%, 0 \%$ in the VF group at $1,2,3,4$ and 5 years respectively. Sudden death occurred more often in the VF group but the difference was not statistically significant.

Our results are similar to those reported after $1(12 \%$ vs $14 \%)$ and 4 years ( $22 \%$ vs $24 \%$ ) by Furukawa et al. (12).

So far little attention has been given to the time course of non-fatal recurrences of ventricular tachycardia. In our population consisting of coronary artery disease patients only and of whom $49 \%$ were treated with amiodarone, non-fatal VT recurrences were more often seen in the first 6 months (Fig 1 and 2). As shown in Fig 2 the actuarial curves indicate a similar incidence of non-fatal VT 
recurrences in the VT and VF group during the first 2 years. Thereafter more VT recurrences were observed in the VT group. Herre et al. (15) reported a recurrence rate of ventricular tachycardia or fibrillation at $1,2,3,4,5$ years of $19 \%$, $7 \%, 7 \%, 8 \%$ and $2 \%$ respectively (cumulative rate at 5 years of $43 \%$ ). However their patients included not only those with coronary artery disease, but also patients with no structural heart disease and right ventricular dysplasia. All patients were treated long-term with amiodarone.

\section{Comparison of long-term outlook of VT and VF patients}

Our data indicate that in a group of patients with the same etiology of heart disease a higher incidence of sudden death was present in the VF as compared to the VT group. It also shows that if 1 year has subsided after an episode of sustained VT or VF after myocardial infarction risk of dying suddenly is relatively small. That information can be of help in selecting type of antiarrhythmic therapy in patients who have suffered from VT/VF outside the acute phase of a myocardial infarction. 


\section{References}

1. Liberthson RR, Nagel EL, Hirschman JC, Nussenfeld SR. Prehospital ventricular fibrillation. Prognostic and Follow-up course. N Engl J Med 1974;291:317-321

2. Baum RS, Alvarez III H, Cobb LA. Survival after resuscitation from out-of-hospital ventricular fibrillation. Circulation 1974;50:1231-1235

3. Cobb LA, Baum RS, Alvarez III H, Schaffer WA. Resuscitation from out-of-hospital ventricular fibrillation: 4 years follow-up. Circulation 1975;51:223-235

4. Schaffer WA, Cobb LA, Recurrent ventricular fibrillation and modes of death in survivors of out-of-hospital ventricular fibrillation. N Engl J Med 1975;293:259-262

5. Graboys TB, Lown B, Podrid PJ, Desilva R. Long-term survival of patients with malignant ventricular arrhythmia treated with antiarthythmic drugs. Am J Cardiol 1982;50:437-443

6. Swerdlow CD, Winkle RA, Mason JW. Determinants of survival in patients with ventricular tachyarrhytmias. N Engl J Med 1983;308:1436-1442

7. Willems AR, Tijssen JGP, Van Capelle FJL, Kingma JH, Hauer RNW, Vermeulen FEE, Brugada P, Van Hoogenhuyze DCA, Janse MJ. Determinants of prognosis in symptomatic ventricular tachycardia or ventricular fibrillation late after myocardial infarction. J Am Coll Cardiol 1990;16:521-530

8. Brugada P, Wellens HJJ, Need and design of a prospective study to asses the value of different strategic approaches for management of ventricular tachycardia or fibrillation. Am J Cardiol 1986;- 57:1180-1184

9. Kaplan EL, Meier P. Nonparametric estimation from incomplete observations. J Am Stat Assoc 1958;53:457-481.

10. Myerburg RJ, Kessler KM, Zaman L, Trohman RG, Fernandez P, Castellanos A. Factors leading to decreasing mortality among patients resuscitated from out-of-hospital cardiac arrest. In: Brugada P, Wellens HJJ eds. Cardiac Arrhythmias. Where to Go From Here?. New York: Futura, 1987:505-525.

11. Myerburg RJ, Kesseler KM, Estes D, Conde CA, Luceri RM, Zaman L, Koslovskis PL, Castellanos A, Long-term survival after prehospital cardiac arrest. Analysis of out come during 8 years study. Circulation 1984;70:538-546

12. Wilbert DJ, Garan H, Finkelstein D, Kelly E, Newell J, McGoveren B, Ruskin JN. Out-of-hospital cardiac arrest: Use of electrophysiologic testing in the prediction of long-term outcome. N Engl J Med 1988;318:19-24

13. Furukawa T, Rozanski JJ, Nogami A, Moroe K, Gosselin AJ, Lister JW. Time-dependent risk of and predictors for cardiac arrest recurrences in survivors of out-of-hospital cardiac arrest with chronic coronary artery disease. Circulation 1989;80:599-608

14. Winkle RA, Mead RH, Ruder MA, Gaudiani VA, Smith NA, Buch Ws, Schmidt P, Shipman T. Long-term outcome with automatic implantable cardioverter-defibrillator. J Am Coll Cardiol 1989;13:1353-1361.

15. Herre JM, Sauve MJ, Malone P, Griffin JC, Helmy I, Langberg JJ, Goldberg H, Scheinman MM. Long-term results of amiodarone therapy in patients with recurrent sustained ventricular tachycardia or ventricular fibrillation. J Am Coll Cardiol $1989 ; 13: 442-449$ 


\section{Chapter 10}

\section{Induction of ventricular fibrillation, but not of sustained monomorphic ventricular tachycardia predicts sudden death in patients on amiodarone treatment because of ventricular tachyarrhythmias after myocardial infarction}

Luz-Maria Rodriguez, MD, Eduardo B. Sternick, MD, Joep LRM Smeets, MD, Carl Timmermans, MD, Karel den Dulk, MD, Giuseppe Oreto MD, Hein JJ Wellens, MD, 


\section{Induction of ventricular fibrillation, but not of sustained monomorphic ventricular tachycardia predicts sudden death in patients on amiodarone treatment because of ventricular tachyarrhythmias after myocardial infarction}

\section{Abstract}

Background: Previous studies suggest that programmed electrical stimulation does not accurately predict recurrences of sustained ventricular tachycardia or ventricular fibrillation during amiodarone therapy.

Patients and Methods: One hundred and six patients with clinically documented sustained monomorphic ventricular tachycardia (77 patients) or ventricular fibrillation (29 patients) were studied. All patients had been on amiodarone for at least 1 month. The endpoints of stimulation (using 3 basic pacing rates, and a maximum of 3 extrastimuli) were: induction of sustained monomorphic ventricular tachycardia, ventricular fibrillation or completion of the protocol.

Results: Eighty out of the 106 patients had either ventricular fibrillation (15 patients) or sustained monomorphic ventricular tachycardia (65 patients) induced. After a mean follow-up of $50 \pm 40$ months (1-144), 13 patients either died suddenly (11 patients) or used their defibrillator (2 patients). By multivariate analysis two predictors for sudden death were found: 1) inducibility of ventricular fibrillation under amiodarone treatment $(p<0.0001)$ and 2$)$ a left ventricular ejection fraction $<40 \%(p<0.05)$. Actuarial curves for sudden death were constructed for induced ventricular fibrillation, sustained monomorphic ventricular tachycardia and absence of induced sustained arrhythmias. The survival rate at $1,2,3$ and 5 years was; $70 \%, 62 \%, 62 \%$ and $40 \%$ respectively for patients in whom ventricular fibrillation was induced and $98 \%, 96 \%, 94 \%$, 94\% for patients with induced sustained monomorphic ventricular tachycardia. In the no sustained arrhythmia group five year survival was $100 \%$.

Conclusion: In patients receiving amiodarone because of life-threatening ventricular arrhythmias after myocardial infarction inducibility of ventricular fibrillation, but not of sustained monomorphic ventricular tachycardia indicates high risk for dying suddenly 


\section{Introduction}

Studies in the early eighties suggested that programmed electrical stimulation can not accurately predict recurrences of ventricular tachycardia/ventricular fibrillation during amiodarone therapy $\left({ }^{1-4}\right)$. That resulted in the suggestion to treat high risk patients with amiodarone empirically without the aid of invasive testing $\left(^{4}\right)$.

More recently, the prognostic value of programmed electrical stimulation in the evaluation of amiodarone treatment for ventricular tachyarrhytmias has again been analyzed $\left({ }^{5-12}\right)$.

Parameters helpful to predict ventricular tachycardia recurrence and sudden death in those studies included: persistent ability to induce the clinical arrhythmia, a change in the mode of induction, and modifications of the index arrhythmia as changes in rate and hemodynamic tolerance while the patient was on amiodarone.

The purpose of our study was to reexamine the value of programmed electrical stimulation of the heart in predicting sudden death in patients receiving amiodarone because of ventricular tachyarrhythmias after myocardial infarction.

\section{Patients and Methods}

\section{Patients}

The study population consisted 106 consecutive patients, 92 males and 14 females with myocardial infarction and ventricular tachyarrhythmias treated with amiodarone in whom a programmed electrical stimulation study was performed while on amiodarone. The mean age was $60 \pm 9(38-84)$ years. Seventy seven patients had documented sustained monomorphic ventricular tachycardia and 29 patients were resuscitated from ventricular fibrillation. Of the 77 patients with ventricular tachycardia six had to be resuscitated from cardiac arrest.

Evaluation of these patients on admission included clinical history, physical examination, 12-lead electrocardiogram, long term-electrocardiographic monitoring, exercise testing and programmed electrical stimulation while off antiarrhythmic drugs (fourteen patients) and on amiodarone in one hundred and six patients. Left ventricular ejection fraction was obtained using various techniques including nuclear or contrast angiography and 2-dimensional echocardiography. Previously given antiarrhythmic drugs had been empirically selected (not by serial drug testing). 
Information on symptoms during the arrhythmia number of previous antiarrhythmic drugs, infarct location, number of involved coronary arteries disease left ventricular ejection fraction and presence of left ventricular aneurysm is given in Table 1.

\section{Amiodarone Therapy}

Amiodarone was given after prior antiarrhythmic drug therapy had failed in all but 14 patients. In 86 patients failure was due to recurrent spontaneous ventricular arrhythmias and in 6 because of side effects of the antiarrhythmic agent. Before amiodarone treatment, 39 patients received a single antiarrhythmic drug, 45 patients 2 antiarrhythmic drugs, 7 patients 3 antiarrhythmic drugs and the remaining patient 4 antiarrhythmic drugs. In 14 patients amiodarone was given as first choice because of the concomitant presence of atrial fibrillation.

Oral amiodarone loading dose consisted of $1 \mathrm{gr} /$ day during 1 week. Thereafter a maintenance dose of $200 \mathrm{mgr}$ per day was given. All patients had a baseline chest X-ray and kidney, liver and thyroid function tests. These tests were repeated every six months.

\section{Electrophysiologic examination}

At the time of electrophysiologic study, all patients had been on oral amiodarone for at least 1 month ( 1 to 48 , mean $8.21 \pm 12.5$ months).

The end points of programmed ventricular stimulation were: induction of sustained monomorphic ventricular tachycardia, ventricular fibrillation or completion of the protocol.

The ventricular pacing protocol used for ventricular tachycardia induction has been described in detail elsewhere $\left({ }^{13}\right)$. Briefly, single and double premature ventricular stimuli were introduced at the right ventricular apex during sinus rhythm and at ventricular pacing cycle lengths of $600,500,430 \mathrm{msec}$, scanning the diastole to ventricular refractoriness. If sustained monomorphic ventricular tachycardia or ventricular fibrillation was not induced a third extrastimulus was introduced during sinus rhythm and repeated at all three different paced cycle lengths.

\section{Follow-up}

The patients were followed-up at our out-patient clinic at regular intervals. The end points of the follow-up were: recurrence of symptomatic sustained ventricular tachycardia, or death either sudden or due to other causes. 
Table 1.Clinical data from the 106 patients studied.

\section{Clinical data}

Age (yr)

Sex (male/female)

Type of arrhythmia:

Sustained monomorphic VT

Ventricular fibrillation

Symptoms during arrhythmia:

\section{Dizziness}

Syncope

Cardiac arrest

Number of previous antiarrhythmic drugs

$$
1
$$

2

\section{$>3$}

Myocardial infarction location:

Anterior

Inferior

Multiple

Number of involved coronary arteries

$>50 \%$ in diameter:

$$
1
$$

2

3

$<50 \%$ in diameter

Left ventricular ejection fraction (mean \%)

Left ventricular ejection fraction (\%)

$<40 \%$

$\geq 40 \%$

Left ventricular aneurysm

\section{$60 \pm 9$ (38-84) \\ $92 / 14$}

77

29

43

28

35

39

45

8

54

34

18

34

35

34

3

$33 \pm 10(15-61)$

79

27

55

Abbreviations: $\mathrm{VT}=$ ventricular tachycardia. 


\section{Definitions}

Recurrent ventricular tachycardia: was defined as a sustained monomorphic ventricular tachycardia occurring spontaneously out-of hospital.

Sustained ventricular tachycardia: was defined as a ventricular tachycardia lasting at least 30 seconds or requiring cardioversion because of hemodynamic intolerance.

Sudden death: sudden unexpected death occurring within 1 hour of onset of symptoms.

Ventricular fibrillation: was defined as a rapid ventricular rhythm without identifiable beginning or end of the QRS complex and the T wave and leading to hemodynamic collapse.

\section{Statistical Analysis}

Statistical analysis was performed using the SAS statistical software package $\left({ }^{14}\right)$. Clinical, hemodynamic and electrophysiologic variables considered relevant to the long-term outcome (as described in table 1) were studied by univariate and multivariate analysis using the Cox hazard model $\left({ }^{15}\right)$. Age was analyzed as a continuous variable. To compare outcome based on the findings at electrophysiologic study, life tables were constructed for sudden death and non-sudden cardiac death and compared between groups using the Wilcoxon and log-rank statistic. Quantitative variables were tested by $t$ test and nominal findings by the chi-square test. Continuous variables are expressed as the mean \pm standard deviation. $P$ values of $\leq 0.05$ were considered as significant.

\section{Results}

\section{Electrophysiologic study on amiodarone}

Sustained ventricular arrhythmias were induced in 80 out of 106 patients (75\%). Sustained monomorphic ventricular tachycardia was induced in 65 patients and ventricular fibrillation in 15 patients. The remaining 26 patients had no sustained ventricular arrhythmia induced.

Type of arrhythmia: The clinical ventricular arrhythmia (ventricular tachycardia or ventricular fibrillation) was reproduced during the electrophysiologic study in 41 patients. A single type of a not clinically documented sustained monomorphic ventricular tachycardia was induced in 19 patients. More than one type of clinically not documented sustained monomorphic ventricular tachycardia was induced in the remaining 20 patients. 
Table 2. Relation between the clinical presentation during the index arrhythmia and outcome.

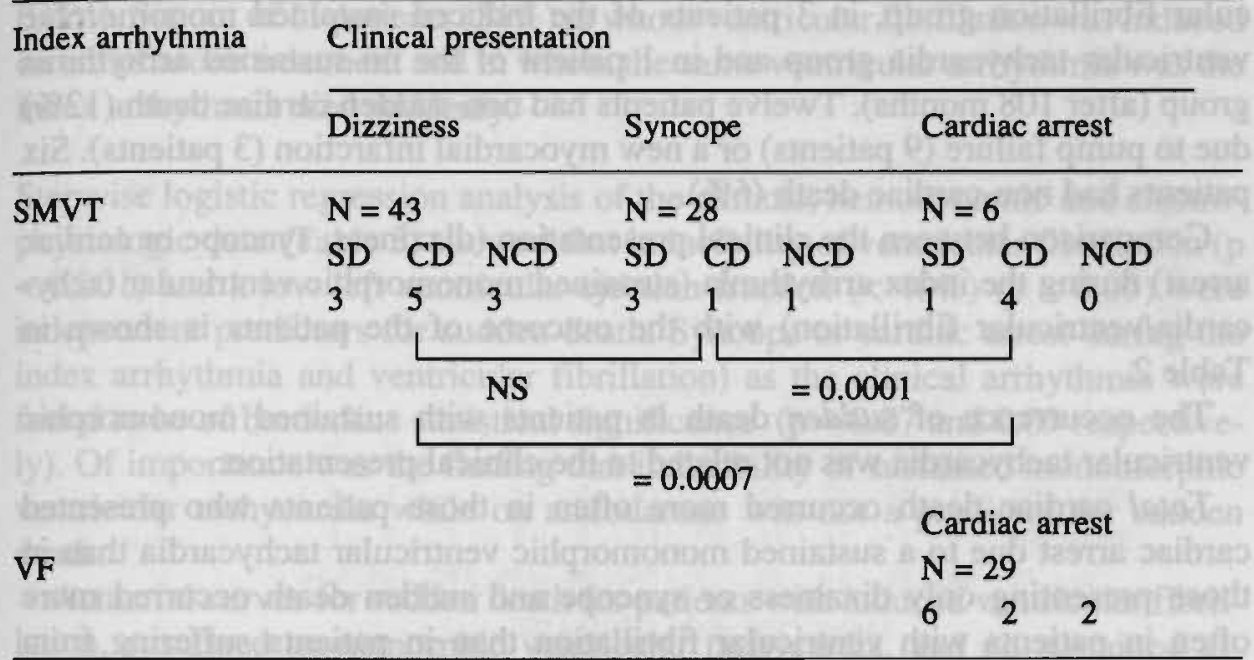

No statistic significance for sudden death between groups.

Abbreviations: $\mathrm{CD}=$ cardiac death, $\mathrm{NCD}=$ non-cardiac death, $\mathrm{N}=$ number, $\mathrm{SD}=$ sudden death, SMVT = sustained monomorphic ventricular tachycardia, VF = ventricular fibrillation.

Mode of induction: Sustained monomorphic ventricular tachycardia and ventricular fibrillation was induced by one ventricular premature beat in 9 and 2 patients respectively. Forty eight patients had monomorphic ventricular tachycardia and 8 patients ventricular fibrillation induced by 2 ventricular premature beats. Eight patients with sustained monomorphic ventricular tachycardia and 5 patients with ventricular fibrillation required 3 ventricular premature beats for initiation of the arrhythmia.

\section{Follow-up}

\section{Arrhythmic events}

During a mean follow-up of $50 \pm 40$ (range 1-144) months, 29 patients died $(27 \%)$. The minimal follow-up period for the living patients was 1 month. Eleven of the deaths were sudden (10\%). Two patients in whom a defibrillator was implanted and who received appropriate shocks for hemodynamically badly tolerated ventricular arrhythmias as documented by ventricular interval measurements (ventricular rates of 200 to $230 / \mathrm{min}$ ) were added to the sudden death group. Therefore, the total group of sudden death patients was considered to 
consist of 13 patients (11 patients with sudden death +2 patients needing a defibrillator shock). Sudden death occurred in 9 patients of the induced ventricular fibrillation group, in 3 patients of the induced sustained monomorphic ventricular tachycardia group and in 1 patient of the no sustained arrhythmia group (after 108 months). Twelve patients had non-sudden cardiac death (12\%) due to pump failure ( 9 patients) or a new myocardial infarction ( 3 patients). Six patients had non-cardiac death (6\%).

Comparison between the clinical presentation (dizziness, syncope or cardiac arrest) during the index arrhythmia (sustained monomorphic ventricular tachycardia/ventricular fibrillation) with the outcome of the patients is shown in Table 2.

The occurrence of sudden death in patients with sustained monomorphic ventricular tachycardia was not related to the clinical presentation.

Total cardiac death occurred more often in those patients who presented cardiac arrest due to a sustained monomorphic ventricular tachycardia than in those presenting only dizziness or syncope and sudden death occurred more often in patients with ventricular fibrillation than in patients suffering from sustained monomorphic ventricular tachycardia ( $20 \%$ vs $9 \%$ )

The parameters shown in Table 3 were first screened by univariate analysis for differences between patients with and without sudden death. Thereafter, the same variables were studied in a multivariate model. Inducibility of ventricular fibrillation while on amiodarone treatment for at least one month was the only parameter in the univariate model with statistical significance. Patients with

Table 3. Results of univariate and multivariate analysis: Correlation with sudden death.

\begin{tabular}{lll}
\hline & Univariate & Multivariate \\
\hline Age & 0.70 & 0.75 \\
Index arrhythmia SMVT/VF & 0.20 & 0.09 \\
Time interval myocardial infarction- first & & \\
arrhythmic event $\leq 2$ months & 0.77 & 0.33 \\
Cardiac arrest during the index arrhythmia & 0.44 & 0.07 \\
Myocardial infarction location (anterior vs inferior) & 0.76 & 0.70 \\
Multiple myocardial infarctions & 0.80 & 0.75 \\
Left ventricular ejection fraction < 40\% & 0.21 & 0.05 \\
Left ventricular aneurysm & 0.48 & 0.80 \\
Inducibility of VF versus SMVT on amiodarone & & \\
treatment & $<0.001$ & $<0.0001$ \\
\hline
\end{tabular}

Abbreviations: See Table 2 
sustained monomorphic ventricular tachycardia as presenting arrhythmia had less ventricular fibrillation induced and a lower incidence of sudden death $(p<$ 0.001 ). Six out of 11 patients (54\%) in whom ventricular fibrillation was induced on amiodarone treatment and in whom the same ventricular arrhythmia was the index arrhythmia died suddenly.

Stepwise logistic regression analysis of the clinical, hemodynamic and electrophysiologic data (Table 3 ) showed that inducibility of ventricular fibrillation ( $p$ $<0.001)$ and a low left ventricular ejection fraction $(<40 \%)(p<0.05)$ were independent predictors for sudden death. Syncope or cardiac arrest during the index arrhythmia and ventricular fibrillation) as the clinical arrhythmia were found to be of borderline statistical significance $(p=0.07$ and 0.09 respectively). Of importance was the finding that inducibility of sustained monomorphic ventricular tachycardia while on amiodarone was not a predictor for sudden death.

Actuarial curves for sudden death for patients with induced ventricular fibrillation, sustained monomorphic ventricular tachycardia, and no sustained arrhythmias were constructed. The survival rate at $1,2,3$ and 5 years was: $70 \%$, $62 \%, 62 \%$ and $40 \%$ in the induced ventricular fibrillation patients group; $98 \%$, $96 \%, 94 \%, 94 \%$ in the induced sustained monomorphic ventricular tachycardia patients groups respectively. Five year survival was $100 \%$ in the no sustained arrhythmia group (Wilcoxon $<0.0001$, Log-rank $<0.0001$ ). (Fig 1)

The positive predictive value, specificity and sensitivity for inducibility of ventricular fibrillation on amiodarone treatment for at least one month was $60 \%$, $94 \%, 69 \%$ respectively.

Interestingly, both ventricular fibrillation as index arrhythmia and the left ventricular ejection fraction $<40 \%$ had a low positive predictive value ( 6 out of $29[21 \%]$ and 12 out of $79[15 \%]$ respectively).

When non-sudden cardiac death was used as end point, no significant differences were found between the three groups (induced ventricular fibrillation [ 3 out of 15 patients, induced sustained monomorphic ventricular tachycardia [ 7 out of 65 patients] and no sustained ventricular arrhythmias [2 out of 26 patients]). The survival rate from non-sudden cardiac death at 1,3 and 5 years was: $85 \%, 71 \%, 71 \%$ in the induced ventricular fibrillation group, $95 \%, 93 \%$, $83 \%$ in the sustained monomorphic ventricular tachycardia group and $96 \%$, $96 \%, 96 \%$ in the no sustained ventricular arrhythmias group respectively. (Fig 2)

Non-fatal recurrent ventricular tachycardia was observed in 49 patients (46\%). Forty two patients had sustained monomorphic ventricular tachycardia and 7 ventricular fibrillation as their index arrhythmia. 


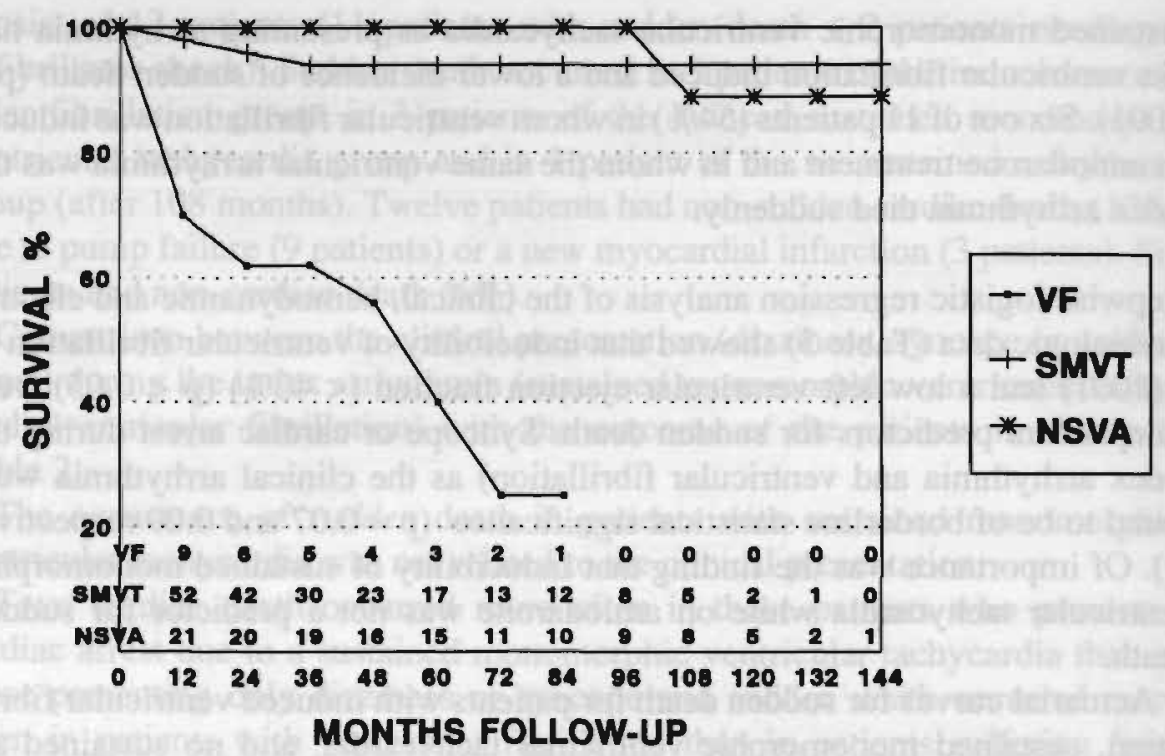

Figure 1: Survival curves showing the percent of patients free from sudden death in relation to the arrhythmia induced during amiodarone treatment. NSVA = no sustained ventricular arrhythmias, SMVT = sustained monomorphic ventricular tachycardia, VF = ventricular fibrillation. The numbers at the bottom of the graph indicate the number of patients who remained available for analysis at each year follow-up period.

\section{Surgery}

During follow-up, 18 patients underwent coronary artery bypass surgery because of new ischemia. Twelve patients had arrhythmia surgery because of ventricular tachycardia recurrences. Three underwent aneurysmectomy alone ( 1 patient died during surgery), 5 patients had endocardial resection and aneurysmectomy, 4 patients underwent cryoablation and aneurysmectomy ( 2 patients died, 1 from chronic lung disease and the other one from pump failure after surgery). One patient who underwent arrhythmia surgery is still on amiodarone.

\section{Side effects}

Side effects were observed in 7 out of 106 patients (7\%). Severe peripheral neuropathy requiring drug discontinuation occurred in 1 patient. Moderate toxicity was observed in 6 patients and included visual disturbances in 1 patient and hypothyroidism in 1 patient. Both patients were continued on amiodarone on a dose of $100 \mathrm{mg}$ daily. Symptomatic AV block either in the AV node (2 patients) or distal to the AV node (2 patients) necessitated permanent cardiac pacing in 4 patients. 


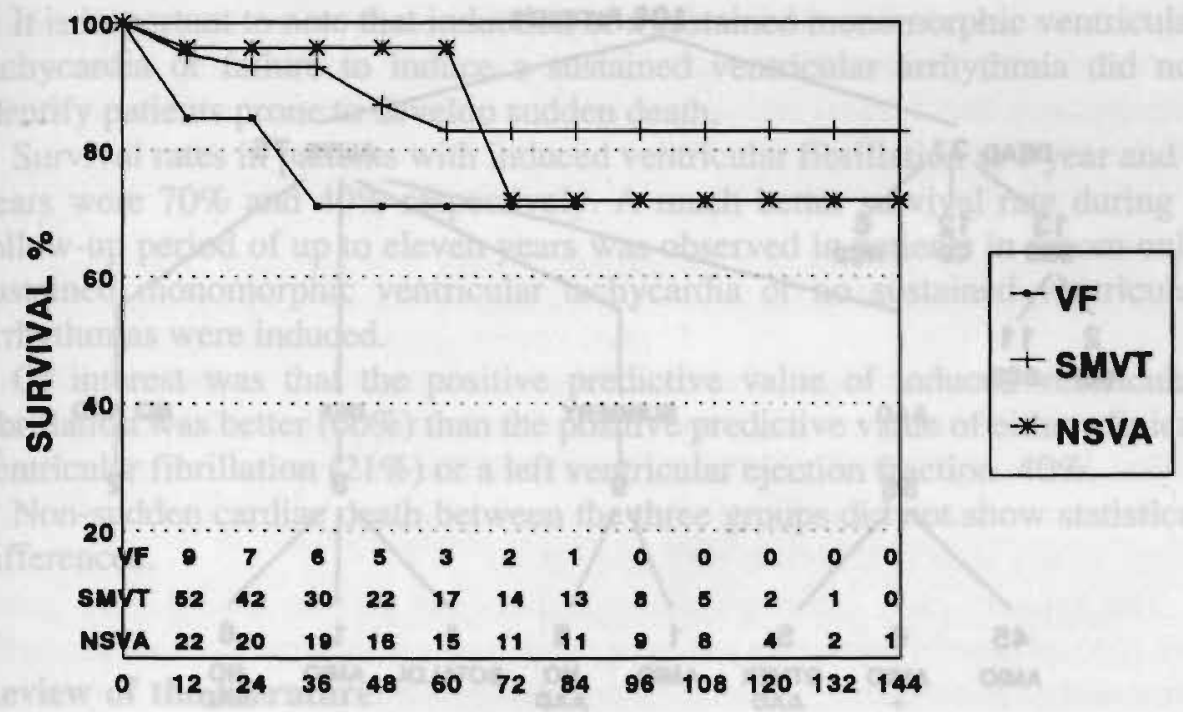

MONTHS FOLLOW-UP

Figure 2: Survival curves showing the percent of patients free from non-sudden cardiac death in relation to the arrhythmia induced during amiodarone treatment. NSVA $=$ no sustained ventricular arrhythmias, SMVT = sustained monomorphic ventricular tachycardia, VF = ventricular fibrillation. The numbers at the bottom of the graph indicate the number of patients who remained available for analysis at each year follow-up period.

\section{Current treatment (Fig 3)}

Fifty six out of the 75 patients who are still alive are receiving antiarrhythmic drugs. Forty five patients are on amiodarone alone. Six patients are taking amiodarone in combination with another antiarrhythmic drug (amiodarone and flecainide: 1 patient, amiodarone and propafenone: 4 patients, amiodarone and mexitil: 1 patient). Antiarrhythmic drugs other than amiodarone are used by 5 patients such as d-sotalol ( 1 patient), sotalol ( 1 patient), beta blockers ( 3 patients). Two patients are without antiarrhythmic drug treatment.

A programmable cardioverter defibrillator was implanted in 9 patients because of spontaneously occurring hemodynamically badly tolerated ventricular tachyarrhythmias in spite of amiodarone treatment. One of these patients died postoperatively from sepsis. Two patients have used their defibrillator because of ventricular fibrillation in one and fast hemodynamically badly tolerated ventricular tachycardia in the other one. One patient had documentation of slow ventricular tachycardias not requiring device therapy. In the remaining 5 patients no spontaneous ventricular tachyarrhythmias necessitating electrical therapy have occurred. Two of these patients are receiving antiarrhythmic drugs, 1 is on amiodarone and the other on D-sotalol. 


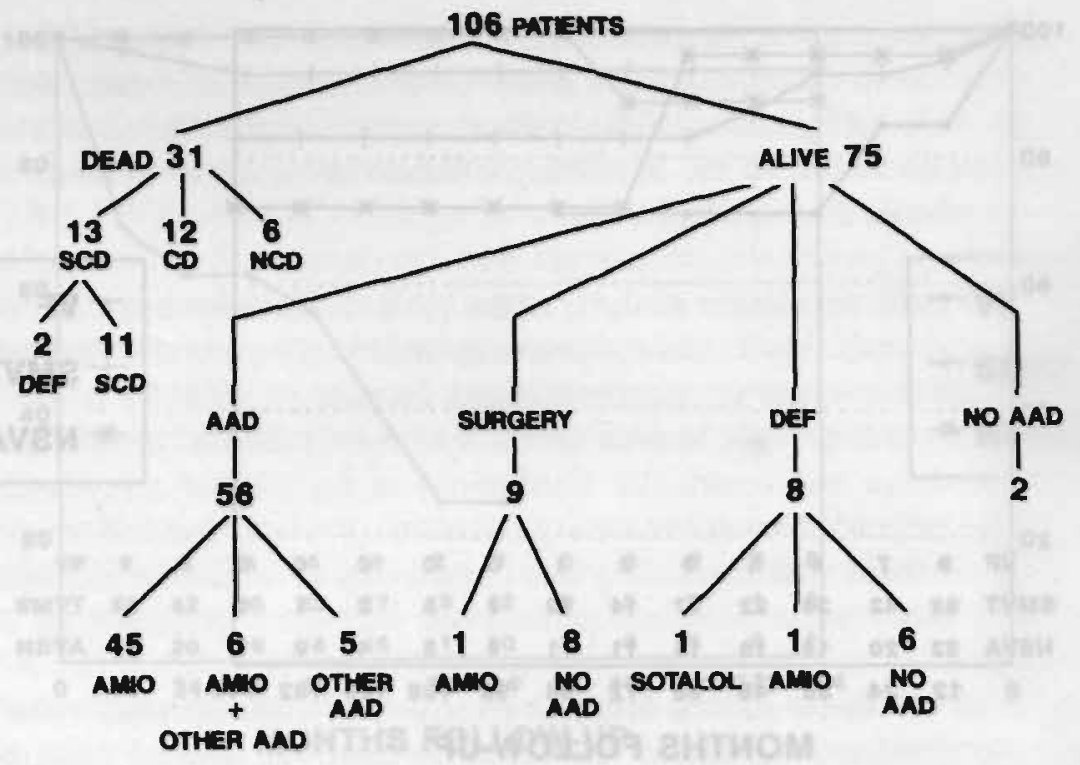

Figure 3: Flow chart showing the follow-up of the patients and their current treatment. AAD = antiarrhythmic drug, Amio = amiodarone, $\mathrm{CD}=$ non-sudden cardiac death, $\mathrm{DEF}=$ defibrillator, $\mathrm{NCD}=$ non-cardiac death, $\mathrm{SCD}=$ sudden cardiac death.

\section{Discussion}

Our study suggests that programmed electrical stimulation of the heart in patients treated with amiodarone because of sustained monomorphic ventricular tachycardia or ventricular fibrillation after a myocardial infarction allows identification of those patients at high risk for dying suddenly.

Inducibility of ventricular fibrillation under amiodarone treatment for at least one month was the strongest predictor for sudden death by uni and multivariate analysis. A low left ventricular ejection fraction $(<40 \%)$ was also an independent predictor for sudden death. Syncope or cardiac arrest during the index arrhythmia and the index arrhythmia (sustained monomorphic ventricular tachycardia/ventricular fibrillation) showed a trend in the multivariate analysis.

Sudden death occurred in $60 \%$ of patients in whom ventricular fibrillation was induced on amiodarone treatment and in $21 \%$ of patients in whom ventricular fibrillation was the index arrhythmia.

Of interest was that patients having sustained monomorphic ventricular tachycardia as their index arrhythmia had less frequently ventricular fibrillation induced $(5 \%)$ and a lower incidence of sudden death (9\%). 
It is important to note that induction of a sustained monomorphic ventricular tachycardia or failure to induce a sustained ventricular arrhythmia did not identify patients prone to develop sudden death.

Survival rates in patients with induced ventricular fibrillation at 1 year and 5 years were $70 \%$ and $40 \%$ respectively. A much better survival rate during a follow-up period of up to eleven years was observed in patients in whom only sustained monomorphic ventricular tachycardia or no sustained ventricular arrhythmias were induced.

Of interest was that the positive predictive value of induced ventricular fibrillation was better $(60 \%)$ than the positive predictive value of either clinical ventricular fibrillation ( $21 \%$ ) or a left ventricular ejection fraction $40 \%$.

Non-sudden cardiac death between the three groups did not show statistical differences.

\section{Review of the literature}

The value of programmed electrical stimulation in assessing efficacy of amiodarone therapy in patients with life-threatening arrhythmias is still controversial.

Some investigators $\left({ }^{1-4}\right)$ have reported a poor predictive value of programmed electrical stimulation in patients taking amiodarone, whereas others $\left({ }^{5-7}\right)$ have indicated that programmed electrical stimulation can be predictive.

Different findings during the stimulation study have been proposed for stratification of risk for recurrent ventricular tachycardia such as persistent inducibility, changes in the mode of induction, or changes in rate and hemodynamic tolerance and other modifications of the index arrhythmia $\left({ }^{9-12}\right)$.

McGovern et al $\left({ }^{6}\right)$ found two significant independent predictors for recurrent arrhythmias: persistence of inducibility of ventricular tachycardia during electrophysiologic testing and a lowered left ventricular ejection fraction. In their study the type of induced ventricular tachycardia (non-sustained or sustained) was not mentioned. Also, in the same study fatal (sudden death) and non-fatal events (recurrent ventricular tachycardia) were analyzed together.

Klein et al $\left({ }^{8}\right)$ found that easier induction of ventricular tachycardia during amiodarone therapy versus control was highly predictive of arrhythmia recurrence. Also, in their article sudden death and recurrent ventricular tachycardia were not differentiated.

Kadish et al $\left({ }^{9}\right)$ looked for predictors for recurrent ventricular tachycardia and sudden death. No predictor for recurrent ventricular tachycardia was found. They did find predictors however for cardiac arrest or sudden death. These included hemodynamic instability of the arrhythmia induced on electrophysiologic testing during amiodarone therapy, younger age, low left ventricular ejection fraction, presence of left ventricular aneurysm and a poorly tolerated 
rhythm at clinical presentation. Survival in their study of patients with poorly tolerated arrhythmias induced at electrophysiologic study during amiodarone therapy, at 1 and 3 years are similar to our results ( $75 \%$ versus $70 \%$ and $70 \%$ versus $62 \%$ respectively).

\section{Limitations of our study}

The optimal time to assess the role of the electrophysiologic study in patients treated with amiodarone because of life-threatening arrhythmias in coronary artery disease patients is still controversial. The pharmacokinetic profile of amiodarone is unusual and not fully understood, making it difficult to determine when steady state is achieved with this agent $\left({ }^{16,17}\right)$.

The value of early electrophysiologic studies in patients taking amiodarone for 10 to 14 days in predicting outcome in patients with ventricular tachyarrhythmias with coronary artery disease have been reported by Manolis et al $\left({ }^{11}\right)$.

Since clinical practice suggests that it may take several weeks of amiodarone loading before full clinical efficacy can be established $\left({ }^{16,17}\right)$, we selected a period of 1 month of amiodarone treatment to evaluate the role of the electrophysiologic study for predicting outcome.

Our study is a retrospective one, from a tertiary referral center with a limited number of patients. To be admitted to the study the patient had to be on amiodarone for at least 1 month, thereby excluding patients dying early after the onset of their arrhythmia. This may explain why we did not find in contrast to previous studies $\left({ }^{18,19}\right)$ that clinical parameters like 1) a time interval of $<2$ months between myocardial infarction and first episode of sustained ventricular arrhythmia, 2) syncope during the presenting arrhythmia, 3) presence of multiple myocardial infarctions and 4) location of myocardial infarction (anterior vs inferior) were of value in predicting risk of sudden death during follow-up.

Another limitation of our study was that only 14 patients underwent baseline electrophysiologic examination. This feature is explained by the fact that the majority of our patients were referred to our hospital already on amiodarone treatment.

Conclusion: Our retrospective study suggests that in patients receiving amiodarone because of life-threatening ventricular arrhythmias after myocardial infarction, inducibility of ventricular fibrillation, but not of a sustained monomorphic ventricular tachycardia indicates a high risk for dying suddenly. We believe that this finding should be evaluated prospectively. It might be of help in selecting patients in whom, because of a high incidence of sudden death non pharmacological treatment should be considered. 


\section{References}

1. Heger JJ, Prystowsky EN, Jackman WM, Nacarelli GV, Warfel KA,Rinkenberger RL, Zipes DP. Amiodarone: Clinical efficacy and electrophysiology during long-term therapy for recurrent ventricular tachycardia or ventricular fibrillation. N Engl 1981;305:539545.

2. Hamer AW, Finerman WB, Peter T, Mandel WJ. Disparity between the clinical and electrophysiologic effects of amiodarone in the treatment of recurrent ventricular tachyarrhythmias. Am Heart J 1981;102:992-1000.

3. Waxman HL, Groh WC, Marchlinski FE, Buxton AE, Sadowski LM, Horowitz LN, Josephson ME, Kastor JA. Amiodarone for control of sustained ventricular tachycarrhythmias. Clinical and electrophysiologic effects in 51 patients. Am J Cardiol 1982;50:1066-1074.

4. Nademanee K, Hendrickson JA, Jannan R, Singh BH. Antiarrhythmic efficacy and electrophysiologic actions of amiodarone in patients with life-threatening ventricular arrhythmias: Potent suppression of spontaneously occurring tachyarrhythmias versus inconsistent abolition of induced ventricular tachycardia. Am Heart J 1982;103:950-959.

5. Horowitz LN, Greenspan AM, Spielman SR, Webb CR, Morganroth J, Rotmensch H, Sokoloff NM, Rae AP, Segal BL, Kay HR. Usefulness of electrophysiologic testing in evaluation of amiodarone therapy for sustained ventricular tachyarrhythmias associated with coronary artery disease.. Am J Cardiol 1985:55:367-371.

6. Mc Govern B, Garan H, Malacoff RF, DiMarco JP, Garant G, Sellers D, Ruskin JN. Long-term clinical outcome of ventricular tachycardia or fibrillation treated with amiodarone. Am J Cardiol 1984;53:1558-1563.

7. Nacarelli GV, Fineberg NS, Zipes DP, Heger JJ, Duncan G, Prystowsky EN,. Amiodarone: Risk factors for recurrences of symptomatic ventricular tachycardia identified at electrophysiologic study. J Am Coll Cardiol 1985;68:814-821.

8. Klein LS, Fineberg N, Heger JJ, Miles WM, Kammerling JM, Chang M-S, Zipes DP, Prystowsky EN. Prospective evaluation of a descriminant function for prediction of recurrent ventricular tachycardia or ventricular fibrillation in coronary artery disease patients receiving amiodarone and having inducible ventricular tachycardia at electrophysiologic study. Am J Cardiol 1988;61:1024-1030.

9. Kadish AH, Buxton AE, Waxman HL, Flores B, Josephson ME, Marchlinski FE. Usefulness of electrophysiologic study to determine the clinical tolerance of arrhythmia recurrences during amiodarone therapy. J Am Coll Cardiol 1987;10:90-96.

10. Zhu J, Haines DE, Lerman BB, DiMarco JP. Predictors of efficacy of amiodarone and characteristics of recurrence of arrhythmia in patients with sustained ventricular tachycardia and coronary artery disease. Circulation 1987;76:802-809.

11. Manolis AS, Urichio F, Estes ME. Prognostic value of early electrophysiologic studies for ventricular tachycardia recurrence in patients with coronary artery disease treated with amiodarone. Am J Cardiol 1989;63:1052-1057

12. Kim SG, Felder SD, Figura I, Johnston DR, Mercado AD, Fisher JD. Prognostic value of changes in the mode of ventricular tachycardia induction during therapy with amiodarone and class 1A antiarrhythmic agent. Am J Cardiol 1987;59:1314-1318.

13. Brugada P, Wellens HJJ. Programmed electrical stimulation of the human heart. In Tachycardias; mechanism, diagnosis and treatment. Josephson ME, Wellens HJJ. (Eds). Lea \& Febiger 1984;61-89. 
14. The SAS software. In PHREG procedure 1990;435-479.

15. Cox DR. Regression models and life tables. J Stat Soc (b) 1972;34:187-220.

16. Holt DW, Tucker GT, Jacson PR, Storey GCA. Amiodarone pharmacokinetics. Am Heart J 1983;106:840.

17. Haffajee CI, Love JC, Canada AT, Lesko LJ, Askourian G, Alpert JS. Clinical pharmacokinetics and efficacy of amiodarone for refractory tachyarrhythmias. Circulation 1983;67:1347-1355.

18. Brugada $P$, Talajic M, Smeets J, Mullenders R, Wellens HJJ. Risk stratification of patients with ventricular tachycardia or ventricular fibrillation after myocardial infarction. The value of the clinical history. Eur Heart J 1989;10:747-752.

19. Willems AR, Tijssen JGP, Van Capelle FJL, et al. Determinants of prognosis in symptomatic ventricular tachycardia or ventricular fibrillation late after myocardial infarction. J Am Coll Cardiol 1990;16:521-530. 


\section{Summary}

The first part of the study (Chapters 2 to 5) reports on new observations in patients suffering from supraventricular arrhythmias while the second part (Chapters 6 to 10 ) describe new findings in ventricular arrhythmias.

In Chapter 2 the age at onset of the first arrhythmic event and gender in relation to the type of tachycardia is reported in 623 consecutive patients suffering from supraventricular tachycardias. The accurate arrhythmia diagnosis was based on an electrophysiologic study. Arrhythmias occurring in patients with accessory pathways were more often seen in male than in female patients (273 male (67\%) / 136 female (33\%)). In contrast, AV nodal tachycardias were more often observed in female than male patients ( 52 males (32\%) / 113 females $(68 \%)$ ). Incidence of atrial tachycardia showed no difference between sexes ( 23 males (47\%) / 26 females (53\%)). The onset of the first arrhythmic event in patients having an accessory pathway occurred most frequently at ages between 10 to 29 years. AV nodal and atrial tachycardias did not show preference for a certain age group.

Chapter 3 describes the characteristic 12-lead electrocardiographic patterns of mid-septal, anteroseptal, posteroseptal, and right free wall accessory pathways in 50 patients with a single anterogradely conducting accessory pathway in one of these 4 locations. The accessory pathway location was confirmed by surgery or radiofrequency catheter ablation. The electrocardiographic data analyzed were: 1) The QRS and 2) delta wave axis in the frontal plane, 3) the angle between QRS and delta wave axis, 4) the R/S ratio in lead III, 5) Presence of negativity of the delta wave in inferior leads and 6) the $R / S$ ratio in precordial leads. Mid-septal and anteroseptal accessory pathways can be differentiated from right free wall and true posteroseptal accessory pathways by the QRS axis and delta wave polarity in inferior leads. Mid-septal can be distinguished from anteroseptal pathways by the difference in QRS and delta wave axis and the R/S ratio in lead III. An angle between the QRS and delta wave axis of $\geq 20^{\circ}$ and an $\mathrm{R} / \mathrm{S}$ ratio equal to 1 in lead III favor a mid-septal accessory pathway.

Chapter 4 gives an example of the treatment of a patient with multiple accessory pathways suffering from symptomatic supraventricular tachycardias by radiofrequency current catheter ablation.

Chapter 5 shows that patients with long-standing (paroxysmal or chronic) atrial fibrillation may show deterioration of their cardiac function. This seems to be related to the duration of the arrhythmia. In those patients, left ventricular 
ejection fraction may improve significantly after ventricular rate control by ablation of the atrio-ventricular conduction system and implantation of a physiologic pacing device. Left heart function was studied in 30 patients with lone atrial fibrillation before and after ablation of atrio-ventricular conduction. Left ventricular ejection fraction, left ventricular end-systolic and end-diastolic and left atrial dimensions were measured by echocardiography before and after ablation. Before ablation left ventricular ejection fraction was $\leq 50 \%$ in 12 patients (group I) and $>50 \%$ in 18 patients (group II). The duration of atrial fibrillation was the only difference found between group I and group II patients (group I: 8-28, mean 11 years, group II: 2-14, mean 5.4 years, $\mathrm{p}<0.05$ ). In group I left ventricular ejection fraction increased after ablation from $43 \pm 8 \%$ to $54 \pm 7 \%(p<0.0001)$. There were also significant decreases in the left ventricular end systolic, left ventricular end diastolic and left atrial dimensions. No such changes were observed in group II patients. Although the exact incidence is unknown our findings illustrate that some patients with longstanding lone atrial fibrillation may develop severe deterioration of left heart function. In those patients, left heart function improves significantly after ventricular rate control by ablation of AV conduction and implantation of a physiologic pacing device.

Chapter 6 analyzes the prognostic significance of serial signal averaged electrocardiograms in 190 patients after a first myocardial infarction, performed during the first 3 days (period 1), in the second week (period 2) and after 6 months (period 3). Multivariate regression analysis using continuous variables showed that the strongest predictor of sustained ventricular tachycardia and ventricular fibrillation was the left ventricular ejection fraction $(p<0.0001)$ followed by the duration of the QRS complex on the signal averaged electrocardiogram recorded during the first 3 days of infarction $(p<0.0005)$. Sudden death was only predicted by the left ventricular ejection fraction $(p<0.02)$. These data suggest that the degree of myocardial damage as assessed by left ventricular ejection fraction is a better predictor of sustained ventricular arrhythmias during follow-up than the signal averaged electrocardiogram and the only predictor of sudden cardiac death after myocardial infarction. Serial recordings of the signal averaged electrocardiogram did not improve information as to occurrence of ventricular tachyarrhythmias or sudden death.

Chapter 7 examines the twelve lead ECG characteristics during ventricular tachycardia (VT) in 73 patients with a postinfarction (group A) and in 73 patients with a non-ischemic etiology of their arrhythmia (group B). Seventy five tracings were available from group B patients (8 right ventricular dysplasia, 24 idiopathic VT and 43 preexcited tachycardia). Presence of a $\mathrm{qR}$ or $\mathrm{QR}$ pattern (with a QR ratio of $25 \%$ or more) in any lead except aVR was found to be the most helpful parameter in differentiating postinfarction from non-ischemic VT (specificity $100 \%$, sensitivity $90 \%$ ). In right bundle branch block VT morphol- 
ogy, (44/73 group A, 44/75 group B) a total R wave amplitude in all precordial leads of more than $80 \mathrm{~mm}$ was of help in differentiating non-ischemic VT from postinfarction VT; (4/44 group A vs $40 / 44$ group B; specificity 90 , sensitivity $90 \%$ ). Also, In right bundle branch block VT morphology, the distance between the onset to the summit of the $R$ wave in lead V1 $(100 \pm 50 \mathrm{msec}$ vs $87 \pm 38$ msec $(p<0.01)$ ), and the distance between the onset to the nadir of $S$ wave in lead V6 $(89 \pm 27 \mathrm{msec}$ vs $71 \pm 18 \mathrm{msec}(\mathrm{p}<0.001)$ ) were longer in group $A$ than in group B patients. In left bundle branch block VT morphology, the total R wave amplitude in the extremity leads was higher in non-ischemic $(41 \pm 23 \mathrm{~mm})$ than postinfarction VT $(29 \pm 12 \mathrm{~mm})(\mathrm{p}<0.001)$. Therefore, the electrocardiogram during ventricular tachycardia may show features that suggest a postinfarction or a non-ischemic etiology.

Chapter 8 demonstrates that by using clinical information a prognostic index for non-fatal VT recurrences can be constructed. This is of help to identify patients at highest or lowest risk of recurrences of ventricular tachycardia after a myocardial infarction. Two hundred and six patients from Maastricht with sustained monomorphic VT or ventricular fibrillation (VF) after healing of an acute myocardial infarction were studied. 74/206 (36\%) (64 VT patients and 10 VF patients) had recurrences of sustained monomorphic VT during $3.4 \pm 9$ years of follow-up. Three clinical variables were selected and weighted by stepwise logistic discriminant analysis of the study group. They were coded as follows: interval myocardial infarction-arrhythmia $(<2$ months $=1,2$ to 6 months $=2$, $>6$ months $=3$ ), drug therapy: sotalol, or no sotalol ( and VT or VF as the presenting arrhythmia $(V T=1, V F=2)$. The prognostic index was: $3.41-(0.56 \mathrm{x}$ interval $)-(1.94 \mathrm{x}$ therapy $)+(0.86 \mathrm{x}$ arrhythmia $)$. When prospectively evaluated in a test group of 158 patients from Heidelberg with sustained monomorphic VT or VF after healing of an acute myocardial infarction, 2 risk classes of patients were identified: a high risk group (61\% VT recurrences) corresponding to those with a negative index, and a low-risk group (4\% VT recurrences) consisting of those with a positive index. This prognostic index may be used for selecting treatment in patients having VT or VF late after myocardial infarction.

Chapter 9 analyzes the incidence and timing of recurrences of sustained VT or sudden death in 206 patients having survived their first episode of VF (52 patients) or sustained VT (154 patients) after a myocardial infarction. All patients were treated with (empirically selected) antiarrhythmic drugs, with 49 $\%$ receiving amiodarone. Incidence of sudden death showed 2 peaks at around 3 and 12 months. Non-fatal VT recurrences were more frequent (most commonly occurring in the first 6 months) in the VT group as compared to the VF group. In only $10 \%$ of patients having survived 1 year, sudden death occurred during the next 3 years. Comparison between patients having a left ventricular ejection 
fraction $\leq 40 \%$ to $>40 \%$ revealed a much higher incidence of sudden death in patients with left ventricular ejection fraction $\leq 40 \%(28 / 65$ vs $3 / 141$; $\mathrm{p}<0.0001$ ). No relation was found between the value for left ventricular ejection fraction and the occurrence of non-fatal VT recurrences.

Chapter 10 examines the value of programmed electrical stimulation of the heart in predicting sudden death in patients receiving amiodarone because of serious ventricular tachyarrhythmias after myocardial infarction. One hundred and six patients with clinically documented sustained monomorphic ventricular tachycardia ( 77 patients) or ventricular fibrillation ( 29 patients) were studied. All patients had been on amiodarone for at least 1 month. Eighty out of the 106 patients had either ventricular fibrillation (15 patients) or sustained monomorphic ventricular tachycardia ( 65 patients) induced. After a mean follow-up of $50 \pm 40$ months (1-144), 13 patients either died suddenly (11 patients) or used their defibrillator (2 patients).

By multivariate analysis two predictors for sudden death were found: inducibility of ventricular fibrillation $(p<.0001)$ and a left ventricular ejection fraction $<40 \%(p<0.05)$. Actuarial curves for sudden death were constructed for induced ventricular fibrillation, sustained monomorphic ventricular tachycardia and absence of induced sustained arrhythmias. The survival rate at 1, 2, 3 and 5 years was $70 \%, 62 \%, 62 \%$ and $40 \%$ respectively for induced ventricular fibrillation patients and $98 \%, 96 \%, 94 \%, 94 \%$ for the induced sustained monomorphic ventricular tachycardia patients. In the no sustained arrhythmia group the 5 year survival was $100 \%$. Therefore, in patients on amiodarone because of life-threatening ventricular arrhythmias after a myocardial infarction, inducibility of ventricular fibrillation, but not of sustained monomorphic ventricular tachycardia suggests a high risk of dying suddenly. 


\section{Samenvatting}

In dit proefschrift worden nieuwe observaties beschreven bij patiënten met supraventriculaire ritmestoomissen (hoofdstuk $2 \mathrm{t} / \mathrm{m}$ hoofdstuk 5) en met kamerritmestoornissen (hoofdstuk $6 \mathrm{t} / \mathrm{m}$ hoofdstuk 10).

In hoofdstuk 2 wordt de relatie bestudeerd tussen type ritme-stoornis, de leeftijd waarop de klachten begonnen en het geslacht. In een groep van 623 patiënten werd het type supraventriculaire ritmestoornis vastgesteld door middel van een invasief onderzoek (geprogrammeerde elektrische stimulatie van het hart). Ritmestoornissen bij patiënten met een extraverbinding tussen boezem en kamer van het hart kwamen vaker voor bij mannen dan bij vrouwen (273 mannen $(67 \%)$ vs. 136 vrouwen (33\%)), terwijl in tegenstelling hiermee AV-nodale tachycardieën vaker bij vrouwen dan bij mannen voorkwamen (52 mannen $(32 \%)$ vs. 113 vrouwen (68\%)). Bij de groep met een boezemtachycardie kon geen verschil tussen beide geslachten worden aangetoond ( 23 mannen ( $47 \%$ ) vs. 26 vrouwen (53\%)). Meestal begonnen de klachten van ritmestoornissen op een leeftijd tussen 10 en 29 jaar bij patiënten met een extraverbinding tussen boezem en kamer. AV-nodale ritmestoomissen en boezemtachycardieën bleken op elke leeftijd te kunnen beginnen.

In hoofdstuk 3 worden de electrocardiografische kenmerken beschreven van extraverbindingen welke ofwel in het voorste, middelste of achterste deel van het septum gelegen zijn dan wel in de vrije wand van de rechter kamer. Bij deze groep van in totaal 50 patiënten werd de ligging van de extraverbinding bepaald tijdens de operatieve onderbreking of catheterablatie ervan. De volgende electrocardiografische gegevens werden geanalyseerd: 1) de frontale as van zowel het QRS-complex als de delta-golf, 2) de hoek tussen QRS en de delta-as, 3 ) de R/S-ratio in afleiding 3,4) de aanwezigheid van een negatieve delta-golf in de onderwandsafleidingen, en 5) de R/S-ratio in de precordiale afleidingen. Extraverbindingen in het voorste of middelste gedeelte van het septum konden onderscheiden worden van de achter in het septum en in de vrije wand van de rechter kamer gelegen extraverbindingen op grond van verschillen in de as van het QRS-complex en de polariteit van de delta-golf in de onderwandsafleidingen. De midseptale kon onderscheiden worden van de anteroseptaal gelegen extraverbinding door verschillen in de as van het QRS-complex en de delta-golf en de R/S-ratio in afleiding 3. Een hoek van meer dan $20^{\circ}$ tussen het QRS-complex en de delta-golf as en een R/S-ratio gelijk aan 1 in afleiding 3 bleek te pleiten voor een midseptaal gelegen extraverbinding. 
Succesvolle onderbreking van de geleiding over drie verschillende extraverbindingen tussen boezem en kamer met behulp van catheterablatie wordt beschreven in hoofdstuk 4.

Patiënten met boezemfibrilleren (hoofdstuk 5) kunnen op den duur een verslechtering van de pompfunctie ontwikkelen, zonder dat er een organisch hartlijden aanwezig is. In een groep van 30 patiënten met boezemfibrilleren (die zowel in aanvallen konden optreden of continu aanwezig konden zijn) werd gekeken of onderbreking van de geleiding van boezem naar kamer door middel van His-bundelablatie en gevolgd door pacemakerimplantatie leidde tot een verandering van de linker kamerfunctie. Hiertoe werden de linker kamerejectiefractie, de eindsystolische en einddiastolische diameters van de linker kamer en de linker boezemgrootte gemeten met behulp van echocardiografie voor en na ablatie. Bij 12 patiënten was voor ablatie een verminderde ejectiefractie (minder dan of gelijk aan 50\%) (groep 1) en bij 18 patiënten een normale linker kamerejectiefractie (boven de 50\%) aanwezig. Patiënten met een verminderde linker kamerfunctie bleken gemiddeld 11 jaar klachten te hebben, terwijl patiënten met een normale linker kamerfunctie gemiddeld $5 \frac{1}{2} 2$ jaar klachten hadden. $\mathrm{Na}$ onderbreking van de geleiding over de His-bundel nam de linker kamerejectiefractie toe van $43 \%$ tot $54 \%(\mathrm{P}<0.0001)$ bij de patiënten met een verminderde linker kamerfunctie. Dit ging gepaard met een significante afname in de diameter van de linker kamer, zowel eindsystolisch als einddiastolisch, en bovendien met een vermindering van de linker boezemgrootte. Deze verschillen werden niet gevonden bij patiënten die voor ablatie een normale linker kamerfunctie hadden (groep 2). De incidentie van linker kamerfunctievermindering bij patiënten met "alleen" boezemfibrilleren is onbekend. Wanneer er een verminderde linker kamerfunctie aanwezig is als gevolg van de hoge kamerfrequenties bij boezemfibrilleren, bleek dus onderbreking van de atrioventriculaire geleiding en implantatie van een fysiologische pacemaker de linker kamerfunctie aanzienlijk te verbeteren.

In hoofdstuk 6 wordt bij een groep van 190 patiënten met een eerste myocardinfarct de prognostische waarde bestudeerd van een signal averaged elektrocardiogram gemaakt binnen de eerste drie dagen (periode 1), in de tweede week (periode 2) en zes maanden (periode 3 ) na het infarct. Bij multivariabele regressie-analyse met continue variabelen bleek het optreden van kamertachycardieën of kamerfibrilleren het best voorspeld te kunnen worden door de linker kamerejectiefractie $(P<0.0001)$, en de duur van het $Q R S-c o m p l e x$ op het signal averaged elektrocardiogram wanneer dit gedurende de eerste drie dagen na het infarct geregistreerd werd $(P<0.0005)$. Plotse dood kon alleen voorspeld worden aan de hand van de linker kamerejectiefractie $(P<0.02)$. Deze gegevens suggereren dat de mate van beschadiging van de hartspier uitgedrukt in de linker kamerejectiefractie de beste voorspeller is voor het optreden van plotse dood na 
het hartinfarct. Bovendien bleek deze parameter ook beter dan het signal averaged ECG om het optreden van langdurige kamerritmestoornissen te voorspellen tijdens de follow up. Het herhaald registreren van het signal averaged ECG leverde geen additionele informatie op ten aanzien van het optreden van kamerritmestoomissen of plotse dood na het myocardinfarct.

In hoofdstuk 7 wordt het twaalfkanaals-ECG tijdens de ritmestoornis vergeleken bij 73 patiënten met een kamertachycardie na een hartinfarct (groep A) en 75 patiënten met een kamerritmestoornis van niet-ischemische oorsprong (groep B). De ECG's van groep B waren afkomstig van patiënten met kamertachycardie bij rechter kamerdysplasie (8), idiopathische kamertachycardie (24) en patiënten met pre-excitatie (43). Afwezigheid van een $\mathrm{qR}$ - of $\mathrm{QR}$-patroon (met een QR-ratio van 25\% of meer) in elke afleiding behalve AVR bleek de beste parameter om kamertachycardieën die niet-infarctgerelateerd waren te identificeren (specificiteit 100\%, sensitiviteit 90\%). Bij kamerritmestoornissen met rechter bundeltakvorm ( $44 / 73$ van groep A, $74 / 75$ van groep B) kon met behulp van de som van de amplitudes van de R-golven in de precordiale afleidingen (meer dan $80 \mathrm{~mm}$ ) een onderscheid gemaakt worden tussen kamertachycardieën gerelateerd aan een infarct vs. kamerritmestoornissen zonder een hartinfarct in de voorgeschiedenis (in 4 van de 44 groep A vs. 40 van de 44 groep B; specificiteit $90 \%$, sensitiviteit $90 \%$ ). Bovendien bleek bij kamertachycardieën met een rechter bundeltakblok-morfologie dat de afstand tussen het begin en het hoogste punt van de R-golf in afleiding V1 $(100 \pm 50 \mathrm{~mm}$ vs. $87 \pm 38 \mathrm{~mm}$ $(P<0.01)$ ), en de afstand tussen het begin en het diepste deel van de S-golf in afleiding V6 $(89 \pm 27 \mathrm{~mm}$ vs. $71 \pm 18 \mathrm{~mm}(\mathrm{P}<0.01))$ langer was in groep A- in vergelijking met groep B-patiënten. Bij kamertachycardieën met een linker bundeltakblok-achtige morfologie bleek de totale R-top-amplitude in de extremiteitsafleidingen hoger te zijn bij de niet-infarctgerelateerde vs. de post-infarct kamertachycardieën $(41 \pm 23 \mathrm{~mm}$ vs. $29 \pm 12 \mathrm{~mm}(\mathrm{P}<0.01))$. Deze kenmerken op het elektrocardiogram gedurende de kamertachycardie kunnen helpen om een onderscheid te maken tussen een hartinfarct of een niet-ischemische oorzaak van een kamer tachycardie.

In hoofdstuk 8 wordt duidelijk gemaakt dat met behulp van klinische informatie een prognostische index gemaakt kan worden voor het hernieuwd optreden van een kamerritmestoornis bij patiënten met levensbedreigende kamerritmestoornissen. Hiermee is het mogelijk patiënten te herkennen met een hoog of laag risico op hernieuwde episodes van kamerritmestoornissen na het hartinfarct. In totaal werden 206 patiënten bestudeerd met een kamertachycardie of kamerfibrilleren die in het verleden een hartinfarct hadden doorgemaakt. Gedurende een follow-up periode van $3,4 \pm 9$ jaar bleken 74 van de 206 patiënten (36\%) een hemieuwde episode te hebben van een kamertachycardie (64 patiënten) of kamerfibrilleren (10 patiënten). Er werden 3 klinische varia- 
belen geselecteerd en met behulp van stapsgewijze logistieke discriminantanalyse gewogen: 1) het interval tussen het hartinfarct en het eerste optreden van de ritmestoornis (kleiner dan 2 maanden is 1,2 tot 6 maanden is 2, groter dan 6 maanden is 3), 2) antiarrhythmische medicatie: Sotalol of geen Sotalol (Sotalol is 1 , geen Sotalol is 2) en 3) het type van de oorspronkelijke ritmestoornis (kamertachycardie is 1, kamerfibrilleren is 2). Met deze gegevens kon de volgende prognostische index worden opgesteld: 3.41 - (0.56 x interval) - (0.94 $x$ therapie $)+(0.86 x$ type ritmestoornis). Daarna werd deze prognostische index gebruikt in een prospectieve studie met 158 patiënten van de afdeling Cardiologie te Heidelberg. Het bleek dat twee risicogroeppatiënten konden worden herkend: een hoge risicogroep (61\% recidieven kamerritmestoomis), welke overeenkwam met de patiëntengroep met een negatieve waarde van de prognostische index, en een groep met een laag risico ( $4 \%$ recidief kamertachycardieën) met een positieve waarde van de index. Deze prognostische index kan dan ook gebruikt worden voor de juiste keuze van de behandeling bij patiënten met kamertachycardie of kamerfibrilleren na een doorgemaakt hartinfarct.

In hoofdstuk 9 wordt in een groep van 206 patiënten met kamerritmestoornissen na een hartinfarct (52 patiënten met kamerfibrilleren, 154 met kamertachycardieën) bestudeerd hoeveel patiënten een recidief ritmestoomis krijgen, en gekeken naar het tijdstip waarop dit optreedt. Alle patiënten werden op empirische basis behandeld met antiaritmica, waarbij $49 \%$ van de patiënten met Amiodarone behandeld werden. De incidentie van plotse hartdood bleek twee pieken te vertonen in de follow-up, namelijk rond drie en twaalf maanden. Recidieven van kamerritmestoomissen, waar de patiënt niet aan overleed, werden frequenter gezien in de groep die kamertachycardie als oorspronkelijke ritmestoornis had dan in de groep met als eerste aritmie kamerfibrilleren (deze hadden de meeste recidieven binnen de eerste 6 maanden na follow-up). Wanneer de patiënt de eerste ritmestoornis één jaar overleefde, bleek slechts $10 \%$ van deze groep patiënten in de daaropvolgende drie jaar plotseling te overlijden. Wanneer de groep patiënten verdeeld werd aan de hand van de linker kamerejectiefractie (kleiner dan $40 \%$ of groter dan $40 \%$ ), bleek dat de incidentie van plotse hartdood groter was in de groep met de lage ejectiefractie $(28 / 65$ vs. $3 / 141$ ( $\mathrm{P}<$ $0.0001)$ ), maar dat die relatie niet bestond voor het hemieuwd optreden van kamerritmestoomissen waaraan de patiënt niet overleed.

In hoofdstuk 10 wordt de waarde beschreven van het geprogrammeerde elektrische stimulatie-onderzoek van het hart om te voorspellen of patiënten die wegens een kamerritmestoornis amiodarone gebruiken tijdens follow-up zullen overlijden. De groep bestond uit 106 patiënten met klinisch gedocumenteerde kamertachycardieën ( 77 patiënten) of kamerfibrilleren ( 29 patiënten). Na meer dan één maand amiodaronegebruik, bleek dat bij 15 patiënten kamerfibrilleren en bij 65 patiënten kamertachycardieën konden worden opgewekt. $\mathrm{Na}$ een follow-up van $50 \pm 40$ maanden ( 1 tot 144 maanden) bleek dat 13 patiënten 
hetzij plotseling overleden waren (11 patiënten) of wegens kamerfibrilleren een schok van een inwendige defibrillator hadden gekregen ( 2 patiënten). Bij multivariaatanalyse bleken twee factoren de plotse dood te kunnen voorspellen: 1) de induceerbaarheid van kamerfibrilleren $(P<0.001)$ en 2$)$ een ejectiefractie lager dan 40\% ( $\mathrm{P}<0.05)$. Overlevingscurves konden worden gemaakt voor patiënten met inductie van kamerfibrilleren, kamertachycardieën of afwezigheid van het induceren van kamerritmestoornissen. Bij patiënten bij wie kamerfibrilleren werd geïnduceerd bleek de overleving na 1,2, 3 à 5 jaar 70, 62, 62 en $40 \%$ te bedragen en bij patiënten met kamertachycardieën bleek deze overleving 98,96 , 94 en $94 \%$. Patiënten waarbij geen ritmestoornissen konden worden opgewekt tijdens geprogrammeerde stimulatie, bleken na vijf jaar allen nog in leven. Bij patiënten die behandeld worden met amiodarone voor levensbedreigende kamerritmestoomissen na het hartinfarct lijkt inductie van kamerfibrilleren, maar niet van kamertachycardieën, samen te gaan met een hoog risico om te overlijden tijdens de follow-up. 


\section{Résumé}

La premier partie de l'étude (Chapitres 2-5) rend compte de nouvelles observations relatives á des patients souffrant d'arythmie supraventriculaire, tandis que la seconde partie (Chapitres 6-10) décrit des résultats nouveaux concernant les arythmies ventriculaires.

Au Chapitre 2, l'age d'apparition d'un premier épisode d'arythmie ainsi que le sexe du sujet sont étudiés en fonction du type de tachycardie chez 623 patients différents souffrant de tachycardie supraventriculaire. Le diagnostic précis de l'arythmie est apporté par une étude électrophysiologique. Les arythmies liées a la présence de faisceaux accessoires ont été plus souvent observées chez des patients masculins (273 hommes (67\%)/136 femmes (33\%)). Inversement, les tachycardies intranodales ont plus souvent été observées chez des patientes que chez des patients [52 hommes (32\%)/133 femmes (68\%)]. L'incidence de la tachycardie auriculaire n' est pas influencée par le sexe [23 hommes $(47 \%) / 26$ femmes $(53 \%)$ ]. Parmi les patients qui présent un faisceau accessoire le premier épisode arythmique apparait plus fréquemment entre 10 et 29 ans. Les tachycardies intranodales et auriculaires n'ont pas une distribution préférentielle en fonction de l'age. Le Chapitre 3 décrit les caractéristiques électrocardiographiques des faisceaux accessoires selon leur localisation medio-septale, anteroseptale, postéroseptale ou au niveau de la paroi libre du ventricule droit chez 50 patients ne présentant qu'un seul faisceau accessoire dans une de ces 4 localisations. La localisation du faisceau accessoire a été confirmée par son ablation, par chirurgie ou au moyen d'un cathéter à radiofréquence. Les paramètres électrocardiographiques analysés sont les suivants: 1) l'axe du QRS, 2) l'axe de l'onde delta 3) la différence entre l'axe du QRS et l'axe de l'onde delta 4) le rapport R/S en dérivation III, 5) la présence d' une négativité de l'onde delta dans les dérivations inférieures et 6) rapport $R / S$ dans les dérivations precordiales. Les faisceaux accessoires medio-septaux et anteroseptaux peuvent être différenciés de ceux de la paroi libre du ventricule droit et des faisceaux accessoires posteroseptaux par l'axe du QRS et la polarité de l'onde delta dans les dérivations inférieures. Les faisceaux accessoires medio-septaux peuvent être distingués des faisceaux accessoires anteroseptaux par la différence des axes du QRS et de l'onde delta ainsi que par le rapport R/S en la dérivation III. Une différence de $\geq 20^{\circ}$ entre les axes du QRS et de l'onde delta ainsi qu'un rapport R/S égal a 1 en dérivation III sont en faveur d'un faisceau accessoire de localisation medio-septale. 
Le Chapitre 4 donne l'exemple du traitement ablatif par courant de radiofréquence d'un patient qui présentait plusieurs faisceaux accessoires auriculoventriculaires et souffrait de tachycardies supraventriculaires symptomatiques.

Le Chapitre 5 montre que les patients souffrant d'une fibrillation auriculaire de longue date (paroxysmale ou chronique) peuvent présenter une détérioration de la fonction cardiaque. Celle-ci semble être proportionnelle à la durée de l'arythmie. Chez ces patients, la fraction d'ejection du ventricule gauche peut s'accroître considérablement après contrôle de la réponse ventriculaire, par ablation du système de conduction auriculo-ventriculaire et implantation d'un pacemaker. La fonction ventriculaire gauche été étudiée avant et après ablation chez 30 patients présentant une fibrillation auriculaire isolée. La fraction d'éjection ventriculaire gauche, les dimensions du ventricule gauche en fin de systole et de diastole ainsi que celles de l'oreillette gauche ont été mesurées par échocardiographie avant et après ablation. Avant ablation, la fraction d'éjection ventriculaire gauche était $\leq 50 \%$ chez 12 patients (group I) et $>50 \%$ chez 18 patients (group II). La durée de la fibrillation auriculaire était la seule différence observée entre les patients du group I et ceux du group II (group I: 8-28 ans, moyenne, 11 ans, group II: $2-14$ ans moyenne 5.4 ans, p < 0.05 ). Après ablation, la fraction d'éjection du ventricule gauche a augmenté de $43 \pm 8 \%$ à $54 \% \pm 7 \%$ ( $p<0.0001$ ) dans le group I. Les dimensions ventriculaires gauches en fin de systole et en fin de diastole étaient diminuée significativement, de même que celles de l'oreillette gauche. De tels changements n'ont pas été observés chez les patients du groupe II. Bien que l'incidence exacte en soit inconnue nos résultats montrent que certains patients présentant une fibrillation auriculaire isolée de longue durée peuvent développer une nette deterioration de la fonction ventriculaire gauche. Cette fonction du ventriculaire gauche s'améliore nettement après contrôle de la réponse ventriculaire par ablation du système de conduction auriculo-ventriculaire et implantation d'un pacemaker.

Le Chapitre 6 analyse de façon prospective la valeur prédictive de l'électrocardiogramme (ECG) moyenné du QRS chez 190 patients ayant présenté un primo-infarctus du myocarde. Les ECG moyennés ont été enregistrés dans les trois premier jours (période 1), au cours de la deuxième semaine (période 2) et après 6 mois (période 3 ). L'analyse multivariée de nombreux paramètres a montré que la fraction d'éjection du ventricule gauche apportait la meilleure valeur prédictive vis à vis des récidives de tachycardie ventriculaire soutenue et de fibrillation ventriculaire $(p<0.0001)$, suivie par la durée du complexe $Q R S$ sur l'ECG moyenné enregistré pendant les 3 premiers jours de l'infarctus $(p<0.0005)$. La mort subite était uniquement prédite par la fraction d'éjection du ventricule gauche $(p<0.02)$. Ces données suggèrent que la détérioration myocardique mesurée par la fraction d'éjection du ventricule gauche a une meilleure valeur prédictive au cours du suivi que l'ECG moyenné vis à vis de la 
survenue d'une arythmie ventriculaire soutenue. Des enregistrements répètés de l'ECG moyenné n'ont pas augmenté les renseignements quant a la fréquence des récidives de tachycardies ventriculaires ni de la survenue d'une mort subite.

Le Chapitre 7 se penche sur les caractéristiques recueillies dans les 12 dérivations de l'ECG de surface au cours d'une tachycardie ventriculaire (TV) chez 73 patients avec une TV survenant après un infarctus du myocarde (TV postinfarctus; groupe A) et chez 73 patients avec une étiologie non-ischémique de leur arythmie (TV non-ischémique; group B). Septante-cinq tracés de patients du groupe B étaient disponibles ( 8 cas de dysplasie ventriculaire droite, 24 cas de TV idiopathique et 43 cas de tachycardie utilisant préférentiellement un faisceau accessoire de façon antérograde). La présence d'un complexe de morphologie $\mathrm{qR}$ ou $\mathrm{QR}$ (avec un rapport $\mathrm{QR}$ de 0.25 ou plus) dans toutes les dérivations sauf dans la dérivation aVR, a été retrouvée comme le paramètre le plus important pour différencier les TV postinfarctus de l'étiologie non-ischemiques. (spécificité $100 \%$, sensibilité $90 \%$ ). Pour les TV avec une morphologie de bloc de branche droit ( $44 / 73$ groupe A, $44 / 75$ groupe B), une amplitude totale de l'onde $R$ dans toutes les dérivations précordiales de plus de $80 \mathrm{~mm}$ était un critère de différenciation entre les TV d'étiologie non-ischemique d'une TV survenant après l'infarctus, (4/44 groupe A contre 40/44 dans le groupe B; spécificité $100 \%$, sensibilité $90 \%$ ). De même, toujours pour les TV avec une morphologie de bloc de branche droit, le délai entre le début et le sommet de l'onde $R$ en la dérivation V1 (groupe $A=100 \pm 50 \mathrm{msec}$ vs groupe $B=87 \pm 38$ msec ( $\mathrm{p}<0.01$ ), ainsi que le délai entre le début et le nadir de l'onde $S$ en V6 (groupe $A=89 \pm 27 \mathrm{msec}$ vs groupe $B=71 \pm 18 \mathrm{msec}$ permettent de reconnaître les TV post-infarctus des TV non-ischémiques. Dans les TV avec morphologie de bloc de branche gauche, l'amplitude totale de l'onde $\mathrm{R}$ dans les dérivations standard était plus élevée dans les étiologies non-ischémiques $(41 \pm 23 \mathrm{~mm}$ ) dans le post-infarctus $(29 \pm 12 \mathrm{~mm})(p<0.001)$. L'ECG 12-derivations enregistré durant la tachycardie ventriculaire peut présenter des caractéristiques qui suggèrent une étiologie postinfarctus ou non-ischémique.

Le Chapitre 8 montre qu'un index pronostique pour des récidives non-fatales de TV peut être établi en utilisant des renseignements cliniques. Ceci aide à identifier les patients à plus haut ou à plus bas risque de récidive de tachycardie ventriculaire après un infarctus du myocarde. Deux cent six patients hospitalisés dans le Service de Cardiologie de l'hopital de Maastricht et présentant une TV monomorphe soutenue ou une fibrillation ventriculaire (FV) après un infarctus du myocarde ont été régulièrement suivis avec un recul de $3.4 \pm 9$ ans. Septante et quatre patients ( $36 \%$ de la population pour 64 avec TV et 10 avec FV) ont présenté des récidives de TV monomorphe soutenue. Trois variables cliniques ont été identifiées au cours d'une analyse logistique et discriminante du groupe d'étude. Elles ont été codées comme suit: intervalle infarctus du myocarde- 
arythmie ( $<2$ mois $=1,2$ a 6 mois $=2,>6$ mois $=3$ ), traitement antiarythmique: sotalol, ou pas de sotalol (sotalol $=1$, pas de sotalol $=2$ ), et TV ou FV comme arythmie clinique initiale ( $\mathrm{TV}=1, \mathrm{FV}=2)$. L'index pronostic était: $3.41-(0.56$ $\mathrm{x}$ intervalle $)-(1.94 \mathrm{x}$ thérapie $)+(0.86 \mathrm{x}$ arythmie $)$. Cet index pronostic a fait l'objet d'une évaluation prospective dans un autre groupe de 158 patients hospitalisés a Heidelberg pour une TV monomorphe soutenue ou une FV après un infarctus du myocarde. Lorsque la valeur numérique de l'index pronostic calculé correspond à un nombre négatif, le patient est dans un groupe à haut risque de récidive de TV ( $61 \%$ de récidives). En revanche, lorsque la valeur calculée correspond à un nombre positif, le taux de récidive de TV est faible (4\%). L'index pronostic que nous proposons peut être utilisé pour choisir le traitement de patients souffrant de TV ou de FV, longtemps après un infarctus du myocarde.

Le Chapitre 9 analyse l'incidence et le délai des récidives de TV soutenue ou de mort subite chez 206 patients ayant survécu à un premier épisode de FV (52 patients) ou de TV soutenue (154 patients) après un infarctus du myocarde. Tous les patients étaient traités par antiarythmiques (choisis empiriquement), et $49 \%$ d'être eux recevaient de l'amiodarone. Le diagramme des récidives de mort subite montrait 2 pics de fréquence à environ 3 et 12 mois. Les récidives non-fatales de TV étaient plus fréquentes (apparaissant le plus souvent au cours des 6 premiers mois) au sein de groupe du TV comparé au groupe de FV. Au cours des 3 années suivantes, il n'y a eu que $10 \%$ de mort subite chez les patients ayant survécu 1 an. Lorsque les patients avec une fraction d'éjection ventriculaire gauche $\leq 40 \%$ ont été comparés aux patients ayant une fraction d'éjection ventriculaire gauche $>40 \%$, une incidence plus élevée de mort subite a été décelée chez les patients ayant une fraction d'éjection $\leq 40 \%(28 / 65(43 \%)$ vs $3 / 141(2 \%) ; p<0.0001)$. Aucune relation n'a été trouvée entre la valeur de la fraction d'éjection ventriculaire gauche et l'apparition de récidives non-fatales de TV.

Le Chapitre 10 examine la valeur de la stimulation ventriculaire programmée pour prédire la mort subite de patients traités par amiodarone pour des arythmies ventriculaires graves après un infarctus du myocarde. Cent-six patients, dont 77 présentant une TV monomorphe soutenue et cliniquement documentée et 29 patients souffrant de FV ont été observés. Tous les patients ont été traités par amiodarone pendant au moins un mois. Chez 80 patients, une FV (15 patients) ou une TV monomorphe soutenue (65 patients) a été induite au cours de l'étude électrophysiologique. Après un suivi moyen de $50 \pm 40$ mois, 13 patients sont morts subitement ( 11 cas) et deux autres qui avaient bénéficié de l'implantation d'un défibrillateur ont reçu des chocs électriques internes appropriés. Deux facteurs prédictifs de mort subite ont été trouvés lors de l'analyse multivariée: l'induction d'une FV au cours de l'étude électrophysiologique $(p<0.0001)$ et 
une fraction d'éjection ventriculaire gauche $<40 \%$ (p 0.05). Des courbes actuarielles pour la mort subite ont été construites selon le résultat de la stimulation ventriculaire programmée: induction d'une FV, d'une TV et l' absence d'arythmie induite. Le taux de survie à 1, 2, 3 et 5 ans était respectivement de $70 \%, 62 \%, 62 \%$ et $40 \%$ pour les patients avec une $\mathrm{FV}$ inductible et $98 \%$, $96 \%, 94 \%$, et $94 \%$ pour les patients présentant une TV monomorphe soutenue et inductible. La survie après 5 ans était de $100 \%$ chez les patients pour lesquels seule une arythmie avait pu être induite. Ainsi, chez les patients traités par amiodarone dans troubles du rythme ventriculaire graves après infarctus myocardique l'induction d'une FV par stimulation ventriculaire programmée constitue un facteur pronostic particulièrement péjoratif vis à vis de la survenue d'une mort subite, à l'inverse de l'induction d'une TV. 


\section{Resumen}

En la primer parte de este estudio (Capítulos 2 al 5) se presentan nuevas observaciones en los pacientes que padecen de taquicardias supraventriculares, mientras que en la segunda parte (Capítulos 6 al 10) se describen nuevos hallazgos en el campo de las arritmias ventriculares.

En el Capítulo 2, se analiza la relación entre la edad de presentación del primer episodio arrítmico, el sexo y el tipo de taquicardia en 623 pacientes consecutivos con taquicardias supraventriculares. El diagnóstico exacto se estableció mediante un estudio electrofisiológico. Las arrítmias en los pacientes con vías accesorias aurículoventriculares fueron más frecuentes en los pacientes del sexo masculino en comparación con los del sexo femenino ( 273 hombres $(67 \%) / 136$ mujeres (33\%)). Por el contrario, las taquicardias intranodales se detectaron más frecuentemente en los pacientes del sexo femenino que en los del masculino (52 hombres (32\%)/113 mujeres (68\%)). En los pacientes con taquicardias auriculares se observó una incidencia similar en ambos sexos (23 hombres $(47 \%) / 26$ mujeres (53\%)). El primer episodio arrítmico en los pacientes con vías accesorias aurículoventriculares se manifestó con mayor frecuencia entre los 10 y los 29 años. En el grupo de pacientes con taquicardias intranodales o taquicardias auriculares no se observó preferencia por ninguna edad de presentación de la arritmia.

En el Capitulo 3 se describen las características electrocardiográficas, obtenidas a partir de las 12 derivaciones del electrocardiograma de superficie, de los pacientes con una vía accesoria aurículoventricular con conducción anterógrada de localización medio-septal, ántero-septal, póstero-septal y la pared libre derecha. Se estudiaron cincuenta pacientes con una vía accesoria y con conducción anterógrada en una de estas 4 localizaciones. La localización de las vías accesorias se confirmó durante la cirugía o mediante la ablación transcatéter con radiofrecuencia. Se analizaron los siguientes datos electrocardiográfic: 1) El eje eléctrico del complejo QRS, 2) el eje eléctrico de la onda delta, ambos calculados en el plano frontal, 3) el ángulo correspondiente a la diferencia entre el eje eléctrico del complejo QRS y el eje de la onda delta, 4) la cociente R/S en la derivación DIII, 5) la presencia de una polaridad negativa de la onda delta en las derivaciones inferiores y 6 ) el cociente R/S en las derivaciones precordiales. Las vías accesorias con una localización en el septum medio y septum anterior (ántero-septal) pueden diferenciarse de las vías accesorias con localización en la región póstero-septal o en la pared libre derecha mediante el eje eléctrico del 
complejo QRS y la polaridad de la onda delta en las derivaciones inferiores. Las vías accesorias localizadas en el septum medio se pueden distinguir de las localizadas en la región ántero-septal mediante la diferencia entre el eje eléctrico del complejo QRS y el eje de la onda delta, así como por el cociente R/S en la derivación DIII. Un ángulo entre los ejes eléctricos del complejo QRS y la onda delta de $\geq 20^{\circ}$ y un cociente R/S igual a 1 en la derivación DIII hablan a favor de una vía accesoria aurículoventricular localizada en el septum medio.

En el Capítulo 4 se muestra un ejemplo de un paciente con 3 vías accesorias y taquicardias supraventriculares sintomáticas tratado mediante la ablación transcatéter por radiofrecuencia.

El Capítulo 5 demuestra que los pacientes con fibrilación auricular prolongada (paroxística o crónica) pueden presentar un deterioro en su función cardíaca. Este deterioro de la función cardíaca parece estar relacionado con la duración de la arritmia. En esos pacientes la fracción de eyección ventricular izquierda puede mejorar significativamente una vez que la frecuencia ventricular ha sido controlada mediante la ablación del sistema de conducción aurículo-ventricular y la implantación de un marcapaso fisiológico. En treinta pacientes con fibrilación auricular sin cardiopatía orgánica demostrable se estudió la función ventricular izquierda antes y después de la ablación de la conducción aurículo-ventricular. Se determinaron mediante echocardiografía la fracción de eyección ventricular izquierda, las dimensiones del ventrículo izquierdo en telesístole y telediástole, así como las dimensiones de la aurícula izquierda antes y después de la ablación. Antes de la ablación la fracción de eyección ventricular izquierda fue $\leq 50 \%$ en 12 pacientes (grupo I) y $>50 \%$ en 18 pacientes (grupo II). La duración de la fibrilación auricular fue la única diferencia observada entre los dos grupos de pacientes (grupo I: 8-28, media 11 años, grupo II: $2-14$, media 5.4 años, $\mathrm{p}<0.05$ ). En el grupo I la fracción de eyección ventricular izquierda aumentó después de la ablación de $43 \pm 8 \%$ a 54 $\pm 7 \%$ ( $<<0001)$. Se observó también una disminución significativa de las dimensiones del ventrículo izquierdo en telesístole y telediástole, así como de las dimensiones de la aurícula izquierda. Estas diferencias no se observaron en los pacientes del grupo II. Aunque la incidencia exacta de la fibrilación auricular sin cardiopatía orgánica demostrable no se conoce, nuestros hallazgos demuestran que en algunos pacientes con fibrilación auricular de este tipo y con una duración prolongada se puede desarrollar un deterioro severo de la función ventricular izquierda. En estos pacientes, la función ventricular izquierda mejora significativamente una vez que la frecuencia ventricular se ha controlado mediante la ablación del sistema de conducción y la implantación de un marcapaso físiológico. 
En el Capítulo 6 se analiza el valor pronóstico del electrocardiograma (ECG) de alta resolución (método de promediación de señales) realizado de una manera seriada en 190 pacientes tras su primer infarto de miocardio. Los ECG de alta resolución se realizaron durante los primeros 3 días después del infarto de miocardio (estadío 1), en la segunda semana (estadío 2) y después de 6 meses (estadío 3). Mediante un análisis de regresión múltiple utilizando variables continuas las dos variables con mayor valor predictivo para identificar los pacientes propensos a desarrollar taquicardia ventricular o fibrilación ventricular han sido: la fracción de eyección ventricular izquierda $(p<0.0001)$, seguida de la duración del complejo QRS en el ECG de alta resolución registrado durante los primeros 3 días después del infarto $(p<0.0005)$. La fracción de eyección ventricular izquierda $(\mathrm{p}<0.02)$ fue el único valor predictivo para identificar a los pacientes con alto riesgo de muerte súbita. Estos hallazgos sugieren que el grado del daño miocardico evaluado mediante la fracción de eyección ventricular izquierda es el mejor parámetro para identificar a los pacientes con riesgo a desarrollar arritmias ventriculares sostenidas durante el seguimiento, comparado con el electrocardiograma de alta resolución y que la fracción de eyección ventricular izquierda ha sido el único valor predictivo en la identificación de pacientes con alto riesgo de muerte súbita tras un infarto de miocardio. Así pues, los electrocardiogramas de alta resolución realizados de manera seriada no aumentaron la capacidad de detectar los pacientes con alto riesgo de taquiarritmias ventriculares o muerte súbita.

En el Capitulo 7 se examina las características de las 12 derivaciones del ECG de superficie durante una taquicardia ventricular (TV) en 73 pacientes con antecedentes de infarto de miocardio (TV postinfarto; grupo A) y en otros 73 pacientes con un TV de etiología no isquémica (grupo B). Se dispuso de setenta y cinco electrocardiogramas de pacientes del grupo B (8 con displasia ventricular derecha, 24 con TV idiopática y 43 taquicardias mostrando una conducción anterógrada preferencial a través de una vía accesoria). La presencia de un complejo $q R$ o $Q R$ (con una cociente $Q / R$ igual o mayor del $25 \%$ ) en cualquiera de las derivaciones excepto en la derivación aVR fue el mejor parámetro para diferenciar una TV postinfarto de una etilogía no isquémica (especificidad $100 \%$, sensibilidad 90\%). En TV con morfología de bloqueo de rama derecha, (44/73 grupo A, 44/75 grupo B) el parámetro más útil en la diferenciación entre una TV postinfarto y una TV de etiología no isquémica ha sido la suma de la amplitud de la onda $\mathrm{R}$ en todas las derivaciones precordiales $>80$ mm.; (4/44 grupo A, $44 / 75$ grupo B); especificidad $90 \%$, sensibilidad 90\%). También en este mismo tipo de TV con imagen de bloqueo de rama derecha la distancia desde el inicio hasta la cima de la onda $\mathrm{R}$ en la derivación V1 ( $100 \pm 50 \mathrm{mseg}$ vs $87 \pm 38 \mathrm{mseg}$ ( $p<0.01)$ ), así como la distancia desde el inicio hasta el nadir de la onda S en la derivación V6 $(89 \pm 27 \mathrm{mseg}$ vs $71 \pm 18$ 
mseg) $\mathrm{p}<0.001$ ) han sido mayores en los pacientes del grupo A que en los del grupo B). En las TV con una morfología de bloqueo de rama izquierda la suma de la amplitud de la onda $\mathrm{R}$ en las derivaciones está ha sido mayor en los pacientes del grupo B (origen no isquémico) $(41 \pm 23 \mathrm{~mm}$ ) que en las TV postinfarto $(29 \pm 12 \mathrm{~mm})$ ( $\mathrm{p}<0.001)$. Por consiguiente, el ECG durante taquicardia ventricular puede mostrar características que sugieren un origen postinfarto o una etiología no isquémica.

En el Capítulo 8 se demuestra que mediante la utilización de información clínica se puede obtener un índice pronóstico útil en la identificación de pacientes con alto o bajo riesgo de recidivas de taquicardias ventriculares tras un infarto de miocardio. Se estudiaron doscientos seis pacientes de Maastricht con TV monomórfica sostenida o con fibrilación ventricular (FV) tras el episodio agudo de un infarto de miocardio. 74/206 (36\%) (64 pacientes con TV y 10 pacientes con FV) presentaron recidivas de TV monomórfica sostenida durante un seguimiento de $3.4 \pm 9$ años. Mediante un análisis logístico descriminante escalonado se seleccionaron 3 variables clínicas en el grupo de pacientes estudiado, que se codificaron del modo siguiente: intervalo de tiempo comprendido entre el infarto de miocardio y la presentación de la arritmia $(<2$ meses = 1,2 a 6 meses $=2,>6$ meses $=3$ ), tratamiento antiarrítmico: sotalol, o no sotalol ( sotalol = 1, no sotalol =2), tipo de arritmia clínica TV o FV ( TV = 1, FV =2). El índice pronóstico determinado de este modo fue: 3.41 - ( $0.56 \mathrm{x}$ intervalo) (1.94 $\mathrm{x}$ tratamiento $)+(0.86 \mathrm{x}$ arritmia $)$. Cuando se evaluó prospectivamente este índice pronóstico en un grupo testigo de 158 pacientes de Heidelberg con TV monomórfica sostenida o FV, detectadas después de la fase aguda del infarto, se identificaron dos clases de pacientes: aquellos con un alto riesgo de recidivas de TV $(61 \%)$ que corresponden a los pacientes con un índice negativo, y los pacientes con un bajo riesgo (4\%) que corresponden a los pacientes con un índice positivo. Este índice pronóstico podría ser utilizado en la selección del tratamiento en los pacientes que presentan taquicardia ventricular o fibrilación ventricular después del infarto de miocardio.

En el Capítulo 9 se analiza la incidencia y el tiempo de presentación de recidivas de TV sostenidas o de la muerte súbita en 206 pacientes que han sobrevivido a su primer episodio de FV (52 pacientes) o de TV sostenida (154 pacientes) tras un infarto de miocardio. Todos los pacientes fueron tratados con fármacos antiarrítmicos (seleccionados empíricamente), $49 \%$ de entre ellos fueron tratados con amiodarona. La incidencia de muerte súbita mostró dos picos, el primero alrededor de los 3 meses y el segundo alrededor de los 12 meses. Las recidivas no fatales de TV fueron mas frecuentes (ocurriendo preferentemente en los primeros 6 meses) en el grupo de pacientes con TV que en el grupo con FV. En los pacientes que sobrevivieron 1 año la muerte súbita ocurrió únicamente en un 10\% durante los 3 años siguientes. Comparando los 
pacientes con una fracción de eyección ventricular izquierda $\leq 40 \%$ o $>40 \%$ se observó una mayor incidencia de muerte súbita en los pacientes con fracción de eyección $\leq 40 \%$ ( $28 / 65$ vs $3 / 141 ; p<0.0001)$. No se encontró ninguna relación entre el valor de la fracción de eyección ventricular izquierda y la presencia de recidivas de TV.

En el Capítulo 10 se examina el valor de la estimulación eléctrica programada del corazón en la predicción de la muerte súbita en pacientes con taquiarritmias ventriculares tras de un infarto de miocardio tratados con amiodarona. Se estudiaron ciento seis pacientes con documentación clínica de TV monomórfica sostenida ( 77 pacientes) o FV ( 29 pacientes). Todos los pacientes habían recibido amiodarone al menos 1 mes antes del estudio electrofisiológico. En 80/106 pacientes se pudo inducir una FV (15 pacientes) o una TV monomórfica sostenida (65 pacientes). Después de un seguimiento de $50 \pm 40$ meses (1-144), 13 pacientes fallecieron de muerte súbita (11 pacientes) o utilizaron su desfibrilador ( 2 pacientes). Mediante un análisis multivariado se detectaron 2 predictores para la muerte súbita: la inducción de una FV $(\mathrm{p}<0.0001))$ y una fracción de eyección ventricular izquierda de $<40 \%(p<0.05)$ ). Se determinaron las curvas actuariales para la muerte súbita en los grupos de pacientes en los que se indujo una FV o TV monomórfica sostenida así como para el grupo de pacientes en los cuales no se puso inducir ninguna arritmia sostenida. La probabilidad de supervivencia estimada a los $1,2,3$ y 5 años fue de $70 \%, 62 \%$, $62 \%$ y $40 \%$ respectivamente en el grupo de pacientes con FV inducida y fue de 98\%, 96\%, 94\%, 94\% en el grupo de pacientes con TV monomórfica sostenida inducida. En el grupo de pacientes en los cuales no se pudo inducir ninguna arritmia sostenida la probabilidad de supervivencia estimada a los 5 años fue del $100 \%$. Por consiguiente, en los pacientes que padecen de arritmias ventriculares malignas tras un infarto de miocardio y son tratados con amiodarona, la inducción de una FV pero no de una TV monomórfica sostenida sugiere un alto riesgo de muerte súbita. 


\section{Curriculum Vitae}

Luz-Maria Rodriguez

Born Guadalajara, Jalisco, Mexico, March 211956

Nationality Mexican

1973-1979 Medical School, University of Guadalajara, Mexico.

1980-1981 Rotating Internship, University Hospital, Guadalajara Jalisco, Mexico.

1981-1984 Residency in Internal Medicine, University of Guadalajara, Mexico.

1984-1987 Residency in Cardiology, University Hospital, Liege, Belgium. 1987-1990 Consultant Cardiologist, Dept. of Cardiology (Prof. HE Kulbertus) University Hospital, Liege, Belgium.

1990-1993 Research Fellow in Clinical Cardiac Electrophysiology. (Prof. HJJ Wellens), Academic Hospital Maastricht, The Netherlands. 


\section{Articles in journals}

1. D'Orio V, Rodriguez LM, Wahlen C, Marcelle R. Effects of escherichia coli endotoxin on pulmonary vascular resistance in intact dogs. Crit Care Med 1986; 14:802-806

2. D'Orio V, Wahlen C, Rodriguez LM, Halleaux J, Fassion A, Juchmes J, Marcelle R. Effects of intravascular volume expansion on lung fluid balance in a canine model of septic shock. Crit Care Med 1987;15:863-868

3. Rodriguez LM, D'Orio V, Dehareng A, Whalen C, Fassion A, Juchmes J, Marcelle R. Pulmonary hydrostatic microvascular pressure changes and lung fluid balance during histamine infusion in intact dogs. Circulatory Shock 1987:22; 83-90.

4. D'Orio V, Rodriguez LM, Wahlen C, Fassion A, Juchmes J, Halleux J, Marcelle R. A comparison of escherichia coli endotoxin single bolus injection with low-dose endotoxin infusion on pulmonary and systemic vascular changes. Circulatory Shock 1987:21;207-216

5. Jordaens L, Waleffe A, Derom F, Rodriguez LM, Clement DL, Kulbertus HE. Experience with the automatic implantable defibrillator. Acta Cardiologica 1988:43;209-218

6. Waleffe A, Nzayinambaho N, Rodriguez LM, Dehareng A, Kulbertus HE. Mechanism of termination of supraventricular tachycardias by intravenous class III antiarrhythmic agents. A comparison of amiodarone and sotalol. Eur Heart J 1989:10;1084-1089

7. Nzayinambaho K, Waleffe A, Rodriguez LM, Kulbertus HE. Anterograde conduction over a concealed accessory pathway after His bundle catheter ablation. Acta Cardiologica 1989:44; 423-428

8. Nzayinambaho K, Waleffe A, Rodriguez LM, Kulbertus HE. Clinical Experience with a New Catheter for His bundle ablation. J Electrocardiography 1990;23:165-169

9. Rodriguez LM, Waleffe A, Brugada P, Dehareng A, Lezaun R, Sternick EB, Kulbertus HE. Exercise-Induced sustained ventricular tachycardia, incidence, clinical, angiographic and electrophysiology characteristics. Eur Heart J 1990;11:225-232

10. Rodriguez LM, Krijne R, van den Dool A, Brugada P, Smeets J, Wellens HJJ. Time course and prognostic significance of serial signal-averaged electrocardiograms after a first myocardial infarction. Am J Cardiol 1990;66:1199-1202 
11. Kulbertus HE, Rodriguez LM. Ventricular arrhythmias. Current Opinion in Cardiology 1991;6:49-55

12. Mont Ll, Seixas T, Brugada P, Brugada J, Simonis F, Rodriguez LM, Smeets J, Wellens HJJ. Clinical and electrophysiologic characteristics of exerciserelated idiopathic ventricular tachycardia. Am J Cardiol 1991;68:897-900

13. Dassen W, Mulleneers R, Bleijlevens N, Den Dulk K, Rodriguez LM, Schläpfer J, Katsivas A, Baiyan X, Wellens HJJ. Determination of the etiology of wide-QRS tachycardias using an artificial neuronal network. In: Computers in Cardiology, IEEE, Ripley K (ed) 1991;165-168

14. Rodriguez LM, Smeets J, Schläpfer J, Katsivas A, Dijkman B, De Chillou C, Wellens HJJ. Radiofrequency catheter ablation of three accessory pathways in a single session. J Cardiovasc Electrophysiology 1992;3:141-149

15. Rodriguez LM, Oyarzun R, Smeets J, Brachmann J, Schmitt C, Brugada P, Geelen P, Lipcsei G, Albert A, Wellens HJJ. Identification of patients at high risk for a recurrence of sustained ventricular tachycardia after myocardial infarction. Am J Cardiol 1992;69:462-464

16. Rodriguez LM, Smeets J, O'Hara GE, Brugada P, Geelen P, Wellens HJJ. Incidence and timing of recurrences of sudden death and ventricular tachycardia during antiarrhythmic drugs treatment after myocardial infarction. Am J Cardiol 1992;69:1403-1406

17. De Chillou C, Rodriguez LM, Schläpfer J, Kappos K, Katsivas A, Xie B, Smeets JLRM, Wellens HJJ. Clinical characteristics and electrophysiologic properties of atrioventricular accessory pathways: Importance of the accessory pathway location. J Am Coll Cardiol 1992;20:666-671

18. O'Hara GE, Brugada P, Rodriguez LM, Brito M, Mont LI, Waleffe A, Kulbertus HE, Wellens HJJ. Incidence, pathophysiology and prognosis of exercise-induced sustained ventricular tachycardia associated with healed myocardial infarction. Am J Cardiol 1992;70:875-878

19. Rodriguez LM, De Chillou C, Schläpfer J, Metzger J, Smeets JLRM, Wellens HJJ. Age at onset and gender of patients with different types of supraventricular tachycardias. Am J Cardiol 1992;70:1213-1215

20. Smeets JLRM, Rodriguez LM, Cheriex EC, Dijkman B, Wellens HJJ. Radiofrequente energie als behandeling voor hartritmestoornissen bij patienten met extra atrioventriculaire verbindingen. Ned Tijdschr Geneeskd 1992;136:2131-2135

21. De Chillou C, Rodriguez LM, Doevendans P, Loutsidis K, Van den Dool A, Metzger J, Bär FWHM, Smeets JLRM, Wellens HJJ. Effects on the signal averaged electrocardiogram, by opening the coronary artery by thrombolytic therapy or percutaneous transluminal coronary angioplasty at the acute phase of myocardial infarction. Am J Cardiol 1993;71:805-809 
22. De Chillou C, Doevendans P, Cheriex E, Rodriguez LM, Metzger J, Pieters F, Smeets JLRM, Wellens HJJ. Echocardiographic wall motion abnormalities and signal averaged electrocardiogram in the acute phase of a first myocardial infarction. Eur Heart J 1993;14:795-798

23. Rodriguez LM, Smeets JLRM, Xie B, De Chillou C, Cheriex E, Pieters F, Metzger J, den Dulk K, Wellens HJJ. Improvement in the left ventricular function by ablation of AV nodal conduction in selected patients with lone atrial fibrillation. Am J Cardiol 1993;72:1137-1141

24. Rodriguez LM, Smeets JLRM, De Chillou C, Metzger J, Schläpfer J, Penn $\mathrm{O}$, Weide A, Wellens HJJ. The 12-lead electrocardiogram in mid-septal, anteroseptal, posteroseptal and right free wall accessory pathways. Am J Cardiol 1993;72:1274-1280

25. Metzger J, De Chillou C, Cheriex E, Rodriguez LM, Smeets JLRM, Wellens HJJ. Value of the 12-lead electrocardiogram in patients with arrhythmogenic right ventricular dysplasia and absence of correlation with echocardiographic findings. Am J Cardiol 1993;72:964-967 


\section{Chapters in books}

1. Wellens HJJ, Smeets J, Rodriguez LM, Gorgels APM. Atrial fibrillation in the Wolff-Parkinson-White syndrome. In: Atrial Fibrillation: Mechanisms and Management, FalK RH and Podrid PJ (eds). Raven Press, Ltd. New York 1992; pp 333-344

2. Wellens HJJ, Rodriguez LM, Smeets JLRM, Cheriex EC, Pieters F, Den Dulk D. Tachycardiomyopathy in patients with supraventricular tachycardia. In: Atrial fibrillation, a treatable disease? Kingma JH et al. (eds) Kluwer Academic Publishers, 1992; pp 183-193

3. Wellens HJJ, Rodriguez LM, Gorgels APM, Smeets JLRM. Risk assessment and prognosis of patients with sudden cardiac death and ventricular tachyarrhythmias.In: Prognosis and risk assessment in cardiovascular disease. Kapoor AS, Singh BN (eds). Churchill Livingstone 1992; pp 403-411

4. Wellens HJJ, Gorgels APM, Rodriguez LM, Vos MA, Smeets JLRM. Supraventricular tachycardias: Mechanisms, electrocardiographic, manifestations, and clinical aspects. In: Tachycardias: Mechanisms and management. Josephson ME, Wellens HJJ (eds) 1993; pp 121-147 

